\title{
Species in lichen-forming fungi: balancing between conceptual and practical considerations, and between phenotype and phylogenomics
}

\author{
Robert Lücking ${ }^{1}$ (D) Steven D. Leavitt ${ }^{2,3}$ (1) $\cdot$ David L. Hawksworth ${ }^{4,5}$ (D)
}

Received: 19 April 2021 / Accepted: 29 June 2021 / Published online: 8 August 2021

(c) The Author(s) 2021

\begin{abstract}
Lichens are symbiotic associations resulting from interactions among fungi (primary and secondary mycobionts), algae and/ or cyanobacteria (primary and secondary photobionts), and specific elements of the bacterial microbiome associated with the lichen thallus. The question of what is a species, both concerning the lichen as a whole and its main fungal component, the primary mycobiont, has faced many challenges throughout history and has reached new dimensions with the advent of molecular phylogenetics and phylogenomics. In this paper, we briefly revise the definition of lichens and the scientific and vernacular naming conventions, concluding that the scientific, Latinized name usually associated with lichens invariably refers to the primary mycobiont, whereas the vernacular name encompasses the entire lichen. Although the same lichen mycobiont may produce different phenotypes when associating with different photobionts or growing in axenic culture, this discrete variation does not warrant the application of different scientific names, but must follow the principle "one fungus = one name". Instead, broadly agreed informal designations should be used for such discrete morphologies, such as chloromorph and cyanomorph for lichens formed by the same mycobiont but with either green algae or cyanobacteria. The taxonomic recognition of species in lichen-forming fungi is not different from other fungi and conceptual and nomenclatural approaches follow the same principles. We identify a number of current challenges and provide recommendations to address these. Species delimitation in lichen-forming fungi should not be tailored to particular species concepts but instead be derived from empirical evidence, applying one or several of the following principles in what we call the LPR approach: lineage (L) coherence vs. divergence (phylogenetic component), phenotype $(\mathrm{P})$ coherence vs. divergence (morphological component), and/or reproductive (R) compatibility vs. isolation (biological component). Species hypotheses can be established based on either L or P, then using either P or L (plus R) to corroborate them. The reliability of species hypotheses depends not only on the nature and number of characters but also on the context: the closer the relationship and/or similarity between species, the higher the number of characters and/or specimens that should be analyzed to provide reliable delimitations. Alpha taxonomy should follow scientific evidence and an evolutionary framework but should also offer alternative practical solutions, as long as these are scientifically defendable. Taxa that are delimited phylogenetically but not readily identifiable in the field, or are genuinely cryptic, should not be rejected due to the inaccessibility of proper tools. Instead, they can be provisionally treated as undifferentiated complexes for purposes that do not require precise determinations. The application of infraspecific (gamma) taxonomy should be restricted to cases where there is a biological rationale, i.e., lineages of a species complex that show limited phylogenetic divergence but no evidence of reproductive isolation. Gamma taxonomy should not be used to denote discrete phenotypical variation or ecotypes not warranting the distinction at species level. We revise the species pair concept in lichen-forming fungi, which recognizes sexually and asexually reproducing morphs with the same underlying phenotype as different species. We conclude that in most cases this concept does not hold, but the actual situation is complex and not necessarily correlated with reproductive strategy. In cases where no molecular data are available or where single or multi-marker approaches do not provide resolution, we recommend maintaining species pairs until molecular or phylogenomic data are available. This recommendation is based on the example of the species pair Usnea aurantiacoatra vs. $U$. antarctica, which can only be resolved with phylogenomic approaches, such as microsatellites or RADseq. Overall, we
\end{abstract}

Handling editor: Jian-Kui Liu.

Extended author information available on the last page of the article 
consider that species delimitation in lichen-forming fungi has advanced dramatically over the past three decades, resulting in a solid framework, but that empirical evidence is still missing for many taxa. Therefore, while phylogenomic approaches focusing on particular examples will be increasingly employed to resolve difficult species complexes, broad screening using single barcoding markers will aid in placing as many taxa as possible into a molecular matrix. We provide a practical protocol how to assess and formally treat taxonomic novelties. While this paper focuses on lichen fungi, many of the aspects discussed herein apply generally to fungal taxonomy. The new combination Arthonia minor (Lücking) Lücking comb. et stat. nov. (Bas.: Arthonia cyanea f. minor Lücking) is proposed.

Keywords Alpha taxonomy - Beta taxonomy · Biological species concept $\cdot$ Cora - Cryptic speciation · Fungal farmers · Gamma taxonomy $\cdot$ Infraspecies $\cdot$ Lichens as ecosystems $\cdot$ Machine learning $\cdot$ Morphological species concept $\cdot$ One fungus $=$ one name $\cdot$ Photomorph $\cdot$ Phylogenetic species concept $\cdot$ Species pair concept $\cdot$ Thamnolia

\section{Table of contents}

Introduction

What are lichens and how should they be named?

Species concepts and their application in lichenized fungi

The species pair concept and dual nomenclature in lichenized fungi

Cryptic speciation and the taxonomic value of phenotype characters

Species versus infraspecific ranks

A quick primer on common molecular complications

Data and taxon sampling

Conclusions: A protocol for consistent alpha (and gamma) taxonomy in lichen-forming fungi

Acknowledgements

Declarations

References

\section{Introduction}

Botanical nomenclature, and with it the nomenclature of fungi including lichen-formers, started with Linnaeus (1753). Only 80 lichens were accepted in that work, in a single genus Lichen, although some were also included in the algal genus Byssus (=Trentepohlia; for authorship and Index Fungorum/MycoBank registration numbers of names used in this paper, see Suppl. File S1). For comparison, while recognizing about the same number of fungi, Linnaeus classified these into ten genera. Prior to Linnaeus various workers had already elaborated more detailed classifications for lichens, regarding the number of species and/or genera. Michelius (1729), in his Nova Plantarum Genera, recognized nearly 300 species, in a single genus Lichen but classified into 38 groups ("ordo"). In Historia Muscorum, Dillenius (1742) also recognized close to 300 species, in several genera (e.g., Byssus, Conferva, Coralloides, Lichen, Lichenastrum, Lichenoides, Usnea), although it remains unclear whether some of these actually corresponded to lichens or to algae, bryophytes, or fungi. Thus, Linnaeus (1753) marked the first substantial change in species concepts in lichen fungi. It was not until Acharius $(1798,1803,1810,1814)$, the "father of lichenology" (Nylander 1858; Vitikainen 1976), when the classification of lichens got back on track and the diversity of this enigmatic group of organisms began to be unraveled.

Another angle on species concepts in lichens was provided by their initial treatment as organisms separate from plants and fungi, although similarities with bryophytes, algae and fungi (Fig. 1) were recognized early on. The separation between lichens and fungi was, however, not clear-cut: Acharius (1810) included some non-lichenized fungi, and Fries (1821) noted analogies between particular genera in his introduction to Systema Mycologicum-one of the key works sanctioning names of fungi. These analogies were, however, superficial and did not relate genera perceived as lichens to their closest fungal relatives (e.g., Verrucaria vs. Sphaeria $=$ Hypoxylon; Graphis vs. Hysterium; Biatora vs. Peziza; Collema vs. Tremella). Just prior to the decade that led to the discovery of the lichen symbiosis (De Bary 1866; Schwendener in Anonymous 1867; Schwendener 1868), the Finnish lichenologist Nylander (1858) published a classification considering lichens an evolutionary link between algae and fungi. This was based on the idea that lichens were overall similar to fungi but contained an additional element not known from other fungi but similar to algae, the so-called "gonidia" (Körber 1939; Berkeley 1857). Thwaites (1849) established a close relationship of lichen "gonidia" with algae, such as Nostoc (in Collema, Leptogium and the species now known as Placynthium nigrum); Pleurococcus sensu lato (in most "lichens proper", including Biatora vernalis, referring to a variety of chlorococcoid photobionts nowadays classified in genera such as Trebouxia, Asterochloris, Coccomyxa, Myrmecia, and others); Coccochloris sensu lato (a rejected name in favour of Aphanothece, actually referring to the Gloeocapsa photobiont in what Thwaites called Synalissa vulgaris and which correctly refers to $S$. ramulosa); and Ulva sensu lato (the photobiont of Mastodia tessellata, subsequently identified as Prasiola crispa subsp. antarctica; see Pérez-Ortega et al. 2010). Besides Sidney 
Fig. 1 Examples of lichens that show superficial similarity with non-lichenized fungi, algae, or bryophytes. a Dibaeis columbiana. b Lichenomphalia lobata. c Coenogonium interplexum. d Dictyonema album. e Pseudohepatica pachyderma. f Ricasolia glaberrima. All photographs by Robert Lücking except $b$ (Bibiana Moncada)
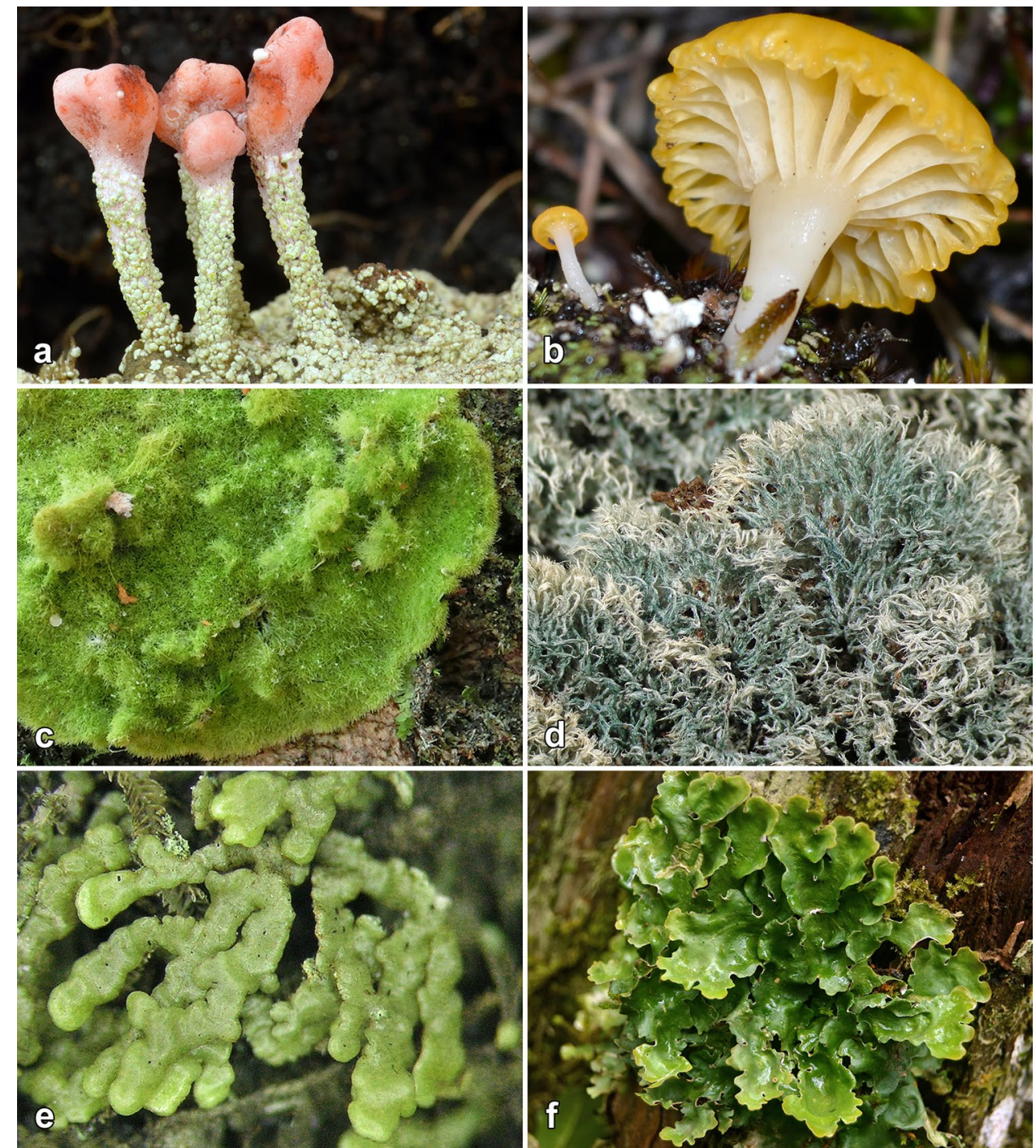

(1846), Thwaites (1849) was among the first to consider gonidia as an essential part of the lichen thallus, not merely a structure for reproduction. However, he did not draw the proper conclusions and instead considered lichens and the corresponding algae closely related, even suggesting that in some cases they should be placed in the same genus.

Prior to the recognition of the lichen as a symbiosis, names given to lichens encompassed the gonidia as specific structures of the thallus. The discovery of the lichen symbiosis made it necessary to not only reconsider the nature of lichens but also their nomenclature and classification. Shortly after the turn of the century, two schools had emerged: the largely Central European school, maintaining lichens as a separate group related to fungi (e.g., Reinke 1896; Zahlbruckner 1907, 1926), and the largely North American school, integrating lichen fungi into the overall fungal classifications (e.g., Lindau 1895; Clements 1897, 1909; Fink 1911; Clements and Shear 1931). In both cases, it was implied that the name given to lichens should refer to the fungal partner, but formally this issue was only resolved well into the twentieth century, when the Stockholm Code specified the scientific name as applying to the fungal component (Lanjouw et al. 1952; Santesson 1953). More than a decade prior, Thomas (1939) had proposed to name lichen fungi in culture differently, by adding the suffix "-myces". The subsequent approach by Ciferri and Tomaselli (1953a, b, 1954a, b, 1955, 1957; see Santesson 1954; Lücking and Hawksworth 2007) is often considered a last attempt at giving different names to lichen fungi whereas retaining the original name for the lichen as a whole. However, this is a misinterpretation of the original intention of these authors, who suggested to apply different names to the fungus in axenic culture vs. the lichen mycobiont in situ. Their approach was similar to dual nomenclature, which at the time was only allowed for so-called pleomorphic fungi, i.e., fungi with both sexual and asexual morphs. 
Lichen-forming fungi continued to be regarded as a separate class from other Fungi, latinized as Lichenes (higher taxon names here placed in italics, following Thines et al. 2020), a practice followed in the appendices of conserved generic names in editions of the International Code of Botanical Nomenclature, right up to the Leningrad Code (Stafleu et al. 1978). This later changed to "Fungi (including lichen-forming fungi)" in the Sydney Code (Voss et al. 1983), and to "Fungi" in the Tokyo Code (Greuter et al. 1994). Alongside these changes, the second half of the twentieth century saw a full integration of lichen mycobionts into fungal classifications, fostered by initiatives such as Ainsworth \& Bisby's Dictionary of the Fungi (Ainsworth et al. 1971), the Index of Fungi (from 1970 onwards), and Systema Ascomycetum, from its inception in 1986 (Hawksworth and Eriksson 1994; Lücking et al. 2021a). Lichen fungi thus became part of regularly implemented updates of fungal classifications and this facilitated a seamless transition into the molecular era, with substantial changes in the higher classification of fungi including lichen-formers in the past three decades (Miądlikowska et al. 2006, 2014a; Nelsen et al. 2009, 2011, 2020; Lumbsch and Huhndorf 2010; Frisch et al. 2014; Chen et al. 2015; Lücking et al. 2017a; Kraichak et al. 2018; Pizarro et al. 2018; Widhelm et al. 2019). Molecular phylogenies were also employed early on to address species delimitation in lichen fungi, first using single-marker approaches focusing on the fungal ITS barcoding marker but also increasingly other approaches such as multi-marker coalescence or phylogenomics, including microsatellites, RADseq and target capture (Franc and Kärnefelt 1998; Lohtander et al. 1998; Thell et al. 2000; Kroken and Taylor 2001; Moncada et al. 2014; Lücking et al. 2017b; Magain et al. 2017; Grewe et al. 2018; Lagostina et al. 2018; LaGreca et al. 2020; Widhelm et al. 2021; Lücking et al. 2021b). These studies have also generated new interest in the application of theoretical species concepts to species-level taxonomy in lichen fungi (Grube and Kroken 2000; Buschbom and Mueller 2006; Crespo and PérezOrtega 2009; Crespo and Lumbsch 2010; Lumbsch and Leavitt 2011; Leavitt et al. 2016a, b; Jørgensen 2019).

Here, we provide a revised overview of the different aspects of species-level taxonomy in lichen fungi, focusing on conceptual and practical aspects and taking into account increasing evidence from phylogenetics and phylogenomics, with numerous examples and practical recommendations.

\section{What are lichens and how should they be named?}

After the discovery of the lichen symbiosis, the definition of what constitutes a lichen has varied considerably (Table 1). Some definitions are descriptive rather than diagnostic, e.g., that of Ahmadjan (1993). Rather than developing over time, definitions also followed particular views, such as Honegger $(1991,2001,2012)$ using the symbiotic phenotype as core element, and Hawksworth and co-workers focusing on the notion of a stable, self-supporting association and the antagonism between the mycobiont as exhabitant and the photobiont as inhabitant (Hawksworth et al. 1983; Hawksworth and Hill 1984; Hawksworth 1988; Hawksworth and Honegger 1994).

There are certain challenges to the accurate and precise definition of a lichen. A merely functional definition, as a symbiosis between a heterotrophic fungus (or fungus-like organism) and a photosynthetic component, would be imprecise, as it would not discriminate between lichens one one hand and ecto- and endomycorrhiza, bryophilous fungi, mycophycosymbioses, and endosymbiotic associations, such as in Geosiphon pyriformis, all of which are not considered lichens (Hawksworth and Hill 1984; Hawksworth 1988). A taxonomic or phylogenetic definition, as a symbiosis between a fungus and an alga or cyanobacterium, would also be challenging, as fungi in the sense of the International Code of Nomenclature for algae, fungi and plants [ICNafp (Shenzen); Turland et al. 2018; May et al. 2018] are not a natural group, encompassing at least three kingdoms, and the known lichen photobionts represent two domains and three kingdoms (Friedl and Büdel 2008; Saini et al. 2019). Given extant lichens, one could specify the fungal component as a member of the kingdom Fungi, but what would a theoretical association involving a member of the Oomycota then constitute and how could one exclude that associations with other fungal-like organisms might exist or might have existed in the past? Associations with photosynthetic algae have also been formed by fungal-like bacteria (Actinomycetes) and by fungi otherwise not forming lichens, such as in the genus Aspergillus, under laboratory conditions (Lazo 1966; Lawrey 1984; Zvyagintsev et al. 2010; Lücking and Nelsen 2018; Krespach et al. 2020). Since photobionts of lichens represent two domains (including Bacteria) and three kingdoms, there would be no logical reason to restrict mycobionts to a single domain (excluding Bacteria) and kingdom. Additional complications arise from facultatively lichenized fungi, e.g., in the genera Schizoxylon and Stictis (Stictidaceae; Wedin et al. 2004; Muggia et al. 2011), from situations where it is unclear whether the fungus is actually lichenized, in species of genera such as Arthonia sensu lato, Arthopyrenia sensu lato, or Mycomicrothelia sensu lato (Hawksworth 2005; Lücking et al. 2017a; Grube and Wedin 2018; Thiyagaraja et al. 2020), and from lichenicolous lichens in which one fungus takes over the photobiont of another lichen, e.g. in Diploschistes muscorum (Friedl 1987).

Thus far, associations broadly accepted as lichens fulfil two criteria: (1) the mycobiont is a member of the kingdom 
Table 1 Selected definitions of the lichen symbiosis according to various sources throughout history, in chronological order

References Definition

Fünfstück (1907, p. 3)

Fink (1913, p. 117)

Ainsworth and Bisby (1943, p. 160)

Alexopoulos (1952, p. 440)

Ainsworth et al. (1971, p. 318) (see also

Hawksworth 1978, p. 212)

Ahmadjian (1982, p. 18)

Hawksworth et al. (1983, p. 216)

Hawksworth and Hill (1984, pp. 2-3)

Hawksworth (1988, p. 17)

Honegger (1991, p. 553)

Ahmadjian (1993, p. 1)

Goward (1994, p. 17)

Hawksworth and Honegger (1994, p. 79)

Honegger (2001, p. 165) (see also Honegger 2012, p. 288)

Kirk et al. (2008, p. 378)

Hawksworth and Grube (2020, p. 1282)
"Die Flechten sind komplexe Gebilde und bestehen aus höheren Fadenpilzen, welche mit bestimmten einzelligen Algen, selten Fadenalgen, gemeinschaftlich vegetieren. Die Flechtenpilze, welche durch relativ dünne Membranen ausgezeichnet sind, gehören mit einer einzigen Ausnahme den Ascomyceten, die Algen, im Flechtenkörper speciell als Gonidien bezeichnet, sowohl den Schizophyceen als auch den Chlorophyceen an." ["The lichens are complex structures and consist of higher filamentous fungi, which vegetate together with certain unicellular algae, rarely filamentous algae. The lichen fungi, which are characterized by relatively thin membranes, belong to the Ascomycetes, with a single exception; the algae, specifically designated as gonidia in the lichen body, belong to both the Schizophyceae and the Chlorophyceae."]

"A lichen is a fungus which lives during all or part of its life in parasitic relation with an algal host and also sustains a relation with an organic or an inorganic substratum."

"The lichens are commonly taken as a special group, but each one is a self-supporting symbiotic association of a fungus and an alga ..."

"... a combination of an alga and a fungus in which the two components are so interwoven as to form what appears to be a single individual."

"... a self-supporting symbiotic association of a fungus (mycobiont) and an alga (photobiont)."

"A lichen is an association of a fungus and a photosynthetic symbiont resulting in a stable thallus of specific structure." [result of and International Association for Lichenology (IAL) Terminology Committee poll in 1981]

"The lichens are a biological and not a systematic group and each is basically a stable self-supporting association of a fungus (mycobiont) and an alga or cyanobacterium (photobiont)."

"A lichen is an association of a fungus and a photosynthetic symbiont resulting in a stable thallus of specific structure" (following Ahmadjian 1982); "... a stable self-supporting association of a mycobiont and a photobiont" (following Hawksworth et al. 1983); "The mycobiont (the exhabitant) is the fungal partner in a lichen association, and the photobiont (the inhabitant) is the photosynthetic partner."

"A lichen is a stable self-supporting association of a mycobiont and a photobiont in which the mycobiont is the exhabitant."

"Lichens are the symbiotic phenotype of nutritionally specialized fungi that live as ecologically obligate biotrophs in symbiosis with algal and/or cyanobacterial photobionts."

"A lichen is a symbiotic association of a fungus (mycobiont) and a photosynthetic partner (photobiont), which may be an alga or a cyanobacterium. ... the fungus produces a thallus, or body, within which the photobionts are housed."

"... lichens are fungi that have taken up agriculture."

"... lichen is an ecologically obligate, stable mutualism between an exhabitant fungal partner and an inhabitant population of extracellularly located unicellular or filamentous algal or cyanobacterial cells."

"Lichens are the symbiotic phenotype of lichen-forming fungi, a polyphyletic, taxonomically heterogeneous [diverse] assembly [group] of nutritional specialists which acquire [derive, in a mutualistic symbiosis, ] fixed carbon from a population of minute, extracellularly located green algal or cyanobacterial cells; these are referred to as the photobiont."

"A lichen is a stable self-supporting association of a fungus (mycobiont) and an alga or cyanobacterium (photobiont). More precisely, a lichen is an ecologically obligate, stable mutualism between an exhabitant fungal partner and an inhabitant population of extracellularly located unicellular or filamentous algal or cyanobacterial cells."

"A lichen is a self-sustaining ecosystem formed by the interaction of an exhabitant fungus and an extracellular arrangement of one or more photosynthetic partners and an indeterminate number of other microscopic organisms."
Fungi; (2) the photobiont is algal-like, i.e., with an undifferentiated, unicellular to filamentous body plan not forming distinct organs (root, stem, leaves). If this is incorporated into the definition, two challenging cases remain that are currently not considered lichens: (1) so-called mycophycobioses, i.e., relationships between marine fungi and macroalgae with a differentiated body plan and in which the algae typically retain their form and sexual reproductive capacity, such as Mycophycias ascophylli in the seaweed genera Ascophyllum and Pelvetia (Kohlmeyer and Kohlmeyer 1972; Hawksworth 1988, 2000; Selosse and Le Tacon 1998; Gimmler 2001; Pérez-Ortega et al. 2018); and 
(2) relationships between certain mushrooms, such as in the genus Arrhenia, and moss protonemata, the latter being "algal-like" (Redhead 1984; Redhead and Kuyper 1987; Döbbeler 1997; Stenroos et al. 2010; Pressel et al. 2014).

Another issue is the biological nature of the symbiosis, which has been classified somewhere between mutualism and controlled parasitism (Ahmadjian 1993; Hawksworth 1988; Honegger 1991, 1998). The fungal partner actively seeks the relationship with a compatible photobiont and controls it, both in terms of morphology and physiology (Honegger 1991, 1998, 2001, 2012; Sanders 2001a, 2005, 2014; Sanders and Lücking 2002). Even some filamentous lichens, which give the impression that the thallus shape is driven by the photobiont, turned out to be remarkable cases of mycobiont-controlled photobiont morphogenesis (Nyati et al. 2007). Filamentous algae of the genus Trentepohlia also change their morphology in lichenization with Coenogonium (Uyenco 1965), even if the latter genus resembles non-lichenized algae (Fig. 1c). Essentially, the mycobiont builds a "greenhouse" for the photobiont, except for cases when the environmental conditions are favorable for the photobiont, such as in filamentous thalli of Coenogonium and Dictyonema in tropical regions (Thomas et al. 1997; Lakatos et al. 2006). For this reason, the definition of lichens being fungi that discovered agriculture has caught some momentum (Goward 1994; Lücking et al. 2009a, b, c; Lücking and Lumbsch 2014). Indeed, patterns of mycobiont and photobiont diversity and photobiont sharing between unrelated mycobionts show analogies to farming (Hyvärinen et al. 2002; Lücking et al. 2009a).

Up to the present, lichens have been defined as an association between a mycobiont and one or two photobionts (Table 1), as these are the elements generally visible under microscopic examination (Fig. 2). However, the frequent presence of lichenicolous fungi and the discovery of a diverse microbiome associated with the lichen thallus have challenged this view (Hawksworth and Grube 2020). Apart from the principal bionts, the lichen microbiome is constituted of at least four additional components: (1) lichenicolous fungi, (2) endolichenic fungi, (3) facultatively associated algae and/or cyanobacteria, and (4) bacteria. Lichenicolous fungi are the best studied group among these (Lawrey and Diederich 2003; Diederich et al. 2018). They can largely be divided into mycoparasites, which attack the lichen mycobiont and often cause substantial damage to the thallus, gallformers, and often symptomless fungi that share the algal partner, sometimes called parasymbionts, although other strategies exist as well (Hawksworth 1988, 2003; Grube and Hafellner 1990; Grube and Lücking 2002). A remarkable case among the latter are the lichenicolous lineages nested within macrolichen clades in the family Parmeliaceae (Divakar et al. 2015). However, the division between lichenicolous fungi and lichen-formers is not clear-cut. New findings raise

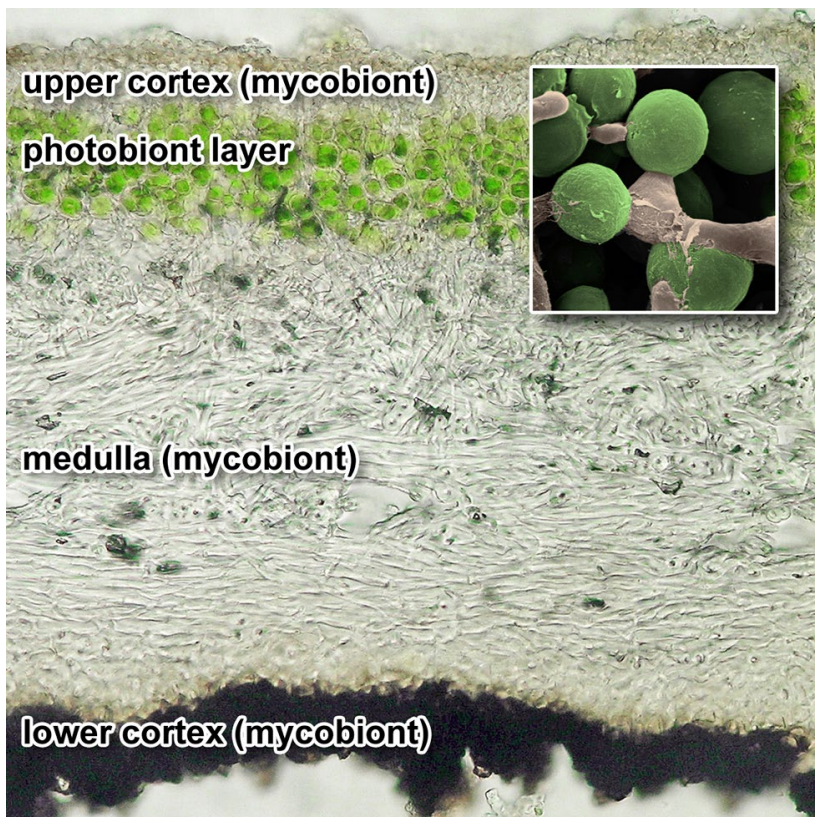

Fig. 2 Section through a lichen thallus (Parmeliaceae) showing the principal components of the lichen symbiosis. The diverse microbiome including endolichenic fungi and bacteria is not immediately visible. Inset shows an SEM magnification of the interface between fungi and algae in Xanthoria parietina, using false colors to indicate the two bionts. Section photograph by Robert Lücking, inset SEM courtesy of Rosemarie Honegger (original in greyscale)

the question whether fungi other than the primary mycobiont, such basidiomycetous yeasts and other fungi inhabiting the cortex of lichen thalli, play a role in the symbiosis or are merely latent stages of lichenicolous gall formers (Spribille et al. 2016; Lücking and Moncada 2017; Černajová and Škaloud 2019; Lendemer et al. 2019; Tuovinen et al. 2019, 2021; Mark et al. 2020).

Endolichenic fungi are a more diffuse group usually detected with high throughput sequencing or culturing, in analogy to endophytic fungi (Arnold et al. 2009; Chagnon et al. 2015; Fernández-Mendoza et al. 2017; Tripathi and Joshi 2019). Endophytic fungi are generally latent saprotrophs or pathogens, but it remains unclear to what extent endolichenic fungi, other than lichenicolous taxa, actually have a latent presence within lichen thalli or whether they just represent spores or hyphae of widespread, weedy taxa accidentally trapped or otherwise associated with the latter. The role of fungi as saprotrophs on dead lichens remains unclear, although decomposition of lichen thalli has been widely studied (Guzman et al. 1990; Greenfield 1993; Biazrov 1994; McCune and Daly 1994; Caldiz et al. 2007; Campbell et al. 2010; Asplund and Wardle 2012; Berdugo et al. 2021). Given the diversity of mycoparasites in general and lichenicolous fungi attacking and damaging lichen mycobionts in particular, it seems feasible that certain fungi play a role in decomposing lichen thalli, although it has also 
been shown that certain lichen substances can prevent fungal attacks and this effect may persist in dead thalli (Lawrey 1995; Torzilli et al. 2002).

The bacterial microbiome of lichens is highly diverse and there is some indication of partial specificity and some functional role in the lichen symbiosis (Cardinale et al. 2012; Grube et al. 2012, 2015; Aschenbrenner et al. 2016; Hawksworth and Grube 2020; Grimm et al. 2021). However, when considering the microbiome in the definition of lichens, it should not be overlooked that microbiomes occur in practically all organisms, most notably in the gut of animals, such as insects or vertebrates including humans (Ohkuma 2008; Brune and Dietrich 2015; Heintz-Buschart and Wilmes 2018; Muñoz-Benavent et al. 2020; Scheelings et al. 2020). In none of these cases, the microbiome, even if highly specific, is included in the definition of the corresponding organism. Humans without their gut microbiome are still defined as humans. The case of lichens is, however, different, as lichens are not single organism but already constitute a symbiosis. Thus, while the definition of each of the principal components of a lichen, the mycobiont and the photobiont(s), is independent of the microbiome, the lichen as a whole may not exist without certain components of the latter. Even so, a definition should be diagnostic rather than descriptive, and hence not include every component potentially found in lichens but only those that are critical for their successful establishment. Therefore, we propose a modified definition, integrating aspects put forward by Ainsworth et al. (1971), Hawksworth (1988), Honegger (1991, 2012),
Goward (1994), Kirk et al. (2008), and Hawksworth and Grube (2020).

A lichen is a stable, self-supporting association of a fungus
or fungal-like organism, the primary mycobiont, and a
morphologically undifferentiated, unicellular to filamentous
alga and/or a cyanobacterium, the primary (and second-
ary) photobiont, along with obligately associated elements
of the fungal and bacterial microbiome contained therein.
The phenotype of the mycobiont in the lichenized state (the
exhabitant) typically functions as a greenhouse around the
photobiont (the inhabitant), the mechanical, physiological
and evolutionary properties of the symbiosis thereby exhibit-
ing analogies with agriculture.

The above considerations about the definition of lichens are of a purely biological and functional nature and primarily unrelated to taxonomic and nomenclatural considerations. It has, however, been argued that the lichen symbiosis is unique in that the mycobiont, in order to build the "greenhouse" for the photobiont, develops morphological structures neither known from other fungi nor from the mycobiont itself when grown in axenic culture (Honegger 1991, 2001, 2012). As a result, mycobionts in axenic culture have entirely different phenotypes compared to lichenized thalli, and the lichen architecture only exists in the presence of both bionts. Through this architecture, lichens acts in their environment as if they were single organisms, functionally and morphologically mimicking plants (Sanders
Fig. 3 Phenotypic divergence of the same mycobiont under different conditions. a Chloromorph and $\mathbf{b}$ dendriscocauloid cyanomorph of Sticta latifrons. c Thallus of Xanthoria parietina (yellow wall lichen) in situ. d axenic culture of $X$. parietina. Photographs by Robert Lücking $(\mathbf{a}-\mathbf{c})$ and Zakieh Zakeri (d, with permission)

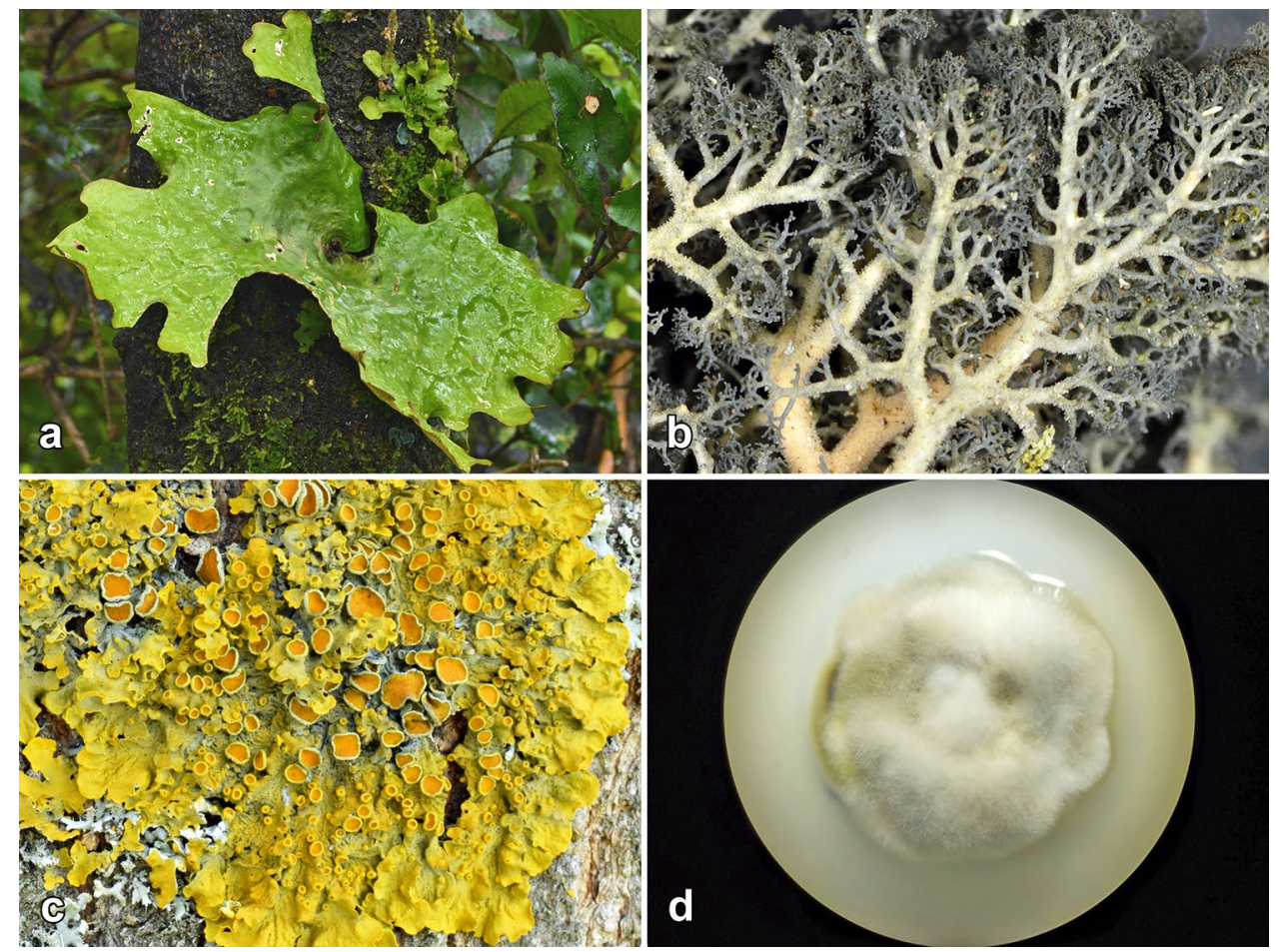


2001b). This morphological differentiation in the presence of a photobiont is particularly striking when considering cephalodia and so-called photosymbiodemes (Fig. 3a-b), in which the same fungus forms different structures or entirely different lichens when associating with either green algae or cyanobacteria (James and Henssen 1976; Armaleo and Clerc 1991; Green and Lange 1991; Purvis 2000; Sanders 2001c; Magain et al. 2012; Moncada et al. 2013a, b; Ranft et al. 2018). The notion that these instances form functionally distinct entities has sparked controversy as to whether they should be named differently (Goward 2008). This extends to the issue that the scientific name of the lichen mycobiont is often used as proxy for the lichen as a whole, in all its complexity, which is misleading at best and inappropriate at worst. In contrast, vernacular names encompass the entire lichen, as they are derived from the overall appearance of the thallus architecture, produced by both the mycobiont and the photobiont(s). Therefore, vernacular names do not precisely correspond to scientific names applied to lichens (Goward 2008). A comparison between the thallus of the yellow wall lichen, with the scientific name Xanthoria parietina for the mycobiont, and the axenic culture of the latter (Fig. 3c-d; see also Purvis 2000, p. 9), immediately demonstrates that the vernacular name cannot apply to the fungus in isolation.

While the above considerations seem to justify the need for a name to encompass the lichen as a whole, or to distinguish between different lichens formed by the same fungus, such as photosymbiodemes, it should be noted that analogous situations are common in the Tree of Life. Examples are rust fungi, red algae, and holometabolous insects. Rust fungi can form up to six morphologically different phases during their life-cycle, partly associated with different hosts (Aime 2006). Traditionally, these have been given different scientific names, especially when based on sexual vs. asexual reproduction, under the concept of dual nomenclature (Briquet et al. 1912). Thus, the phase of Puccinia graminis on Berberis was named Aecidium berberidis. However, during the past decade, this concept has been abandoned in favor of "one fungus= one name" (Taylor 2011; Hawksworth et al. 2011). A similar situation is found in red algae, where the so-called chantransia stages in the genus Batrachospermum sensu lato may have been classified in separate genera, such as Audouinella, Chantransia, Ptilothamnion, and others (Necchi and Zucchi 1997; Chiasson et al. 2005; Vis et al. 2006; Necchi et al. 2019). Vis et al. (2006) proposed to formally maintain the chantransia stages in the genus Chantransia, which is not allowed by the Code [ICNafp (Shenzen) Art. 52.1]. Holometabolous insects form strikingly different developmental stages, occupying quite different niches in ecosystems. These were rarely treated as separate taxa but from early on received informal names, such as larva, pupa, and imago (Johnson and Triplehorn 2005; Miller et al. 2005). The fact that the same species can form strikingly disparate morphs, triggered by environment, ontogeny, epigenetics, genotype, or other factors, is thus well-documented across the Tree of Life, and in modern nomenclature these are not treated separately. As a consequence, the appears to be no particular reason why the same fungus forming disparate phenotypes under different conditions should receive different scientific names. Rather, in such instances, the scientific name should be accompanied by a standardized, informal designation, in analogy to e.g., insect stages, such as chloromorph and cyanomorph in the case of photosymbiodemes (Goffinet and Bayer 1997).

This issue also relates to the effort initiated by Thomas (1939) and formally implemented by Ciferri and Tomaselli (1953a, b, 1954a, b, 1955, 1957) to generate separate scientific names for lichen mycobionts in axenic culture. While the latter authors recognized the newly implemented provision by the Code that the scientific name originally given to lichens applies to the mycobiont, they argued that the lichen fungus behaves strikingly different in the lichen symbiosis as compared to its axenic culture. In particular, they concluded that from the thousands of lichens recognized at the time, only a much smaller number of fungi could be isolated in culture. Thus, in their interpretation different lichens shared the same fungus, just as different lichens shared the same photobiont, and so the diversity of lichens was caused by variable combinations of a low number of fungi and algae or cyanobacteria. Their approach was thus ill-defined both scientifically and nomenclaturally (Lücking and Hawksworth 2007).

Recommendation 1: The scientific nomenclature applied to the
fungal and algal or cyanobacterial components of lichens follow
the ICNafp (Shenzen), according to which each biont has its
separate scientific, latinized name. The scientific name denot-
ing lichens corresponds to the primary mycobiont. The scientific
name of the primary mycobiont does not encompass any of the
other components, such as the photobiont or other associated
fungi, algae, cyanobacteria, or bacteria. Therefore, in taxonomic
or nomenclatural works focusing on the mycobiont, the terms
"lichenized fungi" or "lichen-forming fungi" are preferred over
the term "lichen". In biological or ecological works focusing on
the lichen as a whole, the term "lichen" along with the scientific
name is acceptable for practical reasons, but it should be made
clear that scientific names cited in such a context refer to the
mycobiont only. For accuracy, the term "lichen species" should be
avoided, in favor of "lichenized species" or "lichen-forming spe-
cies". In contrast, vernacular names refer to the lichen as a whole
and taxonomic or nomenclatural works should avoid the use of
scientific and vernacular names in exact correspondence. Follow-
ing the principle of one fungus = one name, different phenotypes
and discrete morphs formed by the same mycobiont are not to be
given separate scientific names. Rather, a broadly agreed informal
nomenclature should be applied to naturally occurring discrete
morphs of the same species, such as chloromorph, cyanomorph,
sexual morph, sorediate or sorediomorph, or isidiate or isidi-
omorph




\section{Species concepts and their application in lichenized fungi}

Since Mayr (1944), the species has been widely recognized as the fundamental unit to classify organisms in biodiversity research (Wilson 1988; Mooers 2007; Freudenstein et al. 2017). This is also embedded in the Code, where the valid establishment of taxa above species (beta taxonomy) and below species level (gamma taxonomy) depend on the prior valid establishment of a species name [ICNafp (Shenzen) Art. 10.1, 10.9, 10.10, 24.1, 35.1]. However, the question what defines species remains complex and approaches to this problem have experienced continuous adjustments depending on conceptual and methodological advances. Numerous species concepts have been established over the past century (Mayden 1997; De Queiroz 2007; Wilkins 2009, 2018; Crous et al. 2015; Zachos 2016), but these can all be based on three basic components (Lücking et al. 2020a): lineage $(\mathrm{L})$, phenotype $(\mathrm{P})$, and reproduction $(\mathrm{R})$. Species are branches in the lines of descent, i.e., segments of metapopulation lineages (De Queiroz 2007), typically expected to be reciprocally monophyletic. While reciprocal monophyly as an exclusivity criterion for species delimitation is intuitively appealing, metapopulation lineages may not be recovered as monophyletic of a number of reasons (Knowles and Carstens 2007), including incomplete lineage sorting in recently diverged species, introgression and hybridization (see below), porous or "semi-permeable" species boundaries, and other evolutionary scenarios (Joly et al. 2009; Steenkamp et al. 2018). Therefore, emerging lineages nested within a paraphyletic residual have been accepted as recently evolving species under certain circumstances (Wheeler and Nixon 1990; Crisp and Chandler 1996; Wheeler and Platnik 2000; Funk and Omland 2003; Freudenstein et al. 2017; MercadoDíaz et al. 2020). It is further expected that diverging lineages also diverge in phenotype, including morphology, anatomy, chemistry, metabolism, and physiology, owing to either neutral mechanisms such as genetic drift, selective forces in diverging environments, selecting of sexual partners, or hybridization (Cohan and Hoffmann 1989; Harrington and Rizzo 1999; Grube and Kroken 2000; McGuigan et al. 2005; Pfennig et al. 2007; Mercader et al. 2009; Schoustra et al. 2012; Vigoder et al. 2015; Ament-Velásquez et al. 2020). The third component, at the heart of the biological species concept, is reproductive compatibility within vs. reproductive isolation between species. Ecological features can be considered an extension of phenotype, whereas distribution is independently assessed and may be used to evaluate reproductive isolation, e.g., in cases of sympatry.

In a best-case scenario, as so-called "gold standard", species should be defined through simultaneous assessment of lineages (coherence vs. divergence), phenotype (coherence vs. divergence), and reproductive biology (compatibility vs. isolation), in what we call the Lineage-Phenotype-Reproduction or LPR approach. However, one mostly has to rely on only one or at best two of these approaches. Indeed, species hypotheses can be established from any type of data, but their reliability depends on data quality and quantity. In addition, species can appear phenotypically cryptic or very recently diverged and hence phylogenetically unresolved, because the properties that are used for delimiting species, e.g., reciprocal monophyly or diagnostic phenotypic and ecological traits, may not manifest themselves at the same time or in a regular order (De Queiroz 1998). This also reflects emphasis on different properties among different biological subdisciplines. Ecologists expect to be able to accurately identify species in the field to understand niche differences and so will have difficulties to accept cryptic species. In contrast, phylogenetic properties, such as monophyly, are key for molecular systematists and population geneticists, even if they may not correlate with diagnostic phenotype characters.

Under the unified species concept, in which species represent segments of metapopulation lineages, any diagnostic property can be interpreted as evidence supporting the existence of a species (De Queiroz 2011). However, robustness arguments hold that hypotheses are more likely to be true when they are confirmed by multiple, diverse lines of evidence (Stegenga and Menon 2017). Thus, species hypotheses should be considered more robust with increasing corroboration from appropriately interpreted, independent data sources (i.e., phylogenetics, morphology, anatomy, chemistry, ecology, etc.), and integrating independent data for empirical species delimitation studies should be a major focus of species delimitation research in lichen fungi (Fujita et al. 2012; Lücking 2020; Lücking et al. 2020a). The paradigm of the unified species concept shifts the emphasis from traditional species criteria, focusing on "visual recognizability", towards utilizing operational criteria that incorporate new methods and quantitative data for species delimitation (Tobias et al. 2010; Camargo and Sites 2013). This may create the uncomfortable sentiment that a species is whatever the contemporary methodology determines it to be, rather than relying on the expertise of taxonomist and naturalists most familiar with the group (Raposo et al. 2020).

Recognizing that species are ontologically subjective entities, dictated by multiple ontological natures, taxonomist face the task of identifying and utilizing the most objective criteria for practical solutions to the potentially conflicting ontological nature of species, including lichen fungi (Laurin 2010). Therefore, phenotypic characters apparent to human observers may not consistently diagnose species. Evidence from molecular sequence data provides unprecedented insight into lineage status and is particularly relevant to 
species delimitation studies when analyzed within a rigorous statistical framework (Grewe et al. 2018). However, with genome-scale data practically every population will be diagnosable given enough resolution power (Zachos et al. 2013; Sukumaran and Knowles 2017; Widhelm et al. 2021), a problem that may also occur with fine-scaled behavioral, ecological and morphological traits. As a consequence, the potential to delimit this "fractal hierarchy of divergences" (Sukumaran and Knowles 2017) may result in infraspecific entities erroneously recognized as species (false positive or type I error, see below), resulting in inflated estimates of species diversity and "taxonomic anarchy" (Garnett and Christidis 2017; Raposo et al. 2020). While these leastinclusive entities may have importance in conservation strategies (Moritz 1994), their invariable recognition as species is taxonomically inaccurate and application of infraspecific categories may be more appropriate (see below). Ultimately, the limit between species (alpha) and infraspecies (gamma) taxonomy can only be determined by empirical or experimental evidence of reproductive compatibility vs. isolation (i.e., the biological component), although phenomena such as hybridization render this approach diffuse and in asexually reproducing lineages it is not readily applicable (Arnold et al. 1999; Schardl and Craven 2003; Wilkins 2009; Ament-Velásquez et al. 2020; Keuler et al. 2020). Indeed, assessment of potential hybridization defies the biological species concept as it may lead to circular reasoning: successful reproduction between two closely related lineages resulting in fertile offspring would imply that they represent a single species, with a proper classification at infraspecies level; however, their interpretation as distinct species, with interspecies hybridization leading to fertile offspring, is equally possible (Taylor 2009; Marchetti and Moyle 2010; Simon 2013). Disentangling such situations is a major challenge in alpha taxonomy, although in practical terms it has only been assessed in detail in few organisms, such as lion/ tiger hybrids (ligers, tigons) or the Neanderthals and modern humans (Schillaci and Froehlich 2001; Clarke 2016).

A more immediate problem is that the assessment of reproductive compatibility and isolation is a challenge in fungi including lichen-formers and, as stated above, may not be applicable when lineages reproduce only asexually. Fungal model species, such as Neurospora crassa, have been used to test reproductive compatibility vs. isolation in the delimitation of species (Bistis 1981; Glass and Kuldau 1992; Dettman et al. 2003; Ni et al. 2011). However, this approach is not feasible as a routine component in the alpha taxonomy of fungi, particularly lichen-formers (Culberson et al. 1993; Magain et al. 2017) and has therefore only been employed in a few cases (e.g., Liu et al. 2016). Indeed, the mechanisms of sexual reproduction in lichen fungi are virtually unstudied in most species, although they can be hypothesized by comparison with related Ascomycota or Basidiomycota and their corresponding underlying structures, such as trichogynes, which have been demonstrated in lichen-formers (Henssen and Jahns 1973; Honegger 1984; Ahmadjan 1993; Jahns et al. 1995; Krishnamurthy and Upreti 2001; Keller and Scheidegger 2016). As a whole, the biological species concept in terms of direct testing of reproductive compatibility or isolation therefore has limited used in the alpha taxonomy of lichen fungi, although indirect evidence of past recombination or the lack thereof can be drawn from molecular data and is employed in coalescent approaches (Leavitt et al. 2011a, b, 2015; Wirtz et al. 2012; Onuț-Brännström et al. 2017; Boluda et al. 2019). As a consequence, modern alpha taxonomy largely aims at combining phylogenetic and phenotypic evidence in a polyphasic approach or integrative taxonomy (Dayrat 2005; Will et al. 2005; Padial et al. 2010; Crous et al. 2015; Goulding and Dayrat 2016; Lücking 2019; Vinarski 2020; Lücking et al. 2020a), and lichen-forming fungi are no exception.

Until the turn of the twentieth century, species of lichenized fungi were delimited based on phenotype, employing the principles of variational discontinuity, using a deviating phenotype as evidence for lineage separation. A thus defined species would exhibit a certain level of variation but also a variational gap compared to its most similar counterpart. Up to the early twentieth century, the concept of variation was either not well understood or the often sparse material did not allow the proper assessment of variation, which in many cases resulted in the description of the same species many times over. Currently, the proportion of accepted vs. described species-level names in lichen fungi oscillates around 50\%, which means that on average, each species has presumably been described twice. However, even if taxa are well-documented, a problem of assessing variation based on phenotype alone is that it may stem from circular reasoning: without an independent criterion to define a group of related individuals, variation is essentially determined ad hoc, by deciding which individuals to include or exclude in a presumed species. One way to address this problem was the introduction of phenetics or numerical taxonomy, which implements quantitative analytical methods and hence unveils variational discontinuities independent of a priori groupings (Sneath and Sokal 1962, 1973; Kendrick and Proctor 1964; Sheard 1978; Park and Hong 1985; Sneath 2005). A main criticism of phenetics has been that it relies on overall similarity (or distance) and not on shared ancestry, but it is precisely the variational discontinuity that provides a first hypothesis on species delimitation, whereas shared ancestry focuses on relationships, not species delimitation. Therefore, methods originally established as part of phenetics, such as multidimensional ordination and statistical group comparisons, continue to be highly useful in integrative taxonomy and should be employed whenever 
possible (Tobias et al. 2010; Arup and Sandler-Berlin 2011; Zahradníková 2017; Lücking et al. 2020a).

While cladistics offered a new tool to establish classifications (Hennig 1950, 1966), it was initially of little use for the purpose of alpha taxonomy, since diagnostic characters at the species level are often morphometric and these are difficult to analyze in a cladistic context. For instance, three measures X, Y, and Z of the same underlying structure (e.g., thallus thickness) will be interpreted as three separate states of equal weight in a cladistic analysis, although they may represent different distances in character space, e.g., $X$ being closer to $\mathrm{Y}$ than to $\mathrm{Z}$. This problem can be remedied by transforming morphometric characters into a series of binary characters, e.g., $X \rightarrow 00, Y \rightarrow 10, Z \rightarrow 11$, to the extent that similarity in a cladistic context reflects actual similarity. Another problem with cladistics is that a cladogram relates units to each other but does not separate them, i.e., it does not reflect variational discontinuities, unless phenetic distances are expressed through branch lengths by computing a phylogram instead of a cladogram. As stated, the notion that a phenotype-based cladogram or phylogram does not usually reflect actual relationships between taxa, due to the usually high level of homoplasy in phenotype data, is of little importance for alpha taxonomy and therefore not usually a limiting factor in the application of cladistics to phenotype data, because alpha taxonomy addresses the distinctiveness of species, not their underlying relationships. Even so, multivariate analytical tools remain overall superior to cladistic approaches when it comes to the analysis of phenotype data, as they are a better fit to the nature of such data, in particular morphometrics (Marhold 2011).
Molecular phylogenetics has provided an entirely new pathway to classify and delimit organisms, from the highest taxonomic levels down to infraspecies, particularly in Fungi and fungus-like organisms (Hibbett et al. 2007; Printzen 2010; Lumbsch and Leavitt 2011; Lücking et al. 2017a; Tedersoo et al. 2018; James et al. 2020; Li et al. 2021). Compared to phenotype data, molecular phylogenetics has four major advantages: (1) molecular data provide a conceptually independent framework to define clade-based units, as long as the employed markers are not causally correlated with diagnostic phenotype characters; (2) the number of characters that can be employed, i.e., sites in a multiple sequence alignment, exceeds phenotype matrices by one to several orders of magnitude (Table 2), providing far superior statistical power; (3) the proportion of putative homoplasies in DNA sequences is much lower than in phenotype characters, particularly in organisms with simple body plans, such as fungi including lichen-formers (Fig. 4); and (4) DNA sequences allow to implement evolutionary models based on the structure of the DNA and the mechanisms of DNA replication, e.g., by distinguishing between purine $(\mathrm{A}, \mathrm{G})$ and pyrimidine bases $(\mathrm{C}, \mathrm{T})$. As a consequence, molecular phylogenies are a priori more reliable than phenotype-based cladograms and thus provide a contextual framework within which to interpret phenotypic variation. However, conflicts often arise between molecular phylogenies and previously established phenotype-based taxonomies. In the overwhelming number of cases, these are resolved by assuming phenotypic homoplasy, rearranging the taxonomy in correspondence with the molecular phylogeny (Schmitt et al.

Table 2 Comparison of the number of phenotypic and molecular characters from selected studies, with the ratio of molecular vs. phenotypic characters indicated in orders of magnitude

\begin{tabular}{|c|c|c|c|c|}
\hline Taxon & $\begin{array}{l}\text { Phenotype } \\
\text { characters }\end{array}$ & $\begin{array}{l}\text { Molecular } \\
\text { characters (sites) }\end{array}$ & $\begin{array}{l}\text { Ratio } \\
\text { (magnitude) }\end{array}$ & Reference \\
\hline Arthoniales & 92 & 1500-2062 (mtSSU, nuLSU, RPB2) & $1-1.5$ & $\begin{array}{l}\text { Tehler (1990), Ertz and Tehler (2011), Frisch } \\
\text { et al. (2014) }\end{array}$ \\
\hline $\begin{array}{l}\text { Allographa vs. Graphis } \\
\text { (Graphidaceae) }\end{array}$ & $48-52$ & 1573 (mtSSU, nuLSU) & 1.5 & $\begin{array}{l}\text { Berger et al. (2011), Rivas Plata et al. (2011) } \\
\text { Lücking and Kalb (2018) }\end{array}$ \\
\hline $\begin{array}{l}\text { Chapsa sensu lato } \\
\text { (Graphidaceae) }\end{array}$ & 59 & 2482 (mtSSU, nuLSU, RPB2) & 1.5 & Parnmen et al. (2012) \\
\hline $\begin{array}{l}\text { Diploschistes } \\
\text { (Graphidaceae) }\end{array}$ & $31-33$ & 578 (ITS), 2350 (ITS, mtSSU, nuLSU) & $1.5-2.5$ & $\begin{array}{l}\text { Lumbsch and Tehler (1998), Martín et al. } \\
\text { (2003), Fernández-Brime et al. (2013) }\end{array}$ \\
\hline $\begin{array}{l}\text { Ocellularia clade } \\
\text { (Graphidaceae) }\end{array}$ & 54 & 2985 (mtSSU, nuLSU, RPB2) & $1.5-2$ & Rivas Plata et al. (2012) \\
\hline Gomphillaceae & 205 & 1036-1610 (mtSSU, nuLSU) & $0.5-1$ & $\begin{array}{l}\text { Lücking et al. (2004), (2005), Xavier-Leite } \\
\text { et al. (2021) }\end{array}$ \\
\hline $\begin{array}{l}\text { Sticta filix, S. lacera } \\
\text { (Peltigeraceae) }\end{array}$ & 4 & $\begin{array}{l}551 \text { (ITS), 250,000 (target capture of } 205 \\
\text { markers) }\end{array}$ & $2-5$ & Lücking et al. 2021b \\
\hline $\begin{array}{l}\text { Cora } \\
\text { (Hygrophoraceae) }\end{array}$ & 20 & 816 (ITS) & 1.5 & Lücking et al. (2017b) \\
\hline
\end{tabular}

Taxa in systematic order 


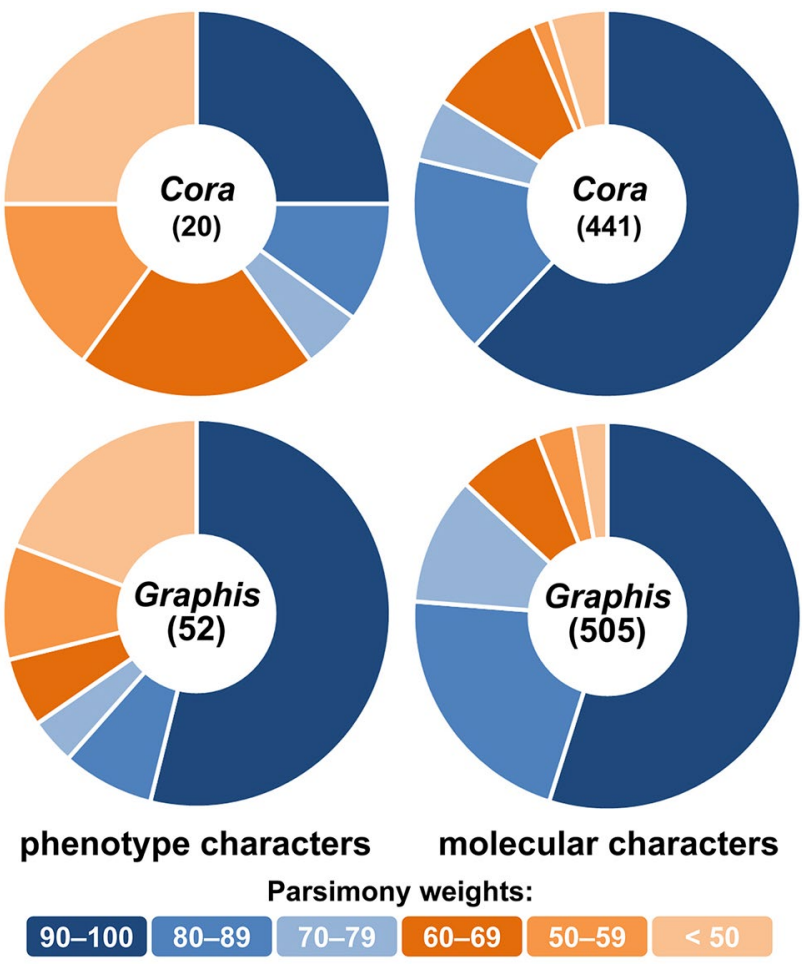

Fig. 4 Quantitative assessment of homoplasy in phenotype vs. molecular characters in the genus Cora (Hygrophoraceae) and in the genera Graphis and Allographa (Graphidaceae). For Cora, a matrix of 20 phenotype characters and an ITS alignment consisting of 441 variable sites was used, whereas for Graphis and Allographa, a matrix of 52 phenotype characters and a concatenated mtSSU and nuLSU alignment consisting of 505 variable sites was employed (data from Berger et al. 2011; Rivas Plata et al. 2011; Lücking et al. 2017b; Lücking and Kalb 2018). In all cases, the underlying phylogeny was reconstructed from the data using a maximum likelihood approach in RAxML 8 (Stamatakis 2014), employing GTRGAMMA for the molecular data and MULTIGAMMA for the phenotype characters. The level of homoplasy was assessed by computing a parsimony weight vector in RAxML 7 (Berger et al. 2011) encompassing all sites or characters for each dataset. The assessed weights oscillate between 100 (no homoplasy) and 0 (high homoplasy) and the resulting weights were divided into six categories. Blue colors denote more or less consistent (weight $=70-100)$ and orange colors more or less homoplasious characters (weight $=0-69)$

2005a; Crespo and Pérez-Ortega 2009; Parnmen et al. 2010; Lumbsch and Leavitt 2011; Rivas Plata and Lumbsch 2011; Leavitt et al. 2011a, b; Bendiksby and Timdal 2013; Fryday et al. 2017; Lücking et al. 2017c). Instances in which a supported phylogeny may be rejected in favor of a previously established taxonomy are rare and usually explained by problems in the molecular data, including unrecognized paralogs, introgression, unrecognized contaminants or sequence labeling errors, or chimeric data sets (Steinova et al. 2013; Lücking and Nelsen 2018; Vondrák et al. 2018; Llewellyn 2019; Keuler et al. 2020; Lücking et al. 2020b; Wilk et al. 2021), problems discussed in detail at the end of this paper.
With the parallel or combined application of phenotype(P) and lineage-based (L) approaches, delimitation of species in lichen fungi currently follows two general strategies:

- Initially delimiting potential species based on phenotype, where possible using a quantitative approach. Such "species hypotheses" may subsequently be tested by molecular approaches. This "first $\mathrm{P}$ then $\mathrm{L} "$ approach is preferred when either molecular methods are not accessible or too resource-intensive or when the material is too old to allow for extraction of suitable DNA. By default, it applies to all names established in the pre-molecular era, although quantitative analytical methods were rarely applied in these cases.

- Initially delimiting potential species based on molecular phylogenies, using a phylogenetic species concept, i.e., a combination of branch support and branch length patterns, or in addition an assessment of coalescence between several markers. This principle is used in quantitative species delimitation methods. The thus delimited lineages are subsequently compared with phenotype features, ideally in a quantitative manner, in a "first $\mathrm{L}$ then $\mathrm{P}$ " approach.

A priori, neither one of the two approaches is superior to the other; rather, the quality of the outcome depends on the quality and resolution of the data and methods employed. Each approach is useful for establishing species hypotheses, even when using only a single phenotype character or a single marker. However, depending on the complexity of the underlying situation (i.e., the complexity of the "truth"), the $\mathrm{P}$ approach alone has a lower probability to be accurate: it may erroneously recognize species that do not represent distinct entities (false positive or type I error), by misinterpreting variational discontinuities or discrete variation, as in the aforementioned cases of photosymbiodemes, or it may erroneously overlooking species that underwent cryptic speciation or in which phenotypic variation is too broadly defined (false negative or type II error), such as in the collective species Cora glabrata and Cetraria aculeata (Lücking et al. 2014, 2017b; Pérez-Ortega et al. 2012; Lutsak et al. 2020). A type I error is much less likely with the $\mathrm{L}$ approach alone but may occur in cases of intragenomic variation such as gene duplication or introgression (Lücking et al. 2020a; see below). A type II error is also less likely with molecular data but depends on the markers employed, since the level of resolution differs between markers, as shown by the example (see below) of Usnea aurantiacoatra vs. U. antarctica (Wirtz et al. 2008, 2012; Grewe et al. 2018; Lagostina et al. 2018; Lücking et al. 2020b). The main difference between the $\mathrm{P}$ and $\mathrm{L}$ approaches, when used without the other, is that with the first, there is a likelihood 
of erroneously delimiting polyphyletic entities, whereas with the second, tha likelihood is close to zero. A striking example is the macrolichen Sticta fuliginosa. Traditionally delimited based on a set of correlated phenotype characters using a $\mathrm{P}$ approach, i.e., broad, sparsely branched lobes with laminal isidia, a pale underside and usually large, somewhat irregular cyphellae (Swinscow and Krog 1988; Brodo et al. 2001; Galloway 2007; Jørgensen and Tønsberg 2007; Smith et al. 2009), this taxon was resolved as highly polyphyletic (Moncada et al. 2014; Magain and Sérusiaux 2015). If the taxonomy of this complex had started by using the L approach, i.e., molecular data, the taxon would never have been established in its traditional sense in the first place.

In both the $\mathrm{P}$ and $\mathrm{L}$ approach, the inclusion of multiple independent characters increases reliability. In a molecular phylogenetic approach, a single marker already consists of multiple characters (sites), typically higher in number than an entire set of phenotype characters (Table 2). However, the individual sites in a molecular marker are not necessarily functionally independent: while replication errors causing the underlying variation are random and independent for each site, their fixation as alleles depends on their position and the relevance for the function of the gene, such as the three-dimensional structure of the transcribed RNA (e.g., ribosomal DNA) or the structural function of the translated amino acid sequence in a protein or enzyme. Thus, increasing the number of molecular markers distributed across the genome increases the statistical power of the analysis and enables the assessment of potential conflict between markers, which is often at a similar level as conflict between complexes of phenotype characters, e.g., in lichen fungi ascoma vs. thallus characters or morphology vs. chemistry (Culberson 1963, 1973; Santesson 2004; Lücking 2009, 2012; Messuti and Archer 2009; Aptroot and Lücking 2016). While single markers such as the fungal ITS barcoding locus may be sufficient to considerably improve the underlying taxonomy of particular genera, such as in ascolichens of the genus Sticta or basidiolichens of the genera Cora and Sulzbacheromyces (Moncada et al. 2014; Liu et al. 2017; Lücking et al. 2017b; Coca et al. 2018; Ranft et al. 2018), additional markers may either support the topology obtained from a single marker or increase resolution where a single marker such as the ITS is not sufficient. For this purpose, a combination of a small number of functionally and genomically distinct markers, in addition to the ITS also the mitochondrial small subunit (mtSSU), the nuclear large subunit (nuLSU), and one or several protein-coding markers (e.g., $M C M 7, R P B 1, R P B 2, T E F 1, T U B 2)$, usually provides sufficient resolution to assess species boundaries (e.g., Wirtz et al. 2008, 2012; Pino-Bodas et al. 2010a, b; Leavitt et al. 2011a, b, 2018; Rivas Plata et al. 2013; Frisch et al. 2014; Gerlach et al. 2017, 2019, 2020).
As mentioned above, an intrinsic problem with molecular phylogenies or cladistic approaches is that the resulting topology cannot be automatically translated into taxonomies, since the underlying philosophies, establishing relationships vs. establishing discrete categories, are different (Hibbett and Donoghue 1998; Franz 2005; Assis 2009; Lücking 2019). However, variational discontinuities in phylogenies can be assessed by employing quantitative species recognition methods, which assess branch length patterns within and between clades, such as the Generalized Mixed Yule Coalescent (GMYC) or the Poisson Tree Processes (PTP) approach (Fujisawa and Barraclough 2013; Zhang et al. 2013), and/or assess coalescence between markers, such as Bayesian species delimitation, the Bayesian Phylogenetics and Phylogeography (BPP) approach and the Accurate Species TRee ALgorithm or ASTRAL (Yang and Rannala 2010; Fujita et al. 2012; Mirarab et al. 2014; Yang 2015). These approaches go beyond the underlying phylogeny as they quantitatively delimit discrete, lineage-based entities. If the underlying study group is sampled with multiple individuals per entity, these methods serve to establish molecular and test morphological species hypotheses, although the taxonomic status of these entities depends on considerations such as distribution (see below). If sampling represents single individuals per entity, these methods can also be hijacked to define higher-level taxa (Humphreys and Barraclough, 2014; Barraclough and Humphreys, 2015; Lücking 2019). A problem with multimarker coalescent approaches is that some markers may result in artifactual topologies when representing paralogs, which may be the case with protein-coding markers (Keeling and Inagaki 2004; Hubka and Kolarik 2012; Zhao et al. 2014; Lücking et al. 2020a, b). This should be carefully assessed before translating coalescent-based species trees into formal taxonomies.

The barcoding gap has also been used as an approach to delimit species, including lichen-forming fungi (Del Prado et al. 2011; Puillandre et al. 2012; Xu et al. 2017). It is conceptually related to single-marker quantitative species delimitation such as GMYC, in that it assesses variational discontinuities in branch lengths. However, the difference is that the barcoding gap usually sets a threshold a priori, through pairwise comparison between species, whereas quantitative species delimitation provides an a posteriori assessment without a fixed threshold. Given that fixed thresholds to dot exist between species, but stem branch length depends on the time since divergence (Nilsson et al. 2008; Collins and Cruickshank 2013; Leavitt et al. 2016a; Lücking et al. 2020a), the barcoding gap approach is generally inferior to quantitative species delimitation methods. An additional disadvantage is that it assesses differences between all possible pairs of species, whereas only those between sister species or closely related species are actually relevant. Therefore, the barcoding gap approach should preferable be 
used in combination with a quantitative species delimitation method, to assess the usefulness of individual markers for subsequent species identification through molecular barcoding (Lücking et al. 2020a).

Whereas testing an existing alpha taxonomy with molecular methods (first $\mathrm{P}$ then $\mathrm{L}$ approach) provides some sort of integrative taxonomy by default, the advent of molecular methods initially challenged the usefulness of traditional taxonomy, not because of conflicting results but because it was soon believed that DNA sequence data alone could solve everything. It took some time to come to the conclusion that the integration of phenotype characters into molecular phylogenies was crucial to obtain sound and stable alpha taxonomies. As such, the approach of integrative taxonomy (i.e., $\mathrm{L}$ and $\mathrm{P}$ approach combined), has long been the aim of taxonomists, even if the term "integrative taxonomy" was only rather recently adopted in systematics (Dayrat 2005; Will et al. 2005). Integrative methods for species delimitation fall across a broad spectrum, ranging from verbal and qualitative assessments of data classes to quantitative methods that allow different data types to contribute to statistically assessed species delimitation. Any study linking at least two kinds of data (L, P and/or R) to support species hypotheses, including simple mapping morphological characters onto a molecular phylogeny, can be considered integrative. In practice, these data are not analysed simultaneously in a "total evidence" approach, but rather one kind of data is repeatedly tested with another in a refined manner, in an iterative, hypotheticodeductive framework (Yeates et al. 2011). As the most basic approach, comparing phenotypic characters to phylogenies is useful to identify the least inclusive monophyletic clade in the topology characterized by at least one unambiguously diagnostic phenotypic trait (e.g., Miralles and Vences 2013). In lichen fungi, previously unrecognized species-level clades with corresponding subtle, or overlooked, phenotypic characters have been commonly observed using this approach (e.g., Crespo and Pérez-Ortega 2009; Pino-Bodas et al. 2010a, b; Arup and Sandler-Berlin 2011; Leavitt et al. 2015; Altermann et al. 2016; Lücking et al. 2017c; Frolov et al. 2016; Orange 2018; Kistenich et al. 2019; Frisch et al. 2020).

Besides mapping of previously established taxonomies onto molecular phylogenies, an additional step is the assessment of type material of names to determine their placement in the revised phylogeny and hence the applicable nomenclature. Given that these steps are time consuming and require expertise far different from what is required to generate and analyse sequence data, linking inferences from integrative taxonomic approaches with formal taxonomic changes remains an often postponed task (Vinarski 2020). Molecularly delimited species-level lineages are frequently treated as "putative" or "candidate" species, using working names or alphanumeric clade designations, rather than providing formal descriptions.
For instance, the seminal work by Kroken and Taylor (2001) on the genus Letharia, pioneering the multimarker coalescent approach in lichen fungi, established that the two traditionally distinguished taxa, L. columbiana (consistently apotheciate) and L. vulpina (always sorediate, rarely also with apothecia) represent between five and six distinct species. It took 15 years for four of these to be formally recognized, as $L$. columbiana s.str., L. gracilis, L. lupina, and L. vulpina s.str. (McCune and Altermann 2009; Altermann et al. 2016), while two entities still retain the provisional names $L$. "barbata" and $L$. "rugosa". Not rarely, such delays reflect the amount of time and resources necessary to provide an updated taxonomy, especially when large numbers of undescribed species are involved, such as in the genera Cora, Peltigera, and Sticta, where many taxonomically and phylogenetically recognized lineages still await formal description (Moncada 2012; Moncada et al. 2013a, b, 2014, 2015; Lücking et al. 2014, 2017b; Magain et al. 2017; Simon et al. 2018).

Effective approaches for encouraging formal taxonomic proposals with robust integrative species delimitations analyses should remedy this problem, such as "turbo-taxonomy" (Butcher et al. 2012; Riedel et al. 2013; Lücking et al. 2017b). However, "turbo" should not mean fast and sloppy, but instead effective while adhering to quality standards in terms of analyzing and documenting the data (Lendemer 2021; Aime et al. 2021). The study of type material and original literature is nowadays much easier through digital repositories such as JSTOR Global Plants [https://www. jstor.org] or the Biodiversity Heritage Library [https://www. biodiversitylibrary.org]. Taxonomic research using integrative approaches will not only result in a solid foundation for biodiversity and conservation studies but also tends to have higher "impact", including higher citation performance and broader readership, than non-integrative studies, due to the immediate appeal beyond taxonomy (Vinarski 2020). For instance, the recent "turbo-taxonomic" study of Cora, describing 70 new species based on a combination of molecular and phenotype data and with the generation of automated descriptions from a comprehensive data matrix (Lücking et al. 2017b), has been cited nearly 50 times in four years, including in non-taxonomic studies and studies unrelated to this genus. In contrast, an earlier work on the taxonomy of Cora and related genera, including a key to all species known at the time (Lücking et al. 2013), has been cited less than 40 times in eight years, almost exclusively in other taxonomic works. The comprehensive, exemplary inventory of lichens and associated fungi from Glacier Bay National Park, integrating expert field work and taxonomy with molecular assessments in a multi-authored study (Spribille et al. 2020) already generated around 20 citations since its publication last year, translating into a high impact factor. Indeed, the combination of taxonomic and other methodological expertise, reflected in multiple authorship, 
increases the impact of taxonomic papers (Lücking 2021). Data assembled for the purpose of integrative taxonomy can also be used to elaborate sophisticated studies on the evolution of the lichen symbiosis, as shown by the study on the Trapeliopsis-Placopsis clade by Schneider et al. (2016).

Beyond iterative approaches to species delimitation, other conceptual and methodological perspectives have been important to better understanding species boundaries and promote taxonomy in lichen fungi, e.g., population genetics and phylogenomics (Grewe et al. 2018; Muggia et al. 2020; Werth et al. 2021; Widhelm et al. 2021), phenotype-based phylogenetic binning (Lücking et al. 2015; Perlmutter et al. 2020), ecological modelling (Lendemer et al. 2015; Smith et al. 2016), or conservation assessments (Miądlikowska et al. 2014b; Lücking et al. 2020c). Other modern approaches, including machine learning and process-based approaches, have not yet been used for lichen fungi but hold tantalizing promise. Machine learning methods can accommodate various data types and are ideally suited for species delimitation (Derkarabetian et al. 2019). Processed-based analyses can evaluate demographic models consistent with a variety of modes of speciation, requiring researchers to use their expertise with the focal system to identify a reasonable model (Smith and Carstens 2020). The difference between machinelearning methods and other quantitative approaches, such as coalescence-based multi-marker phylogenies or quantitative character mapping, is that machine learning methods can be trained with well-established species-level taxa, integrating both molecular and phenotype data and even approaches such as distribution modeling. As a result, and depending on the quality and quantity of the training data, these methods provide a more flexible approach tailored to each group and are potentially able to reliably distinguish between species- and population-level lineages, potentially providing a quantitative framework to resolve between alpha and gamma taxonomy. However, this should not be misinterpreted as an approach to fully automate taxonomy, seemingly making taxonomic expertise superfluous. In reality, such methods require explicit predictions driven by familiarity with the target group, accurately identified training taxa, and proper connection of the thus delimited species to the evolutionary processes by which they were formed. One should also not misconceive the idea of taxonomic expertise as an undesired subjective approach to science. Good taxonomists do not just define species ad hoc or memorize large quantities of names; they able to perform effective pattern recognition and filtering of diagnostic characters upon visual inspection of a set of samples, processes for which non-taxonomists need the help of computerized tools.
Recommendation 2: The delimitation of species in lichen-forming fungi should not be dogmatically driven by the application of one or another particular, formalized species concept. Rather, species should be delimited empirically from the underlying evidence, choosing the solution that best explains the data in each case. However, where applicable and feasible, the main underlying components of formalized species concepts should be considered: lineage coherence vs. divergence (L), variational continuity vs. discontinuity in the phenotype $(\mathrm{P})$, and evidence for reproductive compatibility vs. isolation (R), either explicitly or implicitly. In analogy to the use of algorithmic approaches when reconstructing phylogenies from molecular data, it is recommended to employ statistical, multivariate methods to assess phenotype variation and divergence and to correlate these with underlying molecular phylogenies where available. In order to increase taxonomic output, it is recommended to streamline formalistic approaches while at the same time maintaining the highest possibly level of quality.

\section{The species pair concept and dual nomenclature in lichenized fungi}

Due to their symbiotic nature, and in contrast to other fungi, lichens have three basic means of reproduction and dispersal: (1) sexually, via meiotic asco- or basidiospores, produced in asco- or basidiomata, usually after fertilization through hyphal fusion or mitotically produced spermatia (usually corresponding to microconidia); (2) asexually via mitotic conidia (usually corresponding to macroconidia), produced in conidiomata of various sorts, including campylidia, hyphophores, and sporodochia; and (3) asexually via structures containing both bionts, such as soredia, isidia, schizidia, and other thallus fragments. In reality, reproduction and dispersal in lichens is arguably much more complex, encompassing a variety of symbiotic and aposymbiotic propagules (Tripp and Lendemer 2018). Although various types of propagules may be produced in the same individual, frequently a lichen thallus exhibits only one reproductive strategy (Fig. 5). As a consequence, individuals may be identical in overall morphology except their means of reproduction and dispersal. Given that alpha taxonomy in lichens was initially based on external morphology, the different means of reproduction and dispersal were interpreted as taxonomically important characters and therefore the specimens displaying such differences assigned to different species. Notably, the potentially close relationship of these morphs was not recognized until early into the twentieth century (Du Rietz 1924). For instance, when establishing Physcia obscurata (now Heterodermia obscurata), Nylander (1863) compared it with $P$. speciosa (now Heterodermia speciosa), on account of the lip-shaped soralia, but not with Parmelia flabellata (now H. flabellata), its apotheciate counterpart (Fig. 5a-b). 
Fig. 5 Different reproductive morphs in lichen fungi. a-b Heterodermia flabellata (apotheciate) and its asexual counterpart, H. obscurata (sorediate). c-d Porina alba with perithecia and disc-shaped phyllidia (previously named Phyllophiale alba). e-f Gyalectidium filicinum with apothecia and squamiform hyphophores (previously named Cristidium pallidum)

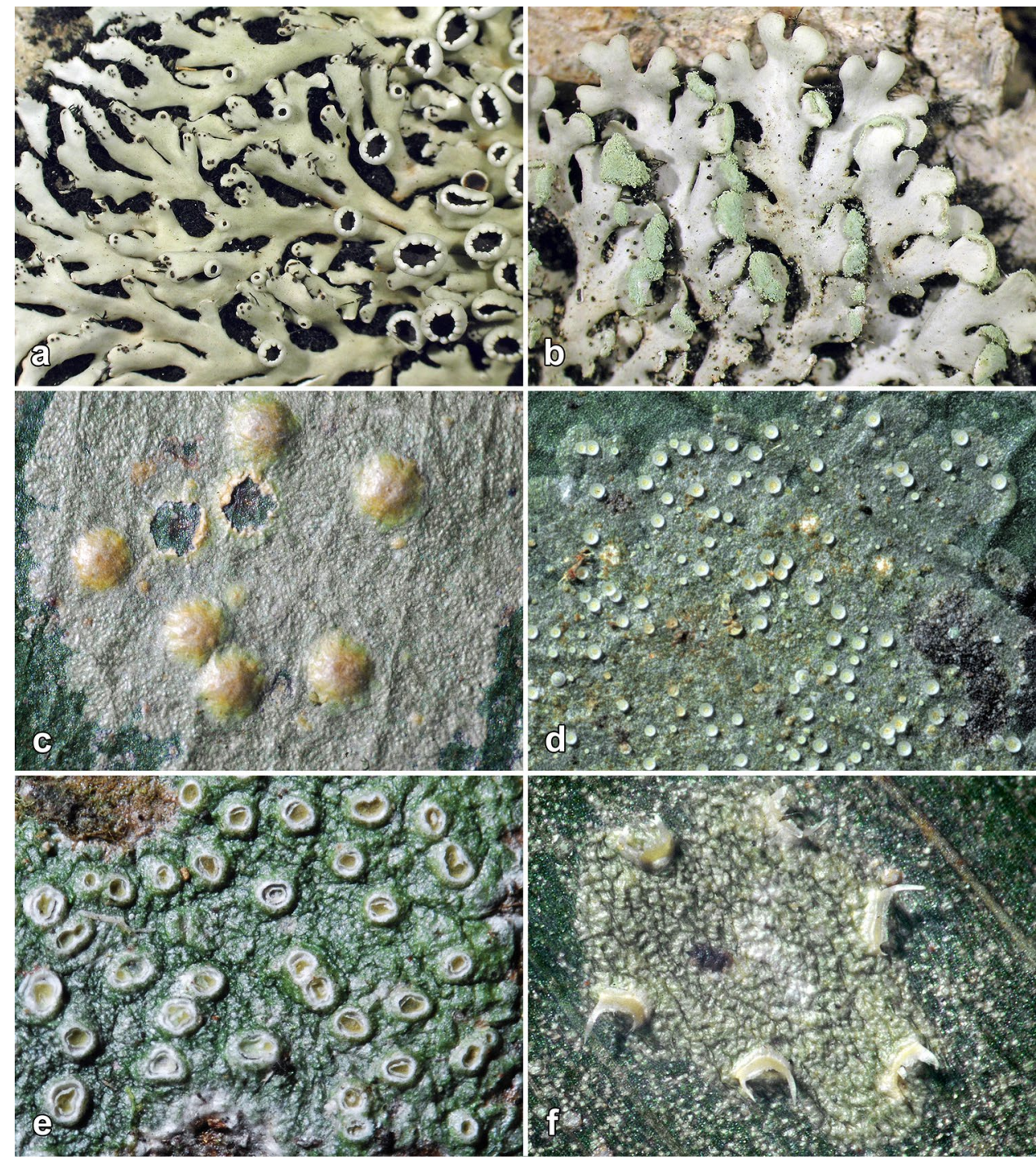

Du Rietz (1924) was the first to establish the hypothesis that phenotypically identical morphs of lichens differing only in their reproductive mode are closely related, and he introduced the concept of so-called "species pairs" for these. Only much later, Poelt (1970, 1972a, b), formalized the species pair concept, calling the apotheciate morphs "primary species" and the asexually reproducing (usually sorediate) morphs "secondary species". Poelt thereby postulated that sexually reproducing morphs must be ancestral to those reproducing asexually, via an "unstable" (i.e., polymorphic) intermediate morphs that produces both ascomata and asexual propagules. Poelt (1970) considered such intermediate morphs rare, but species producing both functional ascomata and asexual propagules on the same thallus are actually quite frequent (Fig. 6). It is thus implied in Poelt's hypothesis that even extant species may represent polymorphic assemblies, depending on their evolutionary history and age. It also means that such polymorphic lineages, not the purely sexually reproducing lineages, are direct ancestors of "species pairs", applying the concept of ancestral polymorphism (Guerrero and Hahn 2017) to the phenotype (Wheeler and Platnik 2000).

Poelt (1970) claimed that species pairs only occur in lineages producing apothecia (i.e., ascomata with exposed discs), typically associated with sorediate (rarely isidiate) counterparts. Indeed, species pairs are rare in lichenized lineages with perithecioid ascomata, simply because soredia or isidia are rare in these groups. However, species pairs have been established in these cases as well, such as Porina imitatrix vs. $P$. distans, $P$. mirabilis vs. Phyllophiale alba (Fig. 5c-d), and P. fusca vs. Ph. fusca (Lücking 1991, 2008; Vězda 1994). Poelt (1970) further observed that, when apothecia are present in otherwise sorediate morphs, these are 
Fig. 6 Different reproductive structures formed on the same thallus. a Dirinaria papillulifera (apothecia and isidia). b Pyxine eschweileri (apothecia and soredia). c Chapsa defecta (apothecia and soredia). d Strigula schizospora (perithecia and pycnidia). e Badimia elixii (apothecia and campylidia).f Gyalideopsis vainioi (apothecia and hyphophores)

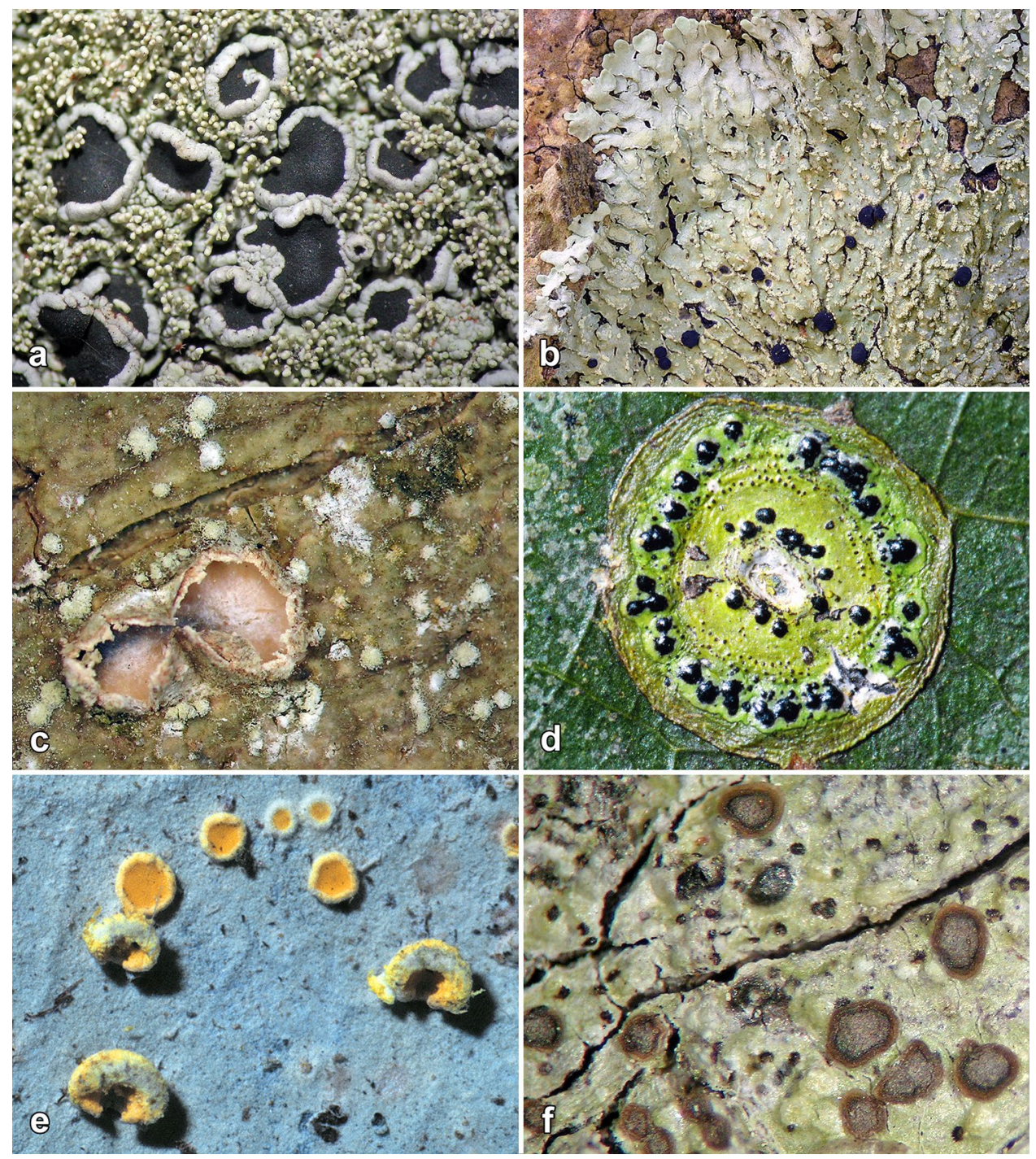

usually depauperate and non-functional. Again, this seems to depend on individual cases.

In his assessment, Poelt (1970) provided a list of 31 examples of presumed "species pairs", explicitly excluding large genera such as Heterodermia, Ramalina, Roccella, and Usnea, where he implied the existence of many additional cases. According to Poelt (1970, 1972a), species pairs should be considered separate taxa, under the assumption that the morph representing the secondary species only evolved once, leaving the primary species as paraphyletic residual. This was challenged by Tehler (1982), who postulated that morphs with asexual reproduction may have evolved multiple times within a lineage and so the entire complex could to be considered a single species with variable modes of reproduction.

Besides empirical data, there are several conceptual challenges to the "species pair" concept. The most obvious is that in many cases, there are two or more "secondary species", one producing soredia and the other isidia or other asexual propagules (e.g., phyllidia). Prominent examples include Coccocarpia erythroxyli (apotheciate) vs. C. palmicola (isidiate) vs. C. pellita (phyllidiate; Arvidsson 1982); Heterodermia flabellata (apotheciate) vs. H. obscurata (sorediate) vs. H. crocea (isidiate) vs. H. flavosquamosa (phyllidiate; Harris 1990); Pannaria rubiginosa (apotheciate) vs. P. conoplea (phyllidiate-sorediate) vs. P. tavaresii (isidiate; Jørgensen 2000); and the striking case of Hypotrachyna physcioides (apotheciate) vs. H. laevigata (sorediate) vs. $H$. imbricatula (isidiate) vs. H. steyermarkii (isidiate with cilia) vs. H. spinulosa (spinulose; Sipman et al. 2012). Since it is difficult to conceive that isidiate morphs evolved from sorediate ancestors or viceversa, one would theoretically have to expand the concept to postulate a polymorphic ancestor producing ascomata, soredia, and isidia simultaneously. However, the simultaneous production of two such distinct types of asexual propagules would make little sense from 
an evolutionary viewpoint and is rarely observed in nature, except in cases where species produce some sort of intermediate propagules, such as broadly isidiate clusters or pustules that break up into soredia or soredia growing into isidia or phyllidia, such as in the Pseudocyphellaria crocata complex (Lücking et al. 2017c). Therefore, the existence of both sorediate and isidiate counterparts of fertile morphs indicates that the evolutionary history of these morphs is more complicated than implied by a simplified species pair concept, perhaps better reflected by ancestral polymorphism in reproductive strategies in these lineages.

Another problem is that the "species pair" concept is only diffusely separated from the comparison of sexual and asexual (i.e., conidia-forming) or asexual and asexually reproducing morphs (e.g., Sundin and Tehler 1996). For instance, the putative species pair Umbilicaria antarctica and $U$. kappenii differs in the production of asexual thalloconidia vs. soredia or thallus fragments (Ott et al. 2004). The differential taxonomic and nomenclatural treatment of sexual and asexual morphs is well documented in non-lichenized fungi, under the now obsolete concept of "dual nomenclature" (see above). Under this concept, different names could be given to different morphs of the same species, with either sexual or one or more asexually reproducing morphs, which were then placed in separate genera. The name with priority was the one covering the sexual morph, with the exception of lichenized fungi in which priority applied irrespective of the morph. There are indeed numerous instances where lichenized morphs producing conidiomata were named differently from their counterparts producing ascomata, even when the connection was known. Thus, the name Ceratopycnidium citricola corresponds to the campyliiform (hooded) pycnidia of Byssoloma citricola, the name Pycnociliospora belluciae to the pycnidia of Strigula antillarum (Lücking et al. 1998, 2002), and the name Phyllophiale fusca to the disc-shaped isidia of Porina fusca (Lücking 1991). The conceptual difference between the "species pair" concept and "dual nomenclature" is that asexual (i.e., conidial) and sexual (e.g., ascoma-bearing) morphs were assumed to belong to the same species but assigned to separate (form-)genera, whereas "species pairs" were presumed to represent closely related, yet separate species in the same genus. However, the underlying biological mechanisms are not really different, since all three morphs (sexual, asexual via conidia, asexual via symbiotic thallus fragments) are means of reproduction and dispersal. Examples where the two concepts are intertwined include the apotheciate, sorediate, and pycnidiate morphs of Dirina massiliensis the sorediate morph called D. stenhammarii and the pycnidiate morph D. massiliensis f. aponina (Tehler et al. 2013).

A further challenge to the "species pair" concept is the level of actual similarity between morphs exhibiting different modes of reproduction. Theoretically, the species pair concept strictly applies only to cases where the underlying phenotype is otherwise identical. This is, however, often not the case. For instance, specimens of Heterodermia flabellata (apotheciate) typically differ in lobe configuration from those of $H$. obscurata (sorediate; Fig. 5a-b). Printzen (2014) argued that apotheciate vs. sorediate species of Biatora usually also differ in other characters and Lohtander et al. (1998) reported minor morphological differences between the apotheciate Dendrographa leucophaea and the sterile D. minor (now D. leucophaea f. minor). More obvious cases include Teloschistes exilis (apotheciate) vs. T. flavicans (sorediate), T. exilis typically forming smaller, more delicate and less brightly pigmented thalli (Almborn 1989, 1992). In addition to morphology, differences in ecology and distribution are often found between putative species pairs. Du Rietz (1924) already noted differences in distribution between Evernia esorediosa (apotheciate) and E. mesomorpha (sorediate), and Poelt (1970) elaborated on this phenomenon in detail. However, mere differences in the extension of distribution ranges cannot support the distinction of reproductive modes at the species level, as they may be a direct consequence of the latter, resulting in circular reasoning. In contrast, ecological differences, when present, are more striking. Thus, Physcia aipolia (apotheciate) typically grows on bark, whereas $P$. caesia (sorediate) is mostly found on rock, including human-made substrata (Myllys et al. 2001). This difference can neither be a cause nor a consequence of the mode of reproduction, as there is no reason why thalli derived from ascospores should only colonize bark and those originating from soredia only rock. Guttová et al. (2014) also reported subtle substrate differences for Solenopsora olivacea subsp. olivacea (apotheciate) vs. subsp. olviensis (sorediate), although in that case, the observed differences (shaded to open rock faces vs. shaded rock faces or crevices) may well be a trigger to switch the mode of dispersal.

A frequent misconception of asexually reproducing lichens is that these represent genetically identical clones or at least should have much lower genetic variation that sexually reproducing lineages (Poelt 1970; Tehler 1982; Huovinen 1985; Hammer 1997). It is thereby overlooked that the positional genetic variation used to reconstruct phylogenies and assess sequence variation consists of positional variation of presumably homologous nucleotides. This variation is caused by errors in DNA replication, which occurs during mitosis, and so affects cell divisions likewise. Thus, point variation in aligned sequences representing asexually reproducing individuals should not differ much from that of sexually reproducing individuals, which has been confirmed by empirical data (Mattson and Lumbsch 1989; Kroken and Taylor 2001; Buschbom and Mueller 2006; Nelsen and Gargas 2009; Altermann et al. 2016; Del Prado et al. 2016; Bellinchón et al. 2018). A major difference in sexual reproduction is mechanisms such as recombination, which does 
not result in point mutations but may be detected through coalescence-based methods when topologies between different markers affected by recombination are incongruent. Since asexually reproducing lineages can diverge in the same way as sexually reproducing lineages, by accumulating point mutations, these lineages do not represent evolutionary dead ends, as sometimes suggested (Poelt 1970; Tehler 1982; Tripp 2016).

Poelt (1970, p. 187) noted: "Flechten vermehren sich im allgemeinen, soweit überhaupt bei einer Gruppe neben der sicher ursprünglichen generativen auch vegetative Fortpflanzung vorkommt, nicht auf beide Weisen nebeneinander oder nacheinander im Leben eines Individuums, sondern in allen Individuen einer Sippe entweder generativ oder vegetativ." This is a central issue in the "species pair" concept that has been perpetuated in evolutionary considerations of sexual vs. asexual lineages, with the consequence that an apparent switch between sexually and asexually reproducing individuals or lineages in phylogenies has been interpreted as repeated loss and gain of either form of reproduction (Tehler et al. 2009; Tripp 2016). However, it is not actually possible to "regain" sexual reproduction; rather, one has to assume that the possibility to produce viable ascomata is generally present in the genome but that certain triggers determine their actual formation. Ascomycota produce ascomata typically after fertilization; if fertilization does not happen, an individual may switsch to an alternative mode of reproduction, similar to selfing in plants in the absence of pollination (Kalisz and Vogler 2003; Moeller 2006). An analogous strategy may apply to lichen fungi. As mentioned above, trichogynes have been repeatedly documented in lichen thalli. Population structure, not environmental conditions, would then be assumed to trigger the production of ascomata as a developmental switch. Heterothallism is widespread in lichen fungi, although homothallism occurs as well (Murtagh et al. 2000; Honegger et al. 2004; Seymour et al. 2005; Ludwig et al. 2017; Pizarro et al. 2019). Facultative homothallism in the absence of fertilization, so-called pseudo-homothallism (Grognet and Silar 2015), has been assumed to occur in some cases (Murtagh et al. 2000), but it is unclear whether absence of fertilization could alternatively cause a switch to asexual reproduction. Given that mixed populations are more likely to occur under favorable conditions (e.g., Walser et al. 2004), one would then predict that asexually reproducing thalli are more frequent under less favorable conditions. The ability of sexually reproducing thalli producing soredia and vice versa was experimentally shown in Knightiella splachnirima (Ludwig 2011, 2015; Molina et al. 2013). If this assumption is correct, the reconstruction of "ancestral reproduction modes" in a phylogenetic tree is actually misleading, since the reproductive mode observed in a terminal (individual) is just a snapshot of its actual condition, but does not reflect its genetic potential. This would affect studies like that of Buschbom and Mueller (2006), who entertained various hypothesis to explain complex patterns of sexually and asexually reproducing individuals in the putative species pair Porpidia flavocoerulescens (now P. flavicunda) (apotheciate) and $P$. melinodes (sorediate) and postulated a selective sweep in a single species with complex phylogeny.

Overall, the advent of molecular phylogeny has permitted the testing of the species pair concept in numerous examples (Table 3). While putative species pairs have been explicitly examined in various studies, an increasing amount of molecular data is becoming available for many more instances, although these data, in particular the fungal ITS barcoding marker, are rarely analyzed in a context revealing the underlying patterns for presumed species pairs (e.g., Stenroos et al. 2019: Cladonia; Lücking et al. 2020b: Usnea). For instance, the available ITS data (Carlsen et al. 2012; Ekman et al. 2014; Marthinsen et al. 2019) for the species pair Fuscopannaria protensa (apotheciate) vs. F. ahlneri (sorediate) (Jørgensen 2000) suggest that two distinct lineages are involved, one apotheciate-sorediate and the other sorediate only. However, no phylogenetic analysis seems to have included these data simultaneously: the study by Carlsen et al. (2012) reported two specimens which correspond to the sorediate lineage, whereas the work by Ekman et al. (2014) includes two other samples, representing the apotheciate-sorediate lineage, giving the impression that apotheciate and sorediate morphs in this species pair are genetically uniform.

While species pairs were first analyzed prior to the turn of the millenium (Lohtander et al. 1998), the work by Kroken and Taylor (2001) on Letharia columbiana (apotheciate and usually with isidia) vs. L. vulpina (sorediate and rarely with few apothecia) can be considered a model study, as it employed a multimarker coalescence approach, demonstrating that putative species pairs may neither represent two distinct taxa nor a single, variable species, but a complex of multiple lineages not strictly correlated with mode of reproduction. Combining ITS and nuSSU data and up to ten anonymous protein-coding markers, the authors distinguished up to six entities. The sorediate $L$. vulpina was thereby split into two species, $L$. vulpina s.str. and the subsequently validated L. lupina (Altermann et al. 2016). The primarily apotheciate $L$. columbiana was divided into four entities: $L$. gracilis (McCune and Altermann 2009), L. "barbata", L. "lucida", and $L$. "rugosa", all except $L$. "lucida" producing isidia in addition to apothecia. Kroken and Taylor (2001) did not associate already available names with these latter entities, as it was unclear at the time which would correspond to $L$. columbiana s.str. or to its synonym, $L$. californica. Altermann et al. (2016) subsequently associated L. columbiana s.str. with the $L$. "lucida" clade. The apotheciate $L$. "rugosa", on the other hand, formed a paraphyletic grade relative to $L$. 


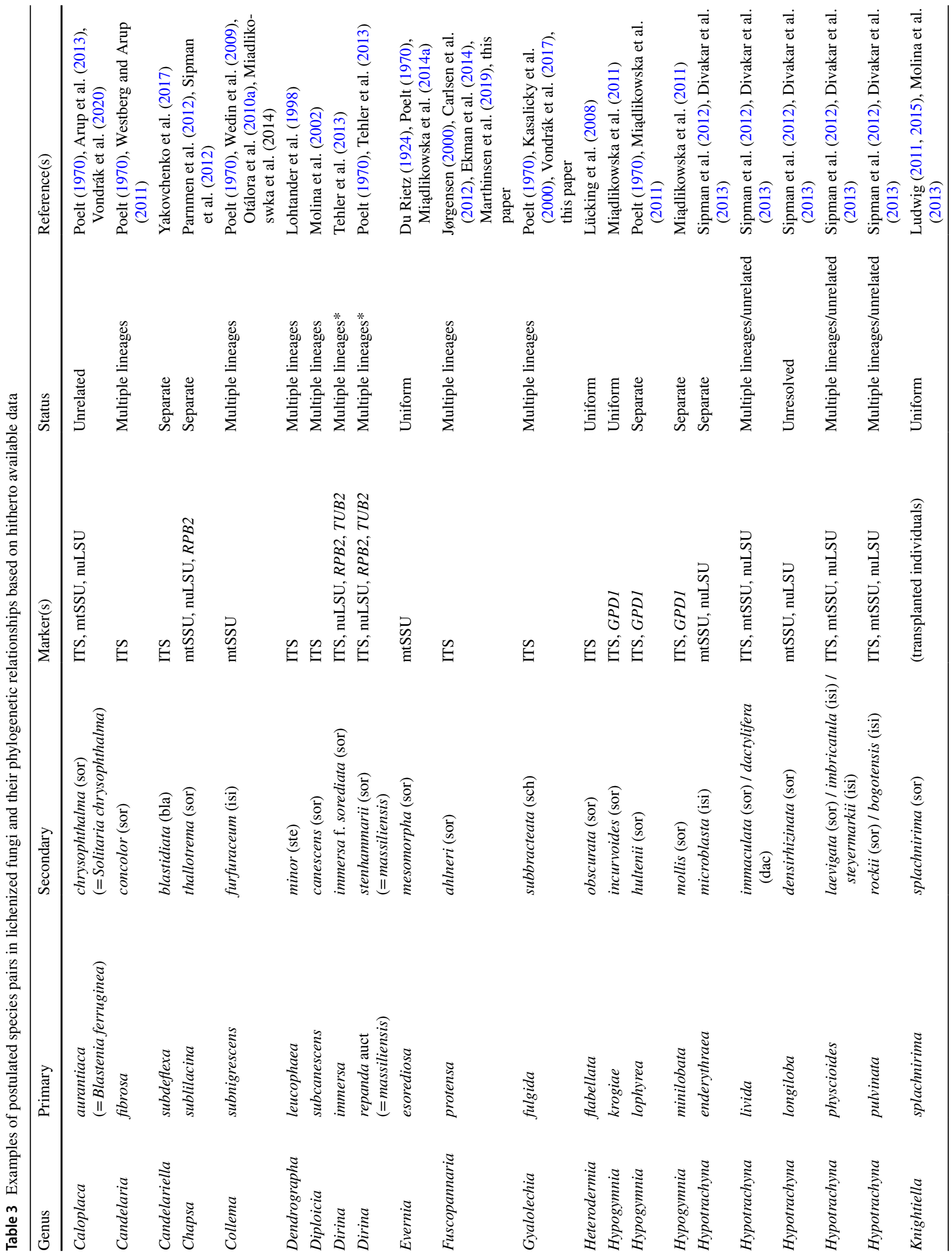




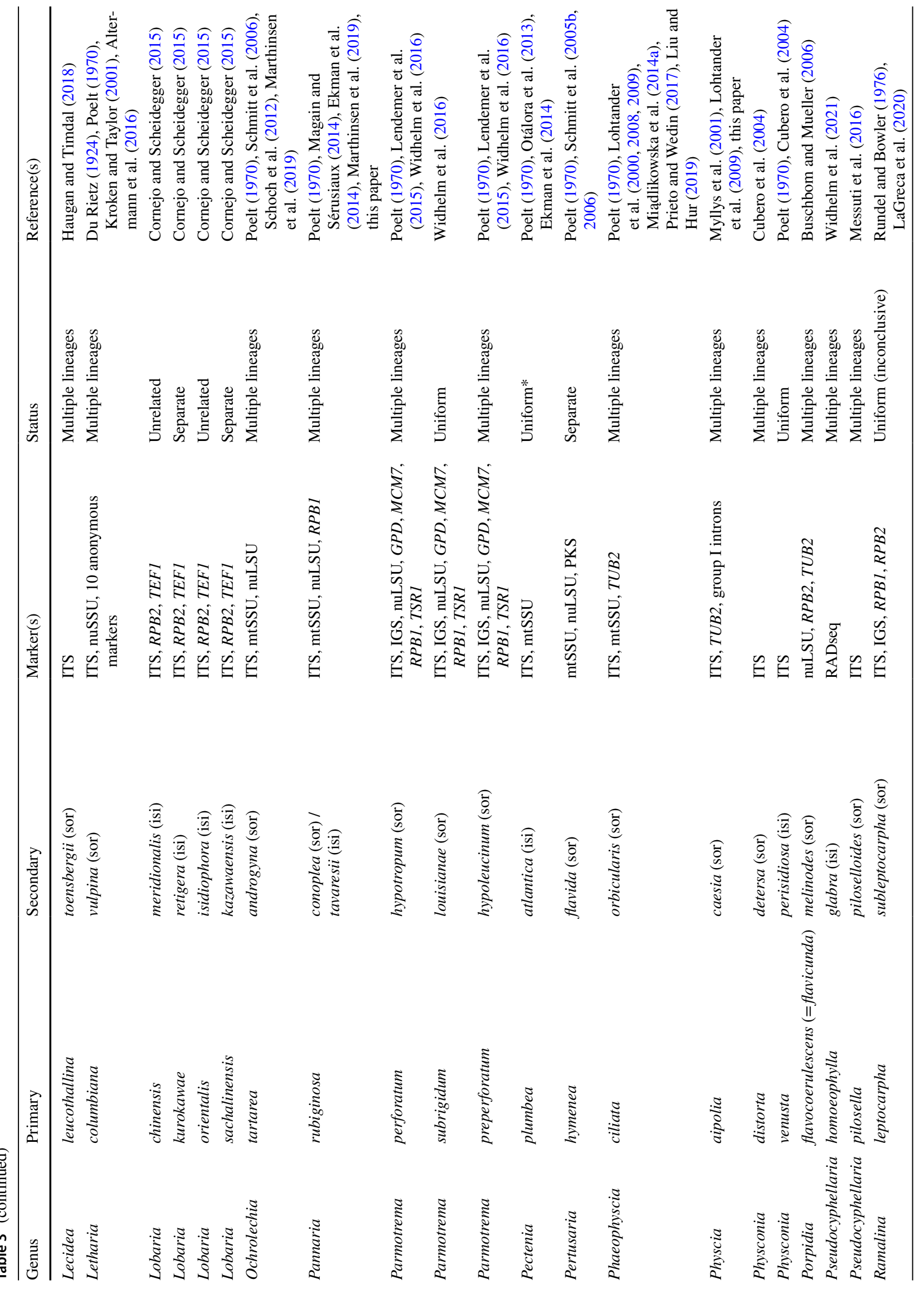




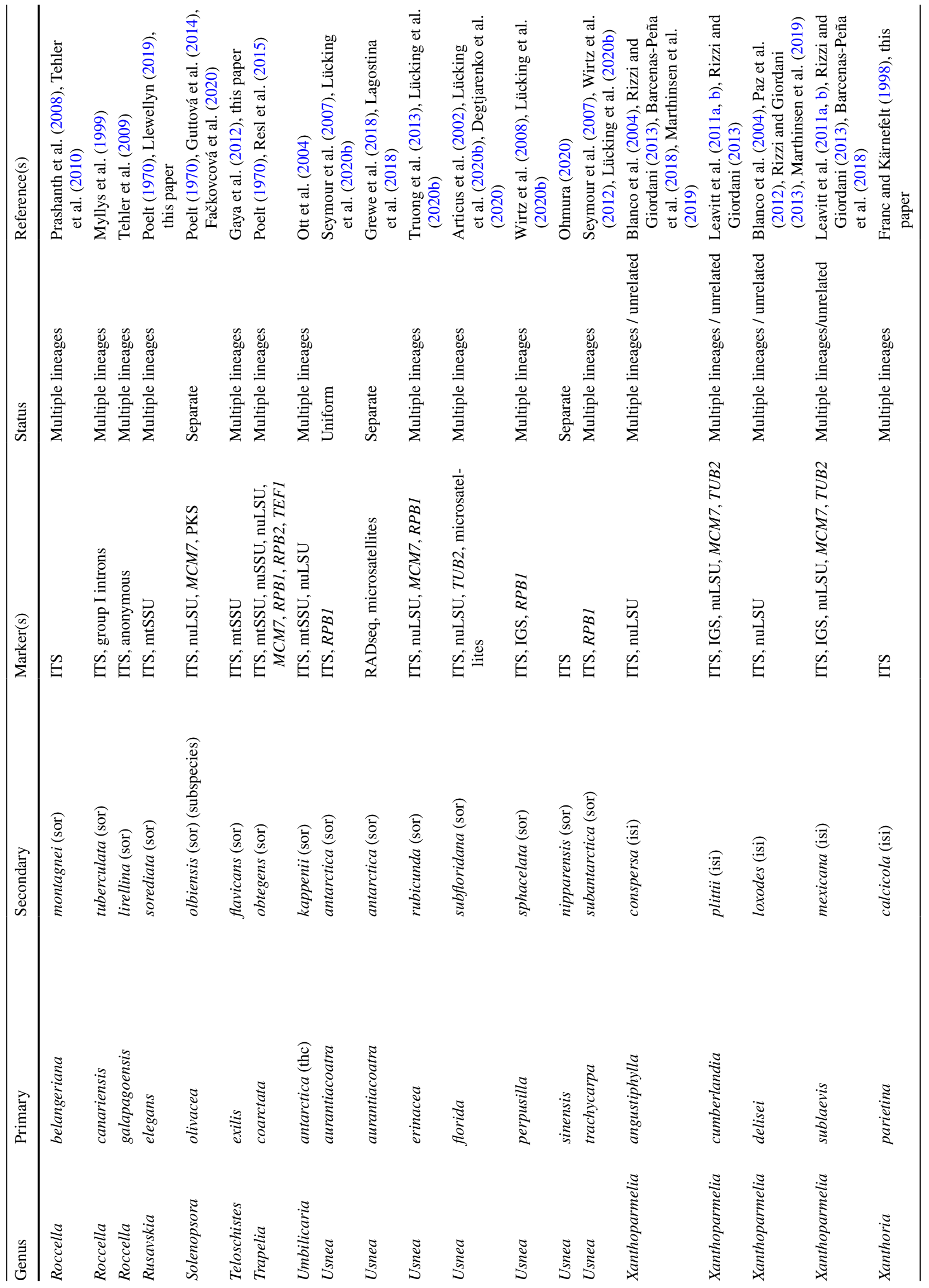


vulpina s.str., offering the possibility to recognize a single species, L. vulpina, producing either sexually or asexually. The resulting six (or five) entities were supported by subtle morphological and chemical characters, as well as distribution, with L. vulpina s.str. being the only species also widespread in Europe (Kroken and Taylor 2001).

Molecular studies on numerous putative species pairs suggest that multiple (semi-)cryptic speciation, as exemplified by the genus Letharia, is the rule rather than the exception: in over 60 examples analyzed, nearly two third (61\%) appear to be species complexes, consisting of various lineages reproducing either sexually, asexually, or both (Table 3). Besides Letharia, the best documented case among these is Usnea florida vs. U. subfloridana (Articus et al. 2002; Mark et al. 2016; Degtjarenko et al. 2020; Lücking et al. 2020b). In only 11 cases (18\%), the separation of an apotheciate and a sorediate or isidiate species was supported, although there were mostly few available data. Among the most convincing cases are Hypogymnia lophyrea vs. $H$. hultenii and $H$. minilobata vs. H. mollis (Miądlikowska et al. 2011). Nine cases $(15 \%)$ exhibit genetic uniformity relative to the studied markers or did not show structured resolution, but the available data in these cases were often limited, e.g., in Evernia esorediosa vs. E. mesomorpha (Miądlikowska et al. 2014a). Considering examples such as Fuscopannaria protensa vs. F. ahlneri, Pectenia plumbea vs. P. atlantica, and the Roccella belangeriana vs. $R$. montagnei species pair (Prashanth et al. 2008; Tehler et al. 2010; Carlsen et al. 2012; Otálora et al. 2013; Ekman et al. 2014; Marthinsen et al. 2019), we predict that in cases were limited molecular data initially indicate conspecifity or would support the species pair concept, additional data will in most cases reveal more complex patterns. In ten cases (16\%), the putative species pairs were, at least in part, not directly related and in one case, Caloplaca aurantiaca (=Blastenia ferruginea) vs. C. chrysophthalma (三Solitaria chrysophthalma), even ended up in different genera (Arup et al. 2013; Vondrák et al. 2020).

Even with the availability of molecular data to test species pairs, two challenges arise. One is the selection of markers. While the ITS has been chosen as the standard barcoding marker for fungi (Schoch et al. 2012), employed in almost all studies including presumed species pairs (Table 3), it may present limited resolution when lineages diverged recently (Lücking et al. 2020a). A striking case is the putative species pair Usnea aurantiacoatra (apotheciate) vs. U. antarctica (sorediate). Being the most frequently sequenced species pair in Usnea, with over 250 accessions, the ITS and the $R P B 1$ markers are remarkably uniform in this case, suggesting a single species (Wirtz et al. 2008, 2012; Lücking et al. 2020b). However, both RADseq and microsatellite markers support the presence of two lineages (Grewe et al. 2018; Lagostina et al. 2018). In the case of Usnea florida vs. $U$. subfloridana, on the other hand, microsatellite markers did 
not clearly resolve the two morphs (Degtjarenko et al. 2020). The other challenge is the application of formal taxonomic classifications to phylogenetically defined lineages. One case is Dirina massiliensis, which exhibits phylogenetic structure, but a rather broad concept was applied to this case, subsuming the various apotheciate and/or sorediate lineages within a single species (Tehler et al. 2013). These different approaches are conflicting, as it seems unlikely that in one case, a single species can diverge strongly in the ITS and other markes, whereas in another case, a species pair with almost no variation in the ITS is recognized as separate species based on highly resolving markers such as RADseq and microsatellites.

The diverse patterns detected in putative species pairs show that there is no consistent pattern, and each case has to be considered individually (Mattson and Lumbsch 1989). Tehler et al. (2009) therefore suggested that the species pair concept should be abandoned. Molecular data largely support this view. However, where conclusive data are not available, species pairs should continue to be recognized as separate taxa.

Recommendation 3: Unless there is conclusive evidence to the contrary, e.g., using phylogenomic approaches, such as microsatellite markers or RADseq (example: Usnea aurantiacoatra vs $U$. antarctica), "species pairs" should continue to be recognized as separate taxa, even if they appear unresolved by application of the standard fungal ITS barcoding marker or in a multi-marker phylogeny (example: Heterodermia flabellata vs. H. obscurata). However, a "species pair" taxonomy should be replaced by an adjusted treatment when it can be conclusively shown that reproductive morphs do not correlate with phylogenetic lineages (example: Letharia colombiana-vulpina complex)

\section{Cryptic speciation and the taxonomic value of phenotype characters}

Traditional taxonomy assumes that taxa should differ in phenotype. However, there is no law in nature that would require phylogenetically diverging sister taxa to also diverge in phenotype by default. Rather, phenotypic similarity within a species is caused by coherence, so one would assume that the absence of coherence should lead to phenotypic divergence. Ultimately, this is the case, but phenotypic divergence may be delayed relative to phylogenetic divergence, which may then lead to cryptic speciation, for a variety of reasons. For one, species may have diverged too recently to have also diverged in phenotype. On the other hand, there might be selective forces at work relative to a particular phenotype, thus preventing phenotypes from diverging. Finally, fungi including lichen-formers exhibit simple body plans which may offer little evidence for phenotypic divergence except for difficult to perceive ultrastructural or physiological features (Lumbsch and Leavitt 2011; Schneider et al. 2016; Lücking 2019). Indeed, cryptic speciation is a matter of perception, and often there are subtle (or simply overlooked) characters that eventually separate phylogenetically distinct lineages (Molina et al. 2011; Nuñez-Zapata et al. 2011; Frolov et al. 2016; Santos et al. 2019). Sometimes, such characters may be difficult to discern or are only unveiled as statistically supported differences in morphometrics, not useful in the field or in keys (Altermann et al. 2014, 2016; Schneider et al. 2016; Zahradníková et al. 2018; Zakeri et al. 2019). For such cases, "near-cryptic" may be a better term. In contrast, Vondrák et al. (2009) redefined the term "semicryptic", previously employed in plant- and algal-taxonomic papers in the sense of near-cryptic, for species that cannot be distinguished by their phenotype but through their distribution and/or ecology (e.g., Lendemer 2011; Hodkinson and Lendemer 2011; Cornejo and Scheidegger 2015).

Cryptic or near-cryptic (including semi-cryptic) speciation is rather well-documented in lichen fungi (Table 4), with an increasing number of examples, particularly in the Parmeliaceae (Feuerer and Thell 2002; Molina et al. 2004, 2011; Argüello et al. 2007; Hodkinson and Lendemer 2011; Altermann et al. 2016; Leavitt et al. 2016b; Haugan and Timdal 2019; Boluda et al. 2019; Corsie et al. 2019; Crespo et al. 2020), but also in other families, such as Graphidaceae (Kraichak et al. 2015; Zhao et al. 2017), Icmadophilaceae (OnuţBrännström et al. 2017, 2018; Jørgensen 2019), Lepidostromataceae (Coca et al. 2018), Peltigeraceae (now including Lobariaceae; Lendemer and O'Brien 2011; Miądlikowska et al. 2014b; Cornejo and Scheidegger 2015), Stereocaulaceae (Lendemer 2011), Trapeliaceae (Resl et al. 2015; Orange 2018), and such unique forms such as the lichenized hypomycete Dictyocatenulata alba (An et al. 2012), although often not reflected in formalized revised taxonomies.

An important argument against the acceptance of phenotypically (near-)cryptic species, identifiable through molecular markers only, is the requirement for advanced technical equipment for their identification and the difficulty to reliable identify such species in the field. While this argument is understandable, it could be logically extended to any technical tool. Thus, one could reject the validity of secondary chemistry because thin-layer chromatography is not accessible, or one could even challenge the need of a microscope to discern anatomical characters such as ascospores. Particularly in crustose lichens, e.g., in the highly diverse families Graphidaceae, Pyrenulaceae, and Trypetheliaceae, species can often only be identified through their ascospores, besides other anatomical characters that cannot be assessed without a microscope, such as hymenial inspersion (Lücking 2009; Lücking et al. 2009a, b, c; Aptroot 2012; Aptroot and Lücking 2016). So-called sporomorphs (Wirth and Hale 1978; 
Table 4 Examples of formally established cryptic, near-cryptic and semi-cryptic species in lichen-forming fungi

\begin{tabular}{|c|c|c|c|}
\hline Family & Original species & Additional cryptic species & References \\
\hline Graphidaceae & Graphis scripta & G. betulina, G. macrocarpa, G. pulverulenta & $\begin{array}{l}\text { Neuwirth and Aptroot (2011), Kraichak et al. } \\
\text { (2015) }\end{array}$ \\
\hline Hygrophoraceae & Cora terrestris & C ixtlanensis & Moncada et al. (2019) \\
\hline Hygrophoraceae & Cora davidia & C. totonacorum & Moncada et al. (2019) \\
\hline Icmadophilaceae & Thamnolia vermicularis & T. taurica, T. tundrae & $\begin{array}{l}\text { Onuţ-Brännström et al. (2017, 2018), Jør- } \\
\text { gensen (2019), this paper }\end{array}$ \\
\hline Lepidostromataceae & Sulbacheromyces caatingae & S. chocoensis, S. tutunendo & Coca et al. (2018) \\
\hline Parmeliaceae & Bryoria fuscescens & B. glabra, B. kockiana, B. pseudofuscescens & Boluda et al. (2019) \\
\hline Parmeliaceae & Letharia vulpina & L. lupina & Altermann et al. $(2014,2016)$ \\
\hline Parmeliaceae & Melanelixia glabra & M. epilosa & Leavitt et al. (2016b) \\
\hline Parmeliaceae & M. fuliginosa & M. hawksworthii, M. robertsoniorum & Leavitt et al. (2016b) \\
\hline Parmeliaceae & M. subargentifera & M. ahtii & Leavitt et al. (2016b) \\
\hline Parmeliaceae & Melanohalea exasperata & M. davidii & Leavitt et al. (2016b) \\
\hline Parmeliaceae & M. olivaceoides & M. beringiana & Leavitt et al. (2016b) \\
\hline Parmeliaceae & M. multispora & M. columbiana, M. tahltan & Leavitt et al. (2016b) \\
\hline Parmeliaceae & M. subolivacea & M. clairii & Leavitt et al. (2016b) \\
\hline Parmeliaceae & Montanelia panniformis & M. occultipanniformis & Leavitt et al. (2016b) \\
\hline Parmeliaceae & M. tominii & M. saximontana, $M$. secwepemc & Leavitt et al. (2016b) \\
\hline Parmeliaceae & Parmelia saxatilis & P. ernstiae, $P$. mayi, $P$. rojoi, $P$. serrana & $\begin{array}{l}\text { Feuerer and Thell (2002), Molina et al. (2004, } \\
\text { 2011), Haugan and Timdal (2019), Corsie } \\
\text { et al. (2019), Crespo et al. (2020) }\end{array}$ \\
\hline Parmeliaceae & Parmelina quercina & P. carporrhizans, $P$. coleae, $P$. elixii & Argüello et al. (2007) \\
\hline Parmeliaceae & Punctelia rudecta & P. guanchica, $P$. ruderata, $P$. toxodes & Alors et al. (2016) \\
\hline Parmeliaceae & Xanthoparmelia tasmanica & $X$. hypofusca & Hodkinson and Lendemer (2011) \\
\hline Peltigeraceae & Lobaria pindarensis & L. isidiophora & Cornejo and Scheidegger (2015) \\
\hline Peltigeraceae & Peltigera gowardii & P. aquatica & $\begin{array}{l}\text { Lendemer and O'Brien (2011), Miądlikowska } \\
\text { et al. (2014b) }\end{array}$ \\
\hline Stereocaulaceae & Lepraria incana & L. hodkinsoniana & Lendemer (2011) \\
\hline Teloschistaceae & Flavoplaca citrina & Scythioria phlogina & Vondrák et al. (2009) \\
\hline Teloschistaceae & Flavoplaca flavocitrina & F. austrocitrina, $F$. nigromarina & Vondrák et al. (2009) \\
\hline Teloschistaceae & Pyrenodesmia albopruinosa & P. alociza & Vondrák et al. (2009) \\
\hline Verrucariaceae & Hydropunctaria orae & H. aractina & Orange (2012) \\
\hline
\end{tabular}

Lücking 2009), i.e., species with identical external morphology and even anatomy but differing in ascospore septation and size, are common (Fig. 7). Indeed, whenever technical advancements were introduced historically, there was some initial opposition against their broad application (Ainsworth 1976). We therefore anticipate that the current reluctance against the acceptance of phenotypically cryptic species will diminish, especially as molecular tools become more easily available. Having said that, cryptic species should be welldocumented phylogenetically, to exclude the possibility of type I errors. The other issue, elaborated in detail below, is the assessment whether phylogenetically distinct lineages are always to be recognized at species level or whether the application of infraspecific ranks is preferrable in an evolutionary framework in certain cases.

Throughout history, alpha taxonomy has faced challenges due to misunderstood variation of characters and conflict between character complexes in the delimitation of species. Prior to the advent of molecular phylogenetic approaches, variation and conflict have been addressed through ad hoc solutions, involving circular reasoning and subjectively defined taxa. Almost two centuries ago, Watson (1843) labeled thus defined species "book species", a concept taken up in McCabe's (2021) Descent and Logic in Biosystematics. Essentially, there is no difference between book species and the modern term "species hypothesis", other than the framework to establish species hypotheses having greatly improved over time. McCabe's (2021) rationale for the term "Linneon" also essentially corresponds to our current understanding of species hypothesis, although in its original sense, Lotsy $(1916,1925)$ defined Linneon as morphologically defined species complexes likely to contain a number of distinct lineages, i.e., cryptic speciation. In our LPR approach (see above), a Linneon in a modern sense would 
Fig. 7 Examples of lichens with identical external morphology but differing in anatomical details such as ascospores (sporomorphs) and/or hymenial insperson (inspersomorphs). a Allographa acharii. b A. angustata. $\mathbf{c}$ A cinerea. $\mathbf{d} A$. macella. e A. pseudocinerea. $\mathbf{f} A$. vestitoides. In $\mathbf{b}, \mathbf{d}$, and $\mathbf{f}$ showing ascospores as examples of different types: transversally septate and fusiform (b), richly muriform and ellipsoid (d), terminally muriform and oblong (f). All photographs by Robert Lücking
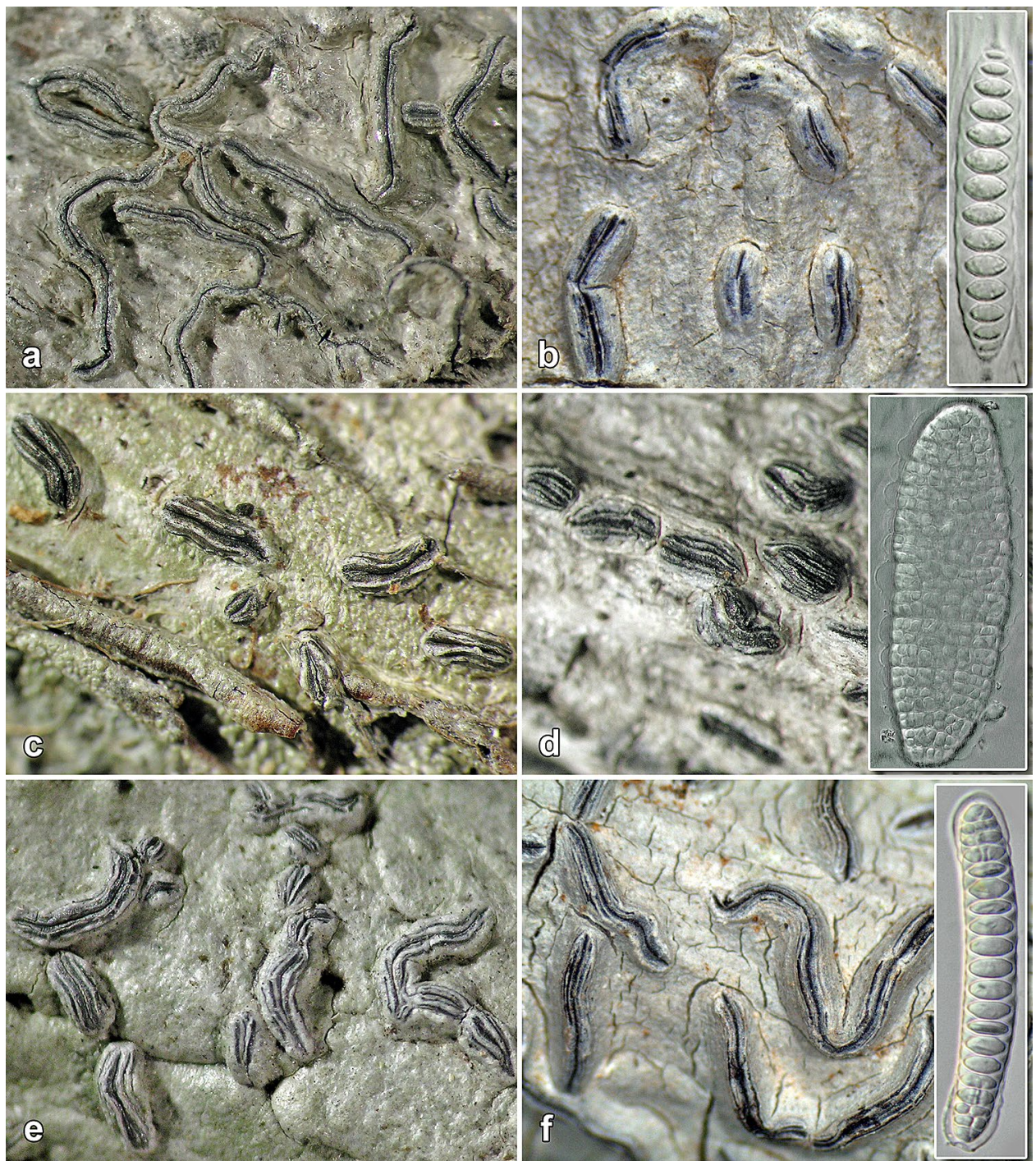

correspond to a species hypothesis based on phenotype characters, although McCabe (2021) extends this concept to species defined by DNA characters.

The assessment of the taxonomic value of characters is closely tied to technological advances in biodiversity research. While early fungal taxonomy was characterized by evaluation of external morphologies, four major advances shaped further developments in this field until today (Ainsworth 1976; Jørgensen 2017): (1) the use of the microscope to assess anatomical characters, in particular ascospores but later on also ultrastructure (Körber 1853; Roux et al. 1986); (2) the assessment of the ontogeny as a taxonomically important character (Letrouit-Galinou 1968; Henssen and Jahns 1973; Eriksson 1982; Honegger 1993; LetrouitGalinou et al. 1994; Döring and Lumbsch 1998); (3) the study of secondary chemical compounds eventually using chromatographic methods (Zopf 1903; Culberson and
Kristinsson 1970; Huneck and Yoshimura 1996); and (4) the advent of molecular phylogeny.

Perhaps the best-documented example for conflicting taxonomies arising from new technological approaches is the application of chemotaxonomy (Duvigneaud 1939; Lamb 1951; Culberson 1960, 1969, 1970; Hale 1955, 1968; Krog 1969; Hawksworth 1976; Brodo 1986; Rogers 1989; Lumbsch 1998). While secondary chemistry has long been accepted as an important tool in taxonomy, forms only differing in their chemical compounds but agreeing in morphology, so-called chemomorphs, were often not accepted at species level, unless the differences were considered substantial. For instance, the presence or absence of pigments or certain cortical substances, such as atranorin and usnic acid, have usually been considered of higher value than differences in medullary chemistry or the presence or absence of lichexanthone (Culberson 1970; Tehler 1983, 1993; Harris 1995). Thus, Parmeliopsis ambigua (cortical usnic acid and 
atranorin) and P. hyperopta (cortical atranorin only) have mostly been considered distinct species, a concept confirmed by molecular evidence (Tehler and Kallersjö 2001). Harris (1995) accepted the presence of lichexanthone as a characteristic feature at species level for many taxa, including Caliciaceae (Pyxine), Graphidaceae, Parmeliaceae, Pertusariaceae, and Pyrenulaceae, but suggested to abandon lichexanthone as a taxonomic character in Trypetheliaceae, e.g., in the genera Astrothelium sensu lato (A. variolosum aggr.), Polymeridium, and Trypethelium sensu lato, and perhaps also in Monoblastiaceae (Anisomeridium). In most cases, this was based on the absence of other correlated characters.

A priori, there appears to be no reason for considering discrete chemomorphs as species in some cases and infraspecific variation in others, and independent evidence is required to assess each case individually or derive general patterns where these exist (Robinson 1975; Lumbsch 1998). However, even this can be misleading. Thus, quantitative analysis of the morphology, chemistry, distribution, and ecology, of variants in the Ramalina siliquosa complex led to the distinction of a variable number of taxa (Culberson and Culberson 1967; Culberson 1969; Sheard 1978; Culberson et al. 1993). In contrast, molecular phylogenetic analysis revealed only two species-level lineages, each with variable chemistry (LaGreca et al. 2020). In the genus Thamnolia (see below), the different chemotypes were usually considered to represent species, whereas discrete morphodemes, e.g., hollow vs. solid thalli, were treated as subspecies (Culberson 1973; Santesson 2004). Molecular phylogeny rejected either as useful taxonomic characters, some lineages being morphologically and chemically uniform and others variable (see below). Molecular phylogeny of the Parmotrema perforatum group, in which species have traditionally been separated by medullary chemistry and reproductive mode (Culberson 1973; Culberson and Culberson 1973), revealed a complex picture: one lineage ( $P$. subrigidum/P. louisianae) chemically and genetically uniform, one lineage ( $P$. perforatum/P. hypotropum s.str.) chemically uniform but divided into two sublineages not corresponding to the two species, and one lineage (P. preperforatum/P. hypoleucinum) chemically variable (including samples with $P$. hypotropum chemistry) and genetically complex (Widhelm et al. 2016), with a correlation between chemotypes and ecology (Lendemer et al. 2015). In some cases, differences in chemical compounds have been used to support the separation of morphologically cryptic species, such as in Parmelia mayi vs. P. saxatilis (Molina et al. 2011). In the Trypetheliaceae, chemically and morphologically distinct forms that have been proposed to be lumped into a single, highly variable species, A. variolosum (Harris 1995), are not only phylogenetically distinct but also contain multiple, often unrelated lineages (Fig. 8; Lücking et al. 2016).
In contrast to discrete chemomorphs, so-called sporomorphs, morphologically identical species that differ in ascospore type (e.g., transversely septate vs. muriform ascospores), have generally been accepted as separate species. These cases are particularly common in crustose lichens, e.g., the families Gomphillaceae, Graphidaceae (Fig. 7), Porinaceae, Pyrenulaceae, and Trypetheliaceae (Wirth and Hale 1978; Lücking 2009; Aptroot 2012; Aptroot and Lücking 2016). Another type of chemical variation is that of so-called inspersomorphs, in which species with the same morphology and ascospore type differ only in the presence or absence of hymenial inspersion with oil droplets, a phenomenon also common in Graphidaceae and Trypetheliaceae (Lücking 2009; Aptroot and Lücking 2016). A unique form of discrete morphological differences are single vs. compound ascomata in perithecioid taxa of the families Pyrenulaceae and Trypetheliaceae (Harris 1995; Aptroot 2012; Aptroot and Lücking 2016). Whereas Harris (1995) suggested to lump these into a single species in some cases, e.g., in the Astrothelium variolosum complex, molecular data suggest that these forms represent not only discrete entities but may not even be closely related (Fig. 8; Lücking et al. 2016).

Historically, thallus morphology was less scrutinized than other character complexes, such as ascospores or secondary chemistry, in relation to its taxonomic value, likely because it is more difficult to quantify and assess in an objective manner. Thus, while in the early period of lichen taxonomy, minor differences in thallus characters often led to the establishment of new species or infraspecific taxa, especially during the second half of the twentieth century, differences in thallus characters were usually ascribed to variation induced by habitat or other factors, even if the variation was discrete (Anderson and Rudolph 1956; Wirth and Hale 1978; Larcher and Vareschi 1988). This approach was based on circular reasoning, because the assessment of variation was affected by the underlying decision of assigning individuals to a particular species, based on the same characters used to assess their variation. Molecular data now show that such broadly defined taxa are often composed of several to numerous, even unrelated lineages, demonstrating that thallus variation is much more limited than previously assumed (Moncada et al. 2014; Lücking et al. 2017b, c). As a consequence, even in the absence of molecular data, species are now much more narrowly defined (Lücking 2014). On the other hand, molecular data have also shown that previously separated taxa may indeed represent discrete variation of a single species (Fryday et al. 2017; Boluda et al. 2019; LaGreca et al. 2020). 


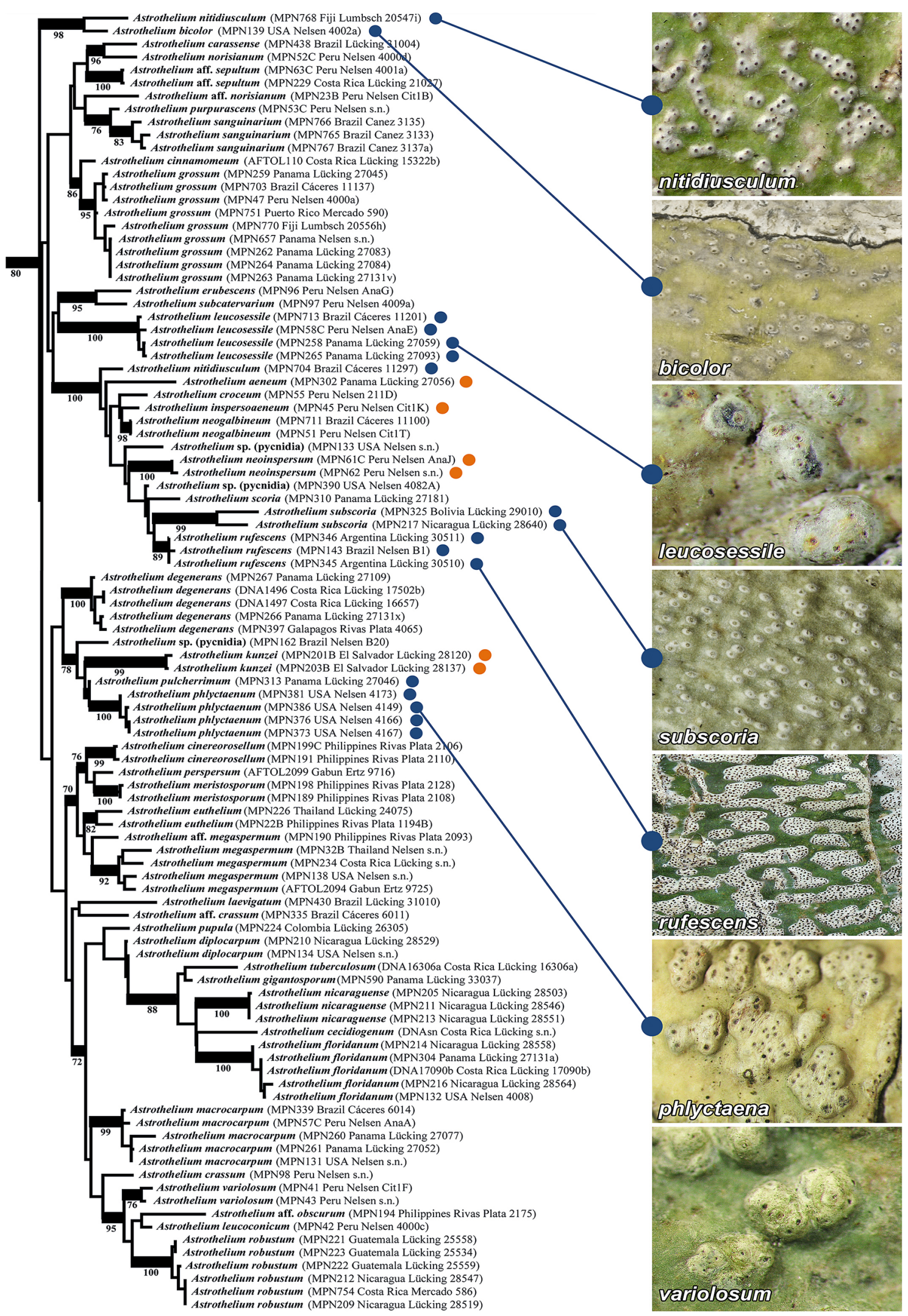


4Fig. 8 Phylogeny of the genus Astrothelium (after Lücking et al. 2016), highlighting the position of species corresponding to the Trypethelium nitidiusculum / Astrothelium variolosum complex sensu Harris (1995), indicated by dark blue dots (with the sequenced species plus $A$. variolosum s.str. depicted on the right). Orange dots indicate species of the A. aeneum complex, also suggested to potentially form part of ad single, highly variable species $A$. variolosum according to Harris (1995). The corresponding taxa do not only form separate lineages but are also partly unrelated to each other, and the separate position of specimens phenotypically corresponding to $A$. nitidiusculum $\mathrm{s}$.str. also indicate homoplasy

Recommendation 4: The formal recognition of demonstrably distinct phylogenetic lineages should not be rejected only because the means of identifying such taxa are not readily accessible or because such taxa are not identifiable in the field, especially given that many species are morphologically cryptic but readily distinguishable using anatomical features such as ascospore type or chemical compounds often detectable through spot tests. Therefore, in inventories, the need for accurate taxonomy and the corresponding requirement for corresponding tools should always be assessed. Taxonomists should offer "proxy" solutions in cases where accurate identifications are not crucial, e.g., Parmelia saxatilis "sensu lato" for monophyletic cryptic species complexes or Sticta fuliginosa "morphodeme" for unrelated but highly similar species. When molecular data are not available for a particular taxon, the taxonomic validity of phenotypic characters and character complexes should not be decided upon ad hoc but should be evaluated within a phylogenetic framework of related taxa, especially when different phenotype character complexes (e.g., thallus morphology, ascospore type, secondary chemistry) would lead to conflicting solutions.

\section{Species versus infraspecific ranks}

As mentioned above, taxonomy can be divided into three levels: alpha taxonomy, the delimitation and recognition of species, beta taxonomy, which refers to higher taxa, and gamma taxonomy, which deals with infraspecific levels (Mayr 1968; Winston 1999; Disney 2000; Tahseen 2014). Lichenologists and other mycologists have made ample use of gamma taxonomy, particularly in historical times (Fig. 9a). Compared to nearly 370,000 fungal species names established between 1753 and 2020, over 61,000 infraspecific names were established during the same time period, resulting in a ratio of about 6:1. Of these, over 29,000 (nearly half) correspond to lichen-formers, although overall, species names of lichenformers make less than $10 \%$ of all fungal species names (see above). Thus, infraspecific names established for lichenized fungi are strongly overrepresented compared to all fungi.

In absolute numbers, the introduction of infraspecific fungal names (including lichen-formers) peaked between 1860 and 1940 (Fig. 9a), during which more than half of all infraspecific names were established. The relative proportion of lichen-formers among these thereby oscillated between less than $10 \%$ and over $80 \%$, with the lowest proportions in the past two decades and in the two decades leading up to 1800 and the highest in the decade up to 1770 and again between 1840 and 1870 (Fig. 9b). Relative to overall species-level names, the highest proportion of infraspecific names in fungi was published between 1800 and 1870, whereas in lichens, three peaks occurred between 1800 and 1820, between 1830 and 1850, and between 1900 and 1910 (Fig. 9c). Overall, the proportion of infraspecific taxa relative to species never exceeded $50 \%$ in all fungi, but during the peak periods, newly established infraspecific names were approximately twice the number of species names in lichenized fungi. These three peaks fell in the Acharius period (1801-1820), the Montagne period (1831-1850), and the Zahlbruckner period (1901-1910). During these periods, most of the infraspecific names were established by A. B. Boistel (953), in his Nouvelle Flore des Lichens (Boistel 1903), E. Acharius (818), and L. E. Schaerer (659), but a considerably number also by J.-B. Lamarck (470), largely in Encyclopédie Méthodique Botanique (Lamarck and Poiret 1813), J. von Flotow (302), H. Olivier (298), E. Fries (275), K. F. W. Wallroth (242), E. A. Vainio (221), G. L. Rabenhorst (206), J. Harmand (185), M. Bouly de Lesdain (134), A. Zahlbruckner (129), and G. Torssell (122), in his Enumeratio Lichenum et Byssacearum Scandinaviae (Torssell 1843).

In the past three decades, which mark the period of molecular taxonomy and systematics, the absolute number and particularly the relative proportion of new infraspecific names has dropped substantially, to distinctly under $10 \%$ up to 2010 and under $5 \%$ up to 2020 , comparing to postLinnean levels leading up to 1800 . This indicates a dramatic shift in the theoretical concept and practical application of infraspecific names, likely a consequence of much improved insight into the phylogenetic structure of presumed infraspecific variation and its taxonomic value.

The use of infraspecific names (gamma taxonomy) has been highly inconsistent throughout history, but has largely followed two main concepts (Du Rietz 1930; Davis and Heywood 1963; Hawksworth 1974; Hamilton and Reichard 1992; McDade 1995; Lücking 2008). The evolutionary concept assigns intraspecific names to diverging lineages within a species that are considered to be reproductively compatible but exhibit some sort of non-biological reproductive isolation, which can be either geographical (allopatric or peripatric) or ecological, e.g., through seasonal or diurnal differentiation of sexual reproductive structures (sympatric). In contrast, the typological concept assigns infraspecific names to phenotypic variation that is deemed worthy of taxonomic recognition but not sufficient to distinguish species. The recognition of taxa at any rank should have some biological 
Fig. 9 Infraspecific names (excluding autonyms) established for fungi including lichen-formers between 1753 and 2020 (in 10-year intervals). a Absolute number of infraspecific names for fungi overall (orange) and lichen-formers (blue). b Proportion of infraspecific names of lichen-formers among all fungi for the same period. c Proportion of infraspecific names of fungi overall (orange) and lichen-formers (blue) relative to species names for the same group and period

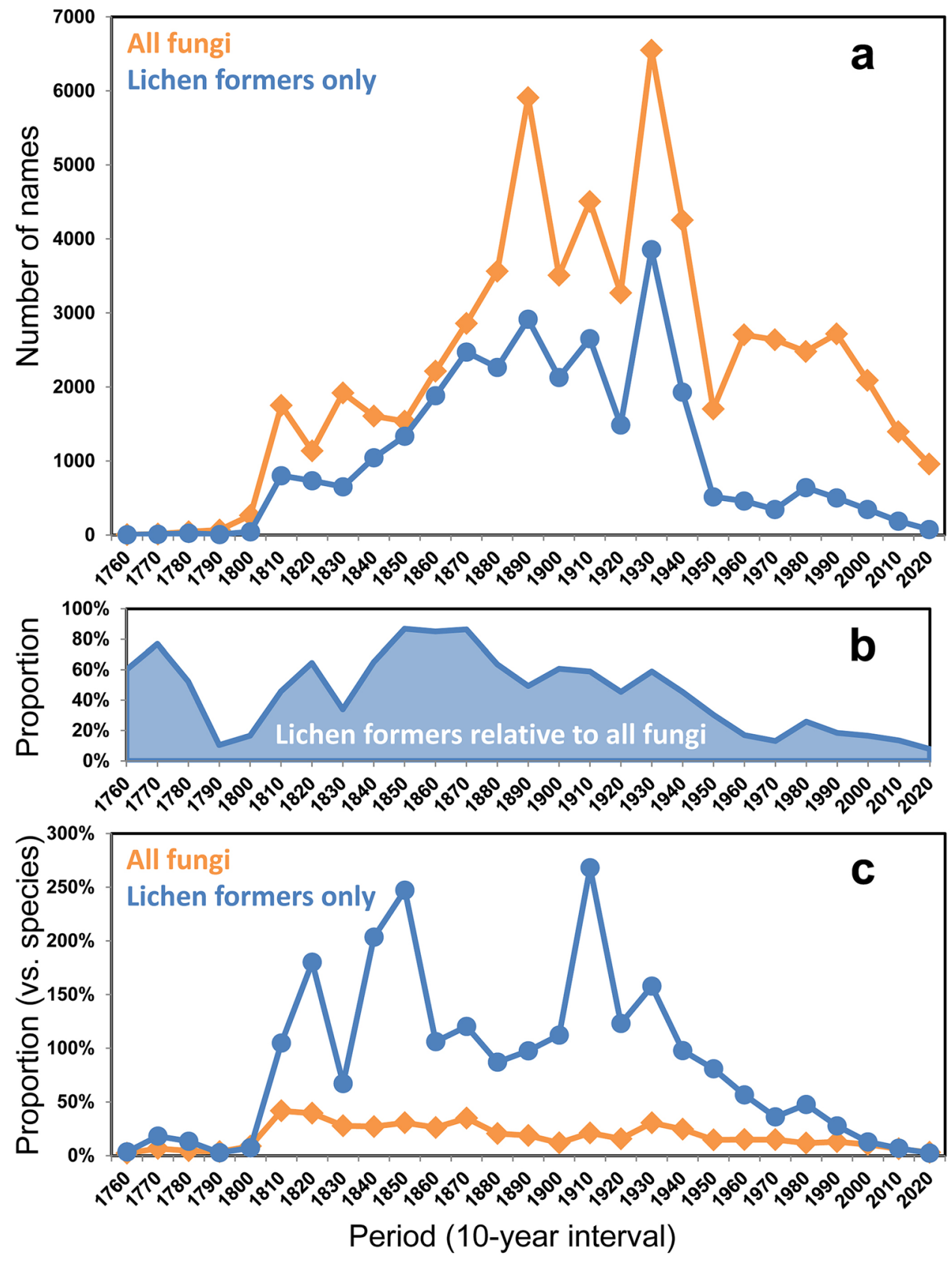

or evolutionary meaning, but the typological concept rarely takes the principle of reproductive isolation into account and hence generally violates modern taxonomic principles. Because of these issues, some workers have dismissed the use of infraspecific taxa, also because the species rank values more in the non-scientific communication with stakeholders in policies regarding biodiversity and conservation (O'Brien and Mayr 1991; De Queiroz 2007; Patten 2015). Moritz (1994) brought to attention the concept of Evolutionary
Significant Units (ESUs), but implicitly equated these to species rather than infraspecies.

Notably, in addition to his pioneering work on species pairs, nearly a century ago Du Rietz (1930) also published a seminal account on the nature of taxonomic units, discussing in detail the principal infraspecific ranks offered by the Code (form, variety, subspecies) and their inconsistent application in the taxonomy of lichen-formers and other organisms, especially regarding the rank forma. He defined the latter 
rank as corresponding to discrete morphological variation unrelated to distribution, population structure, or lineage descent, thus essentially of polyphyletic origin. In contrast, the rank variety and subspecies applied to natural entities with differing degree of range extension (local vs. regional). While these definitions seem straightforward and partially agree with what is being set forth below, Du Rietz (1930) noted that, particularly in botanical (including mycological) nomenclature, the corresponding ranks had rarely been applied following this concept. This is especially true of the ranks variety and form, as applied in the 19th and early twentieth century, but also including more recent cases; for instance, Thamnolia taurica has been variably recognized at the rank of species, subspecies, variety, and form (see below). There also appears to have been a temporal change in concept, particularly when using variety vs. subspecies. Thus, in lichen fungi, the rank subspecies was not only much less popular than variety (606 vs. 16,811 instances), but also less frequently used in the 19th compared to the 20th century (142 vs. 464 instances). Furthermore, the two peak periods for the use of the subspecies rank (1861-1890: 113 instances; 1971-2000: 225 instances) do not correlate with the overall peaks for infraspecific taxonomy. In general, both in mycology and botany, the rank subspecies appears to have a more clearly defined geographical component, while the rank form is often used typologically and the rank variety may favor one or the other component, in contrast to the more strict definition of variety by Du Rietz (1930).

The proper application of infraspecific ranks requires a thorough understanding of the mechanisms of spatiotemporal reproductive isolation. Fungi, including lichen-formers, generally lack specific, vector-based fertilization mechanisms that would allow ecological divergence, and hence spatiotemporal separation, in sympatry. Such mechanisms are often found in related plant species, including seasonally or diurnally different flowering periods associated with different pollination vectors (e.g., Schlueter et al. 2009). On the other hand, selfing, another mechanism proposed to facilitate sympatric evolution in plants (e.g., Wendt et al. 2002; Matallana et al. 2010) is found in homothallic fungi (Honegger et al. 2004; Lin and Heitmann 2007; Ni et al. 2011). However, as long as an underlying biological mechanism supporting spatiotemporal reproductive isolation in sympatry has not been demonstrated, infraspecific taxa in fungi including lichen-formers are expected to exhibit spatiotemporal reproductive isolation primarily through geographic differentiation, in form of allopatry or peripatry or at least limited overlap. Therefore, the application of infraspecific names to widely distributed entities that largely or fully overlap with the typical (nominal) infraspecies, or other infraspecific taxa within the same species, is ill-defined. As a consequence, the bulk of infraspecific names historically established in fungi, including lichen-formers, has been either subsumed into synonymy under particular species or these taxa have been raised to species level.

An additional conceptual issue in traditional botanical and mycological nomenclature is the notion that the three principal infraspecific ranks, subspecies, variety, and form, should theoretically follow a hierarchy, similar to supraspecific ranks [ICNafp (Shenzen) Art. 4, 24]. Thus, in a strict sense, variety should correspond to the subdivision of a subspecies and form to the subdivision of a variety. Historically, infraspecific ranks have mostly be applied to subdivisions of species, independent of rank, and often in a simplified sense, especially with respect to form vs. variety, i.e., the smaller the perceived deviation, the lower the applied rank. In a biological sense, a situation where hierarchical infraspecific ranking would be applicable at the infraspecies level can be theoretically conceived, e.g., a geographically isolated population that, while not yet reproductively isolated from the mother population, already undergoes further geographic isolation. On the other hand, one could argue that infraspecific ranks reflect the temporal dynamics of speciation, i.e., when a new lineage emerges, the differences towards its ancestor become gradually more distinct, and so a new lineage would gradually pass through taxonomic recognition at different infraspecific levels and ultimately at specific level, and the proper rank would then reflect the inferred stage and not a nested taxonomic structure. A third approach would be to invariably treat infraspecific lineages at the level of subspecies, independent of the degree of deviation. Zoological and prokaryote nomenclature have long adopted this practice and abandoned the use of infraspecific ranks below subspecies, recognizing all infraspecific ranks by default as subspecies, even if originally designated otherwise, e.g., as variety or form [ICZN Art. 45.5, 45.6 (Ride et al. 1999); ICNP Rule 5c, 14a (Parker et al. 2019)]. Here, we consider that the rank of subspecies should be the default when the distribution ranges are not nested, i.e., cases of allo-, para- or peripatry, whereas variety should be applied when a narrow range is nested within a broader range, always assuming that the underlying phylogeny allows for such an interpretation (Fig. 10). Variety should also be used when indeed a hierarchically nested pattern can be demonstrated (see below). The rank forma should, however, be abandoned.

Within a modern taxonomic framework, based on the findings from molecular phylogenetic studies, the use of infraspecific taxa in fungi including lichen-formers has decreased considerably and, where continued to be employed, has been based on a more solid evolutionary rationale, although not necessarily in all instances. In a modern context, infraspecific (gamma) taxonomy offers the possibility to deal with structured infraspecific variation, providing a tool to mediate between splitting and lumping of species. In theory, the decision whether lineages should be considered species or infraspecific taxa is reproductive 
isolation (species) vs. compatibility (infraspecies) in sympatry, either in nature or experimental. While sympatry in nature can be assessed from distribution data, experimental approaches pose challenges in terms of practicability and hence have only rarely been used in fungal taxonomy (Dettman et al. 2003; Liu et al. 2016; Lücking et al. 2020a). In lichen-formers, an experimental approach to reproductive isolation vs. compatibility is even more difficult, but indirect

\begin{tabular}{|c|c|c|c|c|c|}
\hline \multirow{2}{*}{\multicolumn{3}{|c|}{ Distribution }} & 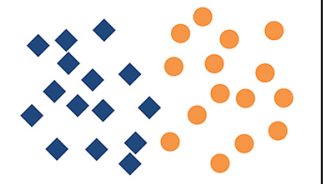 & 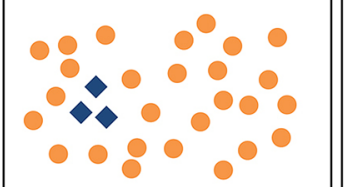 & 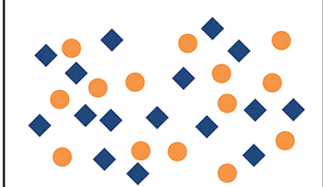 \\
\hline & & & $\begin{array}{l}\text { Allo-/para- } \\
\text { /peripatric }\end{array}$ & $\begin{array}{c}\text { Nested } \\
\text { (endemic) }\end{array}$ & Sympatric \\
\hline & \multirow{2}{*}{$\begin{array}{c}\text { Reciprocally } \\
\text { monophyletic } \\
\text { (long stem } \\
\text { branches) }\end{array}$} & distinct & $\begin{array}{c}\text { s p e c i e s } \\
\text { (Peltigera gowardii } \\
\text { vs. P. hydrothyria) }\end{array}$ & $\begin{array}{c}\text { s p e c i e s } \\
\text { (Melanelixia hawkswor- } \\
\text { thii vs. M. fuliginosa) }\end{array}$ & $\begin{array}{c}\text { s p e c i e s } \\
\text { (Lobariella reticulata } \\
\text { vs. L. pallida) }\end{array}$ \\
\hline & & $\begin{array}{l}\text { (near-) } \\
\text { cryptic }\end{array}$ & $\begin{array}{c}\text { s p e c i e s } \\
\text { (Xanthoparmelia hypo- } \\
\text { fusca vs. X. tasmanica) }\end{array}$ & $\begin{array}{l}\text { s p e c i e s } \\
\text { (Thamnolia taurica } \\
\text { vs. T. vermicularis) }\end{array}$ & $\begin{array}{c}\text { s p e c i e s } \\
\text { (Parmelia ernstiae } \\
\text { vs. P. serrana) }\end{array}$ \\
\hline & \multirow{2}{*}{$\begin{array}{l}\text { Reciprocally } \\
\text { monophyletic } \\
\text { (short stem } \\
\text { branches) }\end{array}$} & distinct & $\begin{array}{c}\text { s p e c i e s } \\
\text { (Cora palaeotropica } \\
\text { vs. C. bovei) }\end{array}$ & $\begin{array}{c}\text { s p e ci e s } \\
\text { (Xanthoria monofoliosa } \\
\text { vs. X. parietina) }\end{array}$ & $\begin{array}{c}\text { s p e ci e s } \\
\text { (Usnea antarctica } \\
\text { vs. U. aurantiacoatra) }\end{array}$ \\
\hline & & $\begin{array}{l}\text { (near-) } \\
\text { cryptic }\end{array}$ & $\begin{array}{c}\text { s p e c i e s } \\
\text { (Cora paraciferrii } \\
\text { vs. C. ciferrii) }\end{array}$ & $\begin{array}{l}\text { s p e c i e s } \\
\text { (Parmelia rojoi } \\
\text { vs. P. saxatilis) }\end{array}$ & $\begin{array}{c}\text { s p e c i e s } \\
\text { (Pseudocyphellaria } \\
\text { sandwicensis vs. } P \text {. } \\
\quad \text { xanthosticta) }\end{array}$ \\
\hline & \multirow[t]{2}{*}{$\begin{array}{l}\text { Nested } \\
\text { (paraphyletic } \\
\text { residual) }\end{array}$} & distinct & $\begin{array}{l}\text { s u b s p e c i e s } \\
\text { (Cora dewisanti } \\
\text { subsp. mexicana vs. } \\
\text { subsp. dewisanti) }\end{array}$ & $\begin{array}{c}\text { s p e cies } \\
\text { (Cora rubrosanguinea } \\
\text { vs. C. elephas) }\end{array}$ & $\begin{array}{c}\text { s p e c i e s } \\
\text { (Pseudocyphellaria } \\
\text { biliana vs. } \\
\text { P. pomaikaiana) }\end{array}$ \\
\hline & & $\begin{array}{l}\text { (near-) } \\
\text { cryptic }\end{array}$ & $\begin{array}{l}\text { s u b s p e c i e s } \\
\text { (Sticta scabrosa } \\
\text { subsp. hawaiiensis } \\
\text { vs. subsp. scabrosa) }\end{array}$ & $\begin{array}{c}\text { v a ri e t y } \\
\text { (Dermatocarpon luridum } \\
\text { var. xerophilum } \\
\text { vs. var. luridum) }\end{array}$ & $\begin{array}{c}\text { no recognition } \\
\text { (Endocarpon tortuosum } \\
\text { vs. Staurothele } \\
\text { pulvinata) }\end{array}$ \\
\hline & \multirow[t]{2}{*}{$\begin{array}{l}\text { Unresolved } \\
\text { (depending } \\
\text { on marker } \\
\text { resolution) }\end{array}$} & distinct & $\begin{array}{l}\text { s u b s p e c i e s } \\
\text { (Caloplaca arnoldii } \\
\text { subsp. arnoldii } \\
\text { vs. subsp. obliterata }\end{array}$ & $\begin{array}{l}\text { va ri e t y } \\
\text { (Endocena informis } \\
\text { var. falklandica } \\
\text { vs. var. informis) }\end{array}$ & $\begin{array}{c}\text { informal } \\
\text { recognition* } \\
\text { (dendriscocauloid } \\
\text { cyanomorph of Sticta } \\
\text { latifrons) }\end{array}$ \\
\hline & & $\begin{array}{l}\text { (near-) } \\
\text { cryptic }\end{array}$ & $\begin{array}{l}\text { no recognition } \\
\text { (Umbilicaria iberica } \\
\text { vs. U. subpolyphylla) }\end{array}$ & $\begin{array}{c}\text { no recognition } \\
\text { (Eumitria pectinata) }\end{array}$ & $\begin{array}{l}\text { no recognition } \\
\text { (Cladonia convoluta } \\
\text { vs. C. foliacea) }\end{array}$ \\
\hline
\end{tabular}

Fig. 10 Categorization of the main patterns of phylogenetic topologies and distribution ranges and their recommended recognition at species or infraspecies rank. References: Caloplaca: Gaya et al. (2011); Cladonia: Pino-Bodas et al. (2010a, b); Cora dewisanti: Moncada et al. (2019); C. paleotropica vs. C. bovei, C. paraciferrii vs. C. ciferrii: Lücking et al. (2017b); Dermatocarpon: Amtoft et al. (2008), Fontaine et al. (2012); Endocarpon/Staurothele: Heiđmarsson et al. (2017); Endocena: Fryday et al. (2017). Leptogium: Otálora et al. (2010b); Letharia: Altermann et al. (2014, 2016); Lobariella: Moncada et al. (2013a, b); Melanelixia: Leavitt et al. (2016b); Parmelia ernstiae vs. P. serrana: Molina et al. (2011); P. rojoi vs. P. saxatilis:: Crespo et al. (2020); Peltigera: Lendemer and O'Brien (2011);
Pseudocyphellaria: Lücking et al. (2017c); Sticta latifrons: Ranft et al. (2018); S. scabrosa: Moncada et al. (2021a, b); Thamnolia: Onuţ-Brännström et al. (2017,2018), Jørgensen (2019), this paper; Umbilicaria: Davydov et al. (2019); Usnea: Grewe et al. (2018), Lagostina et al. (2018); Xanthoparmelia: Hodkinson and Lendemer (2011); Xanthoria: Kondratyuk et al. (2008). *In certain cases, taxonomic separation is warranted, if there is no immediate explanation for discrete variation and the underlying molecular data are suspected to provide insufficient resolution; examples are Physcia caesia vs. $P$. aipolia (see above) and Sticta limbata vs. S. fuliginosa (Moncada et al. 2020b) 
evidence through mating genes and molecular patterns of past recombination and gene flow have been employed (Leavitt et al. 2011a, b, 2015; Wirtz et al. 2012; Ludwig et al. 2017).

As detailed approaches to reconstruct the reproductive biology of lichenized fungi are rare, so far there has been no widespread and consequent implementation of infraspecific taxonomy in a modern, evolutionary sense, such as practiced in zoology (Wilson and Brown 1953; Mallet 2007; Patten 2015). On the contrary, competing solutions are often applied to such cases. A recent example is the genus Thamnolia. Between 1850 and 2020, 67 names were established in this genus, 22 of which correspond to unrelated genera in other lineages and 45 to Thamnolia sensu stricto, representing 30 heterotypic entities (Table 5). Of these, 19 were only recognized at infraspecific level. Taxa in this genus have traditionally been distinguished based on few phenotype characters: a hollow vs. solid, cylindral to flattened thallus, branching pattern, and secondary chemistry, with individuals producing either thamnolic (and decarboxythamnolic) acid (UV-) or squamatic and baeomycesic (UV + yellow) acids (Culberson 1963; Santesson 2004; Jørgensen 2019). Given the lack of correlation between morphology and secondary chemistry, the taxonomy in this genus has been disputed and concepts varied between recognizing a single, variable species or various taxa with emphasis on either morphology or chemistry, or both, at species or infraspecific rank (Culberson 1963; Santesson 2004; Jørgensen 2019). A recent molecular phylogenetic study based on six markers (Onuţ-Brännström et al. 2017, 2018) resolved three main, supported lineages, one widespread, one subarctic, and one restricted to the Alps. In the widespread lineage, there was little or no correlation with morphological or chemical features. The authors recognized the three lineages as three species, the widespread lineage under the name T. subuliformis, the subarctic lineage as new species, T. tundrae, and the alpine lineage as T. vermicularis s.str. Jørgensen (2019) subsequently corrected an apparent error in typification, so that the widespread lineage would carry the name vermicularis and the alpine lineage the name taurica; however, he recognized the three lineages only at the subspecies level, as T. vermicularis subsp. vermicularis (syn.: T. subuliformis), T. vermicularis subsp. taurica, and $T$. vermicularis subsp. tundrae.

Given that the underlying phylogeny is known, the correct application of alpha and/or gamma taxonomy in this case can be assessed. The topological patterns, in particular the long stem branches and the somewhat structured internal variation in the widespread lineage (Onuţ-Brännström et al. 2017, 2018) support the recognition of each lineage at the species level, reflecting the separate evolutionary history of each lineage. The allopatric distribution of the subarctic (tundrae) vs. the alpine lineage (taurica) allow the application of infraspecific taxonomy, if both were sister groups and showed little phylogenetic divergence. Whereas the ITS marker resolved both as sister clades (Onuţ-Brännström et al. 2018), the six-marker phylogeny did not resolve the relationships between the three lineages but suggested that the subarctic and the alpine lineage split more recently (0.6-4.1 Mya) from each other than either from the widespread lineage (1.5-6.6 Mya; Onuţ-Brännström et al. 2017). The widespread lineage (vermicularis) is present in the range of both taurica and tundrae, so the latter two fully overlap with vermicularis within their corresponding range. Therefore, it appears that in the overlapping ranges, taurica and tundrae are reproductively isolated from vermicularis, because otherwise one would expect them to interbreed. This consideration is of course complicated by the notion that extant sexual reproduction in Thamnolia is not known, making the application of the biological species concept difficult. The molecular data show signs of past recombination within but not between lineages (Nelsen and Gargas 2009; Onuţ-Brännström et al. 2017), supporting their distinction at species level and also indicating that sexual reproduction happened in the past. The data also suggest that taurica and tundrae are relict species with a broader ancestral distribution, whereas vermicularis shows signatures of a recent expansion. Given this evidence, the proposal by Jørgensen (2019) is not in accordance with the evolutionary history of these lineages and they are better recognized as species, with the revised names $T$. vermicularis for the widespread lineage (=T. subuliformis sensu Onuţ-Brännström et al. 2018), T. tundrae for the subarctic lineage, and T. taurica for the lineage in the Alps.

Unfortunately, few cases offer the amount of data available as in Thamnolia to assess the feasibility of infraspecific taxonomy in species complexes. Another example is Ramalina celastri subsp. ovalis, now recognized as a separate species, $R$. ovalis (Hayward et al. 2014). Therefore, great care should be applied when opting for infraspecific taxonomy and the reasoning for such an approach should always include an evolutionary component, even if only inferred from indirect evidence. For instance, Lücking and Lücking (1995) established Arthonia cyanea var. cocosensis for an isolated population on the oceanic Cocos Island in the eastern Pacific that slightly deviates from other material of the widespread A. cyanea var. cyanea in the ascospores becoming 3-4-septate and greyish-brown (2-3-septate and colourless in A. cyanea var. cyanea). Subsequently, Lücking (2008) divided the latter into f. minor Lücking (ascospores predominantly 2-septate) and f. cyanea (ascospores predominantly 3 -septate). The phylogenetic relationships between these phenotypes are unknown and the current taxonomic concept is therefore an untested hypothesis. However, given that $\mathrm{f}$. minor, although comparatively rare, is widespread in the Neotropics (Lücking 2008; van den Boom and Sipman 
Table 5 Names validly published in Thamnolia and their current status

\begin{tabular}{|c|c|c|c|}
\hline Epithet & Name & Current name & Reference(s) \\
\hline andicola & T. andicola & T. vermicularis & Culberson (1963) \\
\hline coloradoensis & T. vermicularis var. coloradoensis & T. vermicularis & Sushan and Anderson (1955), Jørgensen (2019) \\
\hline elegans & T. elegans & Unresolved & Culberson (1963) \\
\hline fruticosa & T. vermicularis var. fruticosa & T. vermicularis & This paper \\
\hline glebosa & $\begin{array}{l}\text { T. vermicularis f. glebosa } \\
{[\text { T. vermicularis var. glebosa }]}\end{array}$ & T. vermicularis & Minks (1874), this paper \\
\hline gracilis & T. vermicularis $\mathrm{f}$. gracilis & T. vermicularis & This paper \\
\hline intricata & T. vermicularis var. intricata & Unresolved & This paper \\
\hline juncea & T. juncea & T. vermicularis & Onuţ-Brännström et al. $(2017,2018)$ \\
\hline lutea & T. vermicularis f. lutea & Unresolved & Motyka (1960), this paper \\
\hline melvilliana & T. vermicularis f. melvilliana & T. vermicularis & This paper \\
\hline minor & $\begin{array}{l}\text { T. vermicularis } \mathrm{f} \text {. minor } \\
\text { T. subvermicularis f. minor } \\
\text { T. subuliformis f. minor }\end{array}$ & T. vermicularis & Yang et al. (2015) \\
\hline nivea & $\begin{array}{l}\text { T. subvermicularis var. nivea } \\
\text { T. subuliformis } \text { var. nivea }\end{array}$ & Unresolved & This paper \\
\hline papelillo & T. papelillo & T. vermicularis & Onuţ-Brännström et al. $(2017,2018)$ \\
\hline qomolangmana & T. vermicularis f. qomolangmana & T. vermicularis & Yang et al. (2015) \\
\hline robusta & $\begin{array}{l}\text { T. vermicularis } \mathrm{f} \text {. robusta } \\
\text { T. vermicularis subf. robusta }\end{array}$ & T. vermicularis & This paper \\
\hline rosea & T. vermicularis f. rosea & T. vermicularis & This paper \\
\hline roseorugosa & T. vermicularis f. roseorugosa & T. vermicularis & This paper \\
\hline rostrata & T. subvermicularis var. rostrata & Unresolved & This paper \\
\hline rugosoides & $\begin{array}{l}\text { T. vermicularis f. rugosoides } \\
\text { T. subvermicularis var. rugosoides }\end{array}$ & T. vermicularis & This paper \\
\hline solida & $\begin{array}{l}\text { T. vermicularis var. solida } \\
\text { T. vermicularis subsp. solida }\end{array}$ & T. vermicularis & Santesson (2004), Onuţ-Brännström et al. $(2017,2018)$ \\
\hline sordida & T. subvermicularis var. sordida & Unresolved & This paper \\
\hline subjuncea & T. juncea var. subjuncea & T. vermicularis & Onuţ-Brännström et al. $(2017,2018)$ \\
\hline subsolida & $\begin{array}{l}\text { T. papelillo var. subsolida } \\
\text { T. subuliformis var. subsolida }\end{array}$ & T. vermicularis & Onuţ-Brännström et al. $(2017,2018)$ \\
\hline subuliformis & $\begin{array}{l}\text { T. vermicularis } \mathrm{f} \text {. subuliformis } \\
\text { T. vermicularis var. subuliformis } \\
\text { T. vermicularis subsp. subuliformis } \\
\text { T. subuliformis }\end{array}$ & T. vermicularis & Jørgensen (2019) \\
\hline subvermicularis & T. subvermicularis & T. vermicularis & Culberson (1963), Jørgensen (2019) \\
\hline taurica & $\begin{array}{l}\text { T. vermicularis } \mathrm{f} \text {. taurica } \\
\text { T. vermicularis var. taurica } \\
\text { T. vermicularis subsp. taurica } \\
\text { T. taurica }\end{array}$ & T. taurica & Onuţ-Brännström et al. $(2017,2018)$, Jørgensen (2019), this paper \\
\hline tenuissima & T. tenuissima & T. vermicularis & This paper \\
\hline tundrae & $\begin{array}{l}\text { T. vermicularis subsp. tundrae } \\
\text { T. tundrae }\end{array}$ & T. tundrae & Onuţ-Brännström et al. (2017, 2018), Jørgensen (2019), this paper \\
\hline undulata & T. undulata & T. vermicularis & Culberson (1963) \\
\hline vermicularis & T. vermicularis & T. vermicularis & Jørgensen (2019) \\
\hline
\end{tabular}

In some cases no modern reference to the current status of a previously established name was found, but where possible, its identity was predicted from the grographic origin of the type and the published description of the taxon, in relation to the presently recognized distribution and ecology of the three taxa distinguished in this genus (indicated as "this paper"); however, revision of these names in a modern context is necessary

2016), it cannot be separated from the widespread f. cyanea based on non-biological reproductive isolation. Therefore, f. minor should either be merged into A. cyanea as a single taxon or, given that intermediate forms have not yet been reported, better recognized at the species level: Arthonia minor (Lücking) Lücking comb. et stat. nov. [Bas.: 
Arthonia cyanea f. minor Lücking, Fl. Neotrop. Monogr. 103: 132 (2008); MycoBank 840275].

Ahti (2000) applied infraspecific taxonomy in various cases of species classified at the time in the genus Cladina, now subsumed within Cladonia, for instance in Cladonia arbuscula, with subsp. boliviana, subsp. imshaugii, and subsp. pachyderma. Two of these had originally been established at the species level, viz. C. boliviana and $C$. imshaugii. The subspecies within $C$. arbuscula were based on a combination of chemical and morphological characteristics and, in part, distribution range, although two subspecies were given as chemically variable. Thus, subsp. arbuscula is characterized by usnic and fumarprotocetraric acids, a robust habit with combed apical branchlets, and a compact ectal layer; it is widespread in temperate regions in both hemispheres. In contrast, subsp. boliviana is principally Andean, with a more slender habit, the apical branchlets not conspicuously combed, and a fibrose extal layer; it has four chemotypes, one corresponding to that of subsp. arbuscula and the others with usnic acid only or additionally with stictic acid (Ahti 2000). The other two subspecies, subsp. imshaugii and subsp. pachyderma, share with subsp. arbuscula the robust habit with combed apical branchlets and compact extal layer, but differ in the mainly dichotomous branching and in other morphological details; both have narrow distribution ranges in Hispaniola (subsp. imshaugii) and the Venezuelan Andes (subsp. pachyderma). In addition, populations in Western North America, eastern Asia and Australasia have been separated as subsp. beringiana and subsp. squarrosa, and C. mitis has also been considered a subspecies of C. arbuscula (Ahti 2000; Myllys et al. 2003; Piercey-Normore et al. 2010). Data of the ITS marker are available for subsp. arbuscula, subsp. beringiana, subsp. boliviana, subsp. mitis, and subsp. squarrosa, indicating that subsp. boliviana is nested on a long, strongly supported branch within a paraphyletic residual formed by intermingled samples of subsp. arbuscula, subsp. beringiana, and subsp. squarrosa; this residual is otherwise nested within subsp. mitis or, depending on sampling and markers, subsp. mitis is nested within subsp. arbuscula or both are reciprocally monophyletic (Myllys et al. 2003; Piercey-Normore et al. 2010; Stenroos et al. 2019; Moncada et al., unpubl. data). The nested topology, together with the largely allopatric distribution and the morpho-anatomical differences, would justify the recognition of subsp. boliviana at precisely that level, comparable to the case of Cora dewisanti (Fig. 10). In contrast, subsp. arbuscula, subsp. beringiana and subsp. squarrosa are not resolved into coherent entities and hence should not be formally recognized, although they show some degree of phenotypic differentiation (Fig. 10). On the other hand, $C$. mitis and $C$. arbuscula have nearly the same broad distribution ranges and hence cannot be recognized at infraspecific level; based on the underlying topology
(Piercey-Normore et al. 2010; Stenroos et al. 2019; Moncada et al., unpubl. data), C. mitis should be recognized as a separate species, similar to the situation in Pseudocyphellaria biliana vs. P. pomaikaiana (Fig. 10).

Clerc (1987) distinguished two varieties in Usnea fragilescens, var. fragilescens and var. mollis. Both show minor morphological and evological divergence and both exhibit broadly overlapping ranges across the Northern Hemisphere (Lücking et al. 2020b). No molecular data are currently available for var. mollis, but the distribution ranges suggest that the distinction is merely typological and hence both should either be merged or separated at the species level (Moncada et al. 2020a).

The subspecies level was applied to recently discovered new taxa in the genera Cora, Peltigera, and Sticta. In the cases of $C$. dewisanti subsp. mexicana vs. subsp. dewisanti and $S$. scabrosa subsp. hawaiiensis vs. subsp. scabrosa (Moncada et al. 2019, 2021a, b), the subspecies exhibit peripatry relative to the typical subspecies: $C$. dewisanti subsp. mexicana in Mexico vs. subsp. dewisanti in South America, and S. scabrosa subsp. hawaiiensis in Hawaii vs. subsp. scabrosa in the Neotropics. In both cases, the two subspecies showed only minor phenotypic differentiation, close to being cryptic. Besides this, the main aspect for their classification as subspecies was their nested placement within the typical subspecies in the underlying phylogeny, on short branches. For such cases, the evolutionary history best justifies the status of subspecies (Fig. 10). A different pattern was found for Peltigera polydactylon subsp. udeghe (Magain et al. 2016), which was resolved as reciprocally monophyletic compared to subsp. polydactylon, differing morphologically in the phyllidiate thallus, and with an allopatric distribution pattern. This would in our view justify the distinction at species level, comparable to the case of Cora palaeotropica vs. $C$. bovei (Fig. 10).

In contrast, Solenopsora olivacea subsp. olivacea and S. olivacea subsp. olbiensis form a species pair with either sexual or asexual reproduction (see above). The limited molecular data (only three specimens in total sequenced) indicate that both are closely related but potentially reciprocally monophyletic, and both have broadly overlapping ranges in the Mediterranean (Guttová et al. 2014). Their separation at infraspecific level is therefore purely typological and subsp. olbiensis should either be subsumed under $S$. olivacea or recognized at the species level, depending on additional molecular data. 
Recommendation 5: Lineages delimited as distinct taxa should by default be recognized at the species level. Infraspecific ranks should only be used in cases of sister group relationships or nested placements with short stem branches and when a biogeographic component in terms of allo-, para- or peripatry or nested, narrowly endemic distribution is given. In cases of allo-, para- or peripatry, the subspecies rank should be employed, following the practice of zoological and prokaryote nomenclature, unless a hierarchically nested distribution pattern of geographically isolated but biologically compatible populations can be demonstrated, in which case the additional rank of variety (varietas) would be applicable, i.e., in obligate combination with the rank of subspecies. Variety should also be used when a phylogenetically nested lineage with distinctive features occupies a narrow range within the broader range of the paraphyletic residual. The rank of form (forma) should be abandoned. In general, infraspecific taxonomy should not be used in a typological manner, i.e., to formally denote discrete phenotypic variation only, without knowledge of phylogenetic relationships or taking into account biogeographic patterns

\section{A quick primer on common molecular complications}

While molecular data are overall superior to phenotype data in establishing evolutionary relationships and delimiting species, they are not free of potential complications, which may lead to type I errors (false positives), i.e., the erroneous establishment of novel taxa. The six most common ones are (1) contaminant sequences, (2) laboratory mixups, (3) chimeric sequences, (4) incomplete lineage sorting, (5) introgression, and (6) gene duplication (Loeffler et al. 1999; Stojanovic et al. 2002; Hugenholtz and Huber 2003; Maddison and Knowles 2006; Joly et al. 2009; Naciri and Linder 2015; Sheik et al. 2018; Lücking et al. 2020a; Aime et al. 2021). As a consequence, molecular phylogenies used to test existing taxonomies should be carefully assessed for such errors, before proposing formal changes or describing new species. To that end, we provide precise definitions and guidelines.

Contaminant sequences are defined as sequences generated from a sample that do not represent the target organism, in this case the primary mycobiont. Frequently, these are attributed to environmental laboratory contaminants accidentally entering the sample, but in reality, such contaminants are much less common than contaminants originating from the sample itself or from DNA contamination of stock solutions (which can be tested by using samplefree controls). Sample contaminants may not only be fungi developing on the sample a posteriori, such as molds, but also lichenicolous, endolichenic, or other fungi occurring as natural components of the sample, although not necessarily growing in the lichen thallus (see above). Contaminants can usually be recognized by blasting the resulting sequence, as it should give results unrelated to the target mycobiont. Surprisingly, such contaminant sequences are not rarely submitted to public repositories, such as GenBank, under the name of the target mycobiont (Sheik et al. 2018); for instance, an ITS sequence labeled Strigula orbicularis (GenBank accession KU509981) represents a contaminant in the genus Aspergillus. This happened more frequently in the earlier days of DNA sequencing, as the lack of proper reference sequences made it more difficult to assess whether a given sequence represented the target fungus or a contaminant, e.g., a dothidealean contaminant mtSSU sequence of Lasallia pennsylvanica (AF356664) leading to an artifactual topology, with Eurotiomycetes nested within Lecanoromycetes (Lutzoni et al. 2001; Lücking and Nelsen 2018). Not rarely, the same sample and DNA extract may provide the desired target sequences for a given set of markers but contaminant sequences for other markers, depending on the affinity of the primers to the target mycobiont vs. any contaminant fungus present in the sample. A recent example is the presence of basidiomycetous fungi in the thalli of certain Verrucariaceae, in which the mtSSU primers consistently recovered the primary mycobiont (Verrucariaceae), whereas the ITS primers generally sequenced the basidiomycetous component (Corticiaceae; Lücking and Moncada 2017). A particular challenge arises when the contaminant sequence represents a (closely) related taxon, which can happen in diffusely delimited lichen phenotypes that may contain small pieces of other lichens (see below; "extraneous mycobiont DNA"). Such cases will not be immediately obvious but should be considered when phylogenetic placement of a set of sequences generated from the same sample results in unexpected placements. The only conclusive way to test for close-relative contamination is to make another DNA extract from the underlying sample.

An often overlooked problem is the decoupling of the underlying specimen from the different steps in the workflow of generating the molecular data, i.e., DNA extract, PCR aliquots, PCR cleaning product, or the actual sequence data file. The underlying connection is ensured by a unique identifier (DNA extract number, tissue sample barcode, etc.); however, errors of mislabeling easily and inadvertently happen, particularly in the last sequencing step, including reverse positioning of the sequencing plate. Apart from attempting to avoid such errors by working carefully and with attention to detail, or using software pipelines to track potential mixups (e.g., Stojanovic et al. 2002), a way to avoid unrecognized mixups is to combine distantly related samples in a single work set and, if resulting sequences from a sequencing plate appear odd, test whether reverse order of the plate labels provide the expected match. If there is evidence for a mixup, the safest way to obtain reliable data is 
repeating the PCR and sequencing steps, rather than trying to make sense of the existing data. Kondratyuk et al. (2019) recently reported "extraneous mycobiont DNA", i.e., unexpected sequences corresponding to a particular lichen mycobiont presumably detected in the thallus of other lichens, e.g., of Biatora longispora (Ramalinaceae) in the thallus of Agonimia pacifica (Verrucariaceae). It is unclear whether these are the result of a laboratory mixup or of natural contamination of the underlying lichen thalli. Proposing a special term ("extraneous mycobiont DNA") and postulating that this may play "... an important role in [the] formation of lichen associations ..." or "... help to understand better [the] taxonomy of some lichen groups ..." (Kondratyuk et al. 2019: 294) is not only fanciful but also far-fetched.

Chimeric sequences are a known problem in next generation sequencing (NGS) techniques (Nilsson et al. 2015). Sanger sequencing does not usually result in chimeras, unless the primer pair shows differential downstream and upstream affinities to fungal lineages. When trying to assemble such sequences, the mismatch is usually immediately detected, unless there is little overlap between forward and reverse sequences in a conserved region. Given that such chimeric contig sequences should contain more or less equally large forward and reverse parts, they are rather easily detectable either by blasting and inspecting the alignment patterns, or in a phylogenetic analysis, by causing the including clade to have a rather long, yet unsupported stem branch. Besides chimeric sequences, chimeric data sets, i.e., concatenating clean sequences that represent different target organisms, have been reported to lead to erroneously established taxa (Vondrák et al. 2018; Llewellyn 2019; Wilk et al. 2021).

Incomplete lineage sorting is a commonly occurring, natural problem in recently emerging species (Maddison and Knowles 2006; Joly et al. 2009; Alexander et al. 2017). It is caused by a temporary shift in the divergence of different genes, usually located in different portions of the genome. When a lineage $\mathrm{L} 0$ diverges into two lineages $\mathrm{L} 1$ and $\mathrm{L} 2$, gene A may diverge first, then represented by alleles $\mathrm{A} 1$ and $\mathrm{A} 2$, subsequently followed by gene B, with alleles B1 and B2. The ancestral lineage is then characterized by the combination A0-B0, whereas the two descendant lineages will eventually exhibit the combinations A1-B1 vs. A2-B2, after sufficient "sorting" time has passed. During the emergence of the two lineages, individuals may show various combinations, including also A1-B2 or A2-B1, leading to conflict when different markers are comparatively analysed. Such incomplete lineage sorting can be recognized when the visible conflict is restricted to closely related sister lineages and when some markers appear to have more resolution than others, i.e., when there is an underlying pattern regarding the timeline of individual gene trees, although in practice this can be difficult to discern with typical sampling sizes.
Introgression occurs after interspecies hybridization, when hybrids backcross with one or both parent lineages (Alexander et al. 2017; Ament-Velásquez et al. 2020; Keuler et al. 2020). If this happens between recently diverged sister species, patterns resulting from introgression are difficult to distinguish from those caused by incomplete lineage sorting (Alexander et al. 2017), although statistical tests have been developed to aid in such cases (Joly et al. 2009). If introgression happened between more distantly related species, the conflict should be visible in that conflicting markers from the same sample cluster in different clades representing other parent species. Again, sampling size, both in terms of individuals and markers (e.g., phylogenomics; Ament-Velásquez et al. 2020; Keuler et al. 2020 ) is critical to properly assess this issue.

Gene duplication denotes the divergence of a given gene into two (or more) copies within the same genome. Once this happens, the different copies (original ortholog and duplicated paralogs) are bound to evolve independently through random DNA replicating errors, unless a mechanism of concerted evolution is in place. Such sequence evolution is independent of lineage evolution, exploring new phylospace, meaning that, contrary to introgression, paralogous sequences do not have exact matches in the genome of other species (Lücking et al. 2020b). However, as in the case of incomplete lineage sorting vs. introgression, this depends on the time passed since the divergence. Also, given that gene duplication is cladebased, the resulting conflicting topologies may resemble those obtained from introgression (Lücking et al. 2020b). The differentiation is further complicated when paralogs remain functional and do not evolve freely, especially, when a functional paralog replaces the original ortholog in the genome, so that the genome contains one copy of the gene (Linder and Rieseberg 2004). In such cases, the absence of more than one copy in genome sequencing approaches does not mean that the gene is not a paralog.

Recommendation 6: When assessing sequence data and molecular phylogenetic trees, always be aware of potential artifacts caused by contaminant sequences, laboratory mixups, chimeric sequences, incomplete lineage sorting, introgression, gene duplication, and other issues. Do not believe your own data until you have made sure they are correct. The best strategy to cross-check molecular data is to have sequence data from at least two samples of the same taxon and various markers representing functionally different parts of the genome, e.g., nuclear ITS, mitochondrial $\mathrm{mtSSU}$, and a protein-coding marker. 


\section{Data and taxon sampling}

An often overlooked issue in taxonomic works is improper or insufficient data and taxon sampling, which can lead to type I errors (false positives) and taxonomic inflation (Leavitt et al. 2011b; Bernstein et al. 2021), rarely also to type II errors (false negatives). Common errors include improper taxon and specimen sampling, improper comparison of different data types, and omitting the search for potentially available names in historic or obscure literature.

When establishing a new species, it should by default be compared to both the most similar and the most closely related species. Most similar species are those deviating in only few characters, for instance with the same morphology but a different chemistry or ascospore type, or with the same (particularly if unusual) chemistry but differing in other features. Most closely related are those species forming part of the same clade, in particular the immediate sister species. Assessing close relationship is often non-intuitive when molecular data are not available, as closely related species may be phenotypically disparate (Lücking et al. 2017b; Esslinger et al. 2020). When a comprehensive taxonomy, such as a global revision or monograph (e.g., Arvidsson 1982; Aptroot and Lücking 2016) and/or a more or less complete set of molecular data, such as for the genera Cora or Melanelixia (Arup and Sandler-Berlin 2011; Leavitt et al. 2016b; Lücking et al. 2017b) exist for a higher taxon, taxon selection for proper comparison is rather straightforward. However, more often than not this is not the case. Therefore, the distinctiveness of a clade in a molecular phylogeny alone is not evidence for a novel species, unless all species in this group have been sequenced. Even in groups for which a large amount of sequence data is available, such as the genus Usnea, with currently over 1750 ITS accessions, the proportion of sequenced vs. known species is generally low, in the case of Usnea little over 25\% (Lücking et al. 2020b). Thus, before introducing taxonomic novelties based on a molecular phylogeny, similar but non-sequenced species in the group in question should be carefully examined and this should be documented in the discussion of the new taxon (Lendemer 2021).

In groups where the majority of the species have already been described and where a large proportion of established names are currently treated as synonyms, such as in vascular plants or reptiles (Joppa et al. 2011; Bernstein et al. 2021), the likelihood for an unfamiliar lineage to already have a name, and hence for the establishment of another, superfluous name, is rather high. In lichen-forming fungi, about half of the established species-level names are currently considered synonyms (see above), whereas the number of undescribed species is estimated to surpass the number of currently accepted species by about fifty percent (Lücking et al. 2009b). Thus, an unfamiliar lineage is about twice more likely to already have a name than to be undescribed. As a result, issues of unrecognized diversity and taxonomic inflation may go hand in hand (Leavitt et al. 2011b; Bradshaw et al. 2020). In fungi overall, the number of available species-level names is about twice the number of currently accepted species, whereas the number of estimated species is about twenty times as high (Hawksworth and Lücking 2018), and so it is statistically ten times more likely to detect an undescribed species than an unfamiliar, yet previously described species. However, this does not release the taxonomist from the responsibility to always carefully check old names and historic or obscure publications, including in foreign languages, that way developing a thorough familiarity with the focal group to appropriately recognizing non-fitting samples. Nomenclatural repositories such as Index Fungorum and MycoBank, with extensive synonymies and often with direct links to protologues, greatly facilitate this task.

In multi-marker phylogenies it is not rare that lineages are only represented by a subset of markers. For instance, in a three-marker phylogeny comprised of mtSSU, nuLSU, and $R P B 2$, any given lineage may be represented by all three, two, or just one of these markers. Problems then arise particularly for terminals (species), when the markers do not overlap. For instance, one species may be represented by a combination of two markers (e.g., mtSSU, RPB2) and another by a single marker only (e.g., nuLSU), which will lead to "phylogenetic orphans" or false polyphyly (e.g., Rivas Plata et al. 2013). For broader phylogenies, e.g., attempting to resolve genera within a family, this is of no concern, as long as each genus-level clade has at least some marker overlap between the lineages contained therein. However, individual species can appear polyphyletic if there is no marker overlap between different samples representing the same species (Rivas Plata et al. 2013). It is therefore conceivable that absence of marker overlap can lead to erroneous recognition of presumably novel taxa, when the marker(s) sequenced for such material do not overlap with the already existing markers sequenced for other specimens of the same taxon. Such problems are fortunately often recognized at the submission stage of manuscripts.

A third problem is the generation of sequence data for presumably widespread species when sequence data for the metapopulation including the type locality are not available. For instance, a species may have originally been described from the Caribbean (e.g., Teloschistes flavicans), but sequence data were first generated from geographically distant regions, such as South Africa, Australia, and Hawaii (Fedorenko et al. 2009). The assumption that such sequence data really represent the species in question, and hence demonstrate its wide distribution, is ill-defined and can lead to potential type II errors, i.e. false negatives. Fortunately, such cases are easily discerned 
when molecular data become available for material from the region encompassing the type locality, although complicated cases where even the type locality may harbor more than one species of a species complex are known, e.g. S. fuliginosa vs. S. fuliginoides (Moncada et al. 2014; Magain and Sérusiaux 2015). In any case, drawing deeper conclusions from cases where presumably widespread species are first sequenced outside their type region should be avoided.

Recommendation 7: Before establishing new species (or new taxa at infraspecific level), make sure that potentially available names have been screened, by inspecting types of synonyms listed in monographic treatments and nomenclatural repositories and by checking historical and obscure literature. Such a check should be reasonably thorough but it is clear that it cannot always be exhaustive. For new species, it is not usually necessary to check published infraspecies names, as they do not have priority outside their rank, even if later discovered to be synonyms, unless they were at some point raised to species level. However, when only few infraspecific names have been published in a group under study, it is recommended to check these and, if appropriate, take up such epithets at the species level (instead of describing a new species), especially if their taxonomy has been properly circumscribed at the infraspecies level by the original author(s). For taxonomic discussions of new species, a representative sample of the most similar and the most closely related species should be included. When testing a species hypothesis through molecular data, proper sampling is crucial, including overlap of the underlying markers between the taxa to be tested and inclusion of the most closely related and most similar species. If such data are not available, they should be generated, because otherwise the results will not be conclusive.

\section{Conclusions: a protocol for consistent alpha (and gamma) taxonomy in lichen-forming fungi}

In conclusion, we present a protocol for a consistent alpha (and gamma) taxonomy in lichen-forming fungi, including practical solutions for different purposes. The underlying logic is in part loosely based on McCabe (2021) but has been placed into a more practical framework and adjusted to modern terminology.

1. Detect a phenotypically or phylogenetically non-fitting sample (individual or group of individuals) within the framework of a previously established taxonomy.

2. Determine the degree of non-fittingness, preferably using a quantitative approach. For phenotype characters, apply a statistical approach when the differences are morphometric (e.g., ascospore size) and not immediately obvious, demonstrating that the non-fitting sample is outside the variation range of already known taxa. For instance, differences in ascospore sizes of 10-20×6-8 $\mu \mathrm{m}$ (non- fitting sample) vs. $20-30 \times 8-10 \mu \mathrm{m}$ (most similar known taxon) should be quantified using a statistical group comparison or a multivariate ordination graph. Qualitative phenotype characters (e.g., presence/absence of particular chemical compounds) should be assessed in comparison to the known variation in related, wellestablished taxa defined with the aid of molecular data, taking into account the underlying nature of the character (e.g., chemosyndromes of related substances vs. different substance classes). For example, norstictic vs. stictic acid (both 1'-6'-OH depsidones) is more likely to represent variation compared to norstictic vs. psoromic (6'-COOH depsidone) or lecanoric acid (depside). If there is no evidence for qualitative variation (discrete phenodemes) in the established taxonomic framework of a genus, always consider a non-fitting sample a separate entity instead of assuming discrete variation ad hoc, unless the qualitative character corresponds to a known discrete variation (e.g., photomorphs associated with different photobionts, reproductive mode). Always check for correlation between at least two functionally uncorrelated characters. For instance, statisticaly correlated differences in ascospore size and chemistry are likely evidence for distinct taxa, whereas statistically correlated differences in ascospore size and numbers of ascospores per ascus (i.e., ascospores are larger in asci with fewer ascospores) may represent a taxonomically meaningless, functional correlation.

For a phylogenetically non-fitting sample, assess the underlying topology (reciprocally monophyletic vs. nested within a paraphyletic residual), as well as branch length and support patterns. Assess congruence between different markers if available (coalescence). Reciprocal monophyly combined with long, strongly supported stem branches (significantly longer than internal branches) in congruence between various markers is strong evidence for separate entities, whereas a nested clade with s short, unsupported stem branch within another clade is not.

Generally, the more pronounced the difference of the non-fitting sample relative to all known taxa, the lower the number of characters needed to establish a species hypothesis. Even single characters may suffice if the difference is immediately convincing (e.g., transversely septate vs. richly muriform ascospores or linear vs. broadly rounded lobes). Similarly, pronounced differences in single-locus phylogenetic trees can be sufficient for establishing a robust species hypothesis, although not for inferring evolutionary relationships with confidence.

3. If the sample has been assessed phenotypically, where possible test the non-fittingness by generating molecular data. Note that this approach is only valid when molecular data exist for the most similar known taxa to which the non-fitting sample is compared. If the molecular data 
result in topological polyphyly of the non-fitting sample, the initial species hypothesis is likely to be rejected. If the phylogeny of the non-fitting sample vs. known taxa is unresolved (i.e., all forming a single lineage), but the phenotypic deviation cannot be explained by known patterns of variation, consider the possibility that the molecular marker(s) employed may not provide sufficient resolution. Testing phenotypic non-fittingness with molecular data is not a requirement (and may not be possible when the underlying material is of a certain age), but the importance of the latter increases when phenotypic non-fittingness is low and particularly when well-established taxonomic concepts are being challenged (Lendemer 2021).

If phylogenetic non-fittingness has been detected first, compare the phenotypes of the underlying individuals. If there are no immediately obvious differences, perform a quantitative analysis of a phenotype character matrix mapped onto the phylogeny. If there are no discernable phenotypic differences but the underlying phylogeny shows distinct clades (i.e., reciprocal monophyly combined with long, strongly supported stem branches), consider cryptic speciation.

4. If the degree of non-fittingness of the sample is deemed sufficient to consider a novelty, it should be made sure that all historically described names have been assessed to rule out there is no fitting name. In particular, heterotypic synonyms of similar and/or closely related taxa should be thoroughly checked. For synonyms, consult taxonomic treatments of the genus in question. For the assessment of type material, JSTOR Global Plants [https://plants.jstor.org] is an excellent source. When considering potentially applicable names, always take into account the geographic origin but consider known broad disjunctions, such as western North American vs. Central Asia (Weber 2003; Melton et al. 2020)

5. If the degree of non-fittingness of the sample is deemed sufficient to consider a novelty and no applicable name appears to exist, the sample should be formally described. Names should not be published "ad interim" or as "nom. provis." or using informal working names, unless their formal description using the same name is immediate. If there is reason for hesitation, the proper solution would be to use the name of the most similar or most closely related taxon, in combination with the prefix "aff.", to denote a non-fitting sample. This latter strategy avoids the propagation of invalid names and ensures tracking down such non-fitters a posteriori, once enough data become available for a formal description. Non-fitters should not simply be subsumed within known taxa, as these will be impossible to trace a posteriori.
6. If the degree of non-fittingness of the sample is deemed sufficient to consider a novelty and it has been decided to describe it formally, the proper taxonomic level needs to be assessed, i.e., whether describing the sample as new species or as new infraspecific taxon of a known species. By default, assume the sample represents a new species. Apply infraspecific (gamma) taxonomy only if the following criteria apply: (a) the phenotypic differences are minor or cryptic; (b) the non-fitting sample and its most similar known counterpart or closest known relative exhibit allopatric or peripatric distribution; (c) the phylogeny shows a shallow topology (i.e., reciprocal monophyly with short stem branches not significantly longer than internal branches) or a nested relationship within a paraphyletic residual. If an infraspecific category appears to be the proper solution, always opt for the subspecies (subspecies, subsp.) category, unless the data support the category of variety (varietas, var.). Do not use the category of form (forma, f.).

7. When formally establishing a new species, follow the rules and guidelines (best practices) for valid publication and proper circumscription (Lendemer 2021; Aime et al. 2021).

8. When phenotypic identification of a novel taxon is challenging, e.g., in ecological studies or monitoring protocols, apply standardized taxonomic designations for less resolved identifications, e.g., aggregate for a monophyletic, cryptic species complex, such as the Bryoria fuscescens aggregate (Boluda et al. 2019) or Thamnolia vermicularis aggregate, or morphodeme for a polyphyletic assembly of phenotypically similar species, such as the Sticta fuliginosa or $S$. weigelii morphodeme. However, the degree of precision should always be adjusted to the objectives of the study, and lack of time and resources alone should never be an argument to reject more precise species concepts. Merging species not readily identifiable in the field or with standard approaches such as light microscopy or chemical spot tests into aggregates or morphodemes is only permissible when their underlying ecology and/or distribution does not generate conflicts with the aims of the study.

Supplementary Information The online version contains supplementary material available at https://doi.org/10.1007/s13225-021-00477-7.

Acknowledgements Paul Kirk is thanked for placing data from Index Fungorum at our disposal and for fruitful discussions on individual cases. Bibiana Moncada kindly provided the field image of Lichenomphalia lobata, Rosemarie Honegger (via David Hawksworth) the SEM image of Xanthoria parietina, and Zakieh Zakeri the photograph of a culture of Xanthoria parietina. 
Author contributions RL wrote the first draft for most of this manuscript and SDL wrote the first draft for the portion on species concepts. DLH contributed information on various historical aspects and perspectives for the initial draft. After integrating the drafts, all authors provided modifications to all parts of the manuscript in three subsequent rounds of revision.

Funding Open Access funding enabled and organized by Projekt DEAL.

Data availability No new data were generated for this review and other data sources are cited.

Code availability No new code was generated for this review.

\section{Declarations}

Conflict of interest The authors declare no conflicts of interest.

Open Access This article is licensed under a Creative Commons Attribution 4.0 International License, which permits use, sharing, adaptation, distribution and reproduction in any medium or format, as long as you give appropriate credit to the original author(s) and the source, provide a link to the Creative Commons licence, and indicate if changes were made. The images or other third party material in this article are included in the article's Creative Commons licence, unless indicated otherwise in a credit line to the material. If material is not included in the article's Creative Commons licence and your intended use is not permitted by statutory regulation or exceeds the permitted use, you will need to obtain permission directly from the copyright holder. To view a copy of this licence, visit http://creativecommons.org/licenses/by/4.0/.

\section{References}

Acharius E (1798) Lichenographiae Suecicae Prodromus. Björn, Linköping

Acharius E (1803) Methodus Lichenum. Marquard, Stockholm

Acharius E (1810) Lichenographia Universalis. Danckwerts, Göttingen

Acharius E (1814) Synopsis Methodica Lichenum. Svanborg, Lund

Ahmadjian V (1982) Definition of the term lichen. Int Lichenol Newsl 15(2): 18

Ahmadjian V (1993) The lichen symbiosis. Wiley, New York

Aime MC (2006) Toward resolving family-level relationships in rust fungi (Uredinales). Mycoscience 47:112-122

Aime MC, Miller AN, Aoki T, Bensch K, Cai L, Crous PW, Hawksworth DL, Hyde KD, Kirk PM, Lücking R, May TW, Malosso E, Redhead SA, Rossman AY, Stadler M, Thines M, Yurkov AM, Zhang N, Schoch CL (2021) How to publish a new fungal species, or name, version 3.0. IMA Fungus 12:1-15

Ainsworth GC (1976) Introduction to the history of mycology. Cambridge University Press, London

Ainsworth GC, Bisby GR (1943) A dictionary of the fungi. The Imperial Mycological Institute, Kew, Surrey

Ainsworth GC, James PW, Hawksworth DL (1971) Ainsworth \& Bisby's Dictionary of the Fungi. Commonwealth Mycological Institute, Kew

Alexander AM, Su YC, Oliveros CH, Olson KV, Travers SL, Brown RM (2017) Genomic data reveals potential for hybridization, introgression, and incomplete lineage sorting to confound phylogenetic relationships in an adaptive radiation of narrow-mouth frogs. Evolution 71:475-488
Alexopoulos CJ (1952) Introductory mycology. Wiley, New York

Almborn O (1989) Revision of the lichen genus Teloschistes in central and southern Africa. Nord J Bot 8:521-537

Almborn O (1992) Some overlooked or misidentified species of Teloschistes from South America and a key to the South-American species. Nord J Bot 12:361-364

Alors D, Lumbsch HT, Divakar PK, Leavitt SD, Crespo A (2016) An integrative approach for understanding diversity in the Punctelia rudecta species complex (Parmeliaceae, Ascomycota). PLoS ONE 11(2): 0146537

Altermann S, Leavitt SD, Goward T, Nelsen MP, Lumbsch HT (2014) How do you solve a problem like Letharia? A new look at cryptic species in lichen- forming fungi using Bayesian clustering and SNPs from multilocus sequence data. PLoS ONE 9(5):e97556

Altermann S, Leavitt SD, Goward T (2016) Tidying up the genus Letharia: introducing $L$. lupina sp. nov. and a new circumscription for L. columbiana. Lichenologist 48:423-439

Ament-Velásquez SL, Tuovinen V, Bergström L, Spribille T, Vanderpool D, Nascimbene J, Yamamoto Y, Thor G, Johannesson H (2020) The plot thickens: haploid and triploid-like thalli, hybridization, and biased mating type ratios in Letharia. bioRxiv. https://doi.org/10.1101/2020.12.18.423428

Amtoft A, Lutzoni F, Miądlikowska J (2008) Dermatocarpon (Verrucariaceae) in the Ozark Highlands, North America. Bryologist 111:1-40

An KD, Degawa Y, Fujihara E, Mikawa T, Ohkuma M, Okada G (2012) Molecular phylogenetic analyses based on the nuclear rRNA genes and the intron-exon structures of the nuSSU rRNA gene in Dictyocatenulata alba (anamorphic Ascomycota). Fungal Biol 116:1134-1145

Anderson E, Rudolph ED (1956) An analysis of variation in a variable population of Cladonia. Evolution 10:147-156

Anonymous (1867) Protokoll der botanischen Sektion. Verhandlungen Der Schweizerischen Naturforschenden Gesellschaft 1867:88-91

Aptroot A (2012) A world key to the species of Anthracothecium and Pyrenula. Lichenologist 44:5-53

Aptroot A, Lücking R (2016) A revisionary synopsis of the Trypetheliaceae (Ascomycota: Trypetheliales). Lichenologist 48:763-982

Argüello A, del Prado R, Cubas P, Crespo A (2007) Parmelia quercina (Parmeliaceae, Lecanorales) includes four phylogenetically supported morphospecies. Biol J Linn Soc 91:455-467

Armaleo D, Clerc P (1991) Lichen chimeras: DNA analysis suggests that one fungus forms two morphotypes. Experim Mycol 15:1-10

Arnold AE, Miądlikowska J, Higgins KL, Sarvate SD, Gugger P, Way A, Hofstetter V, Kauff F, Lutzoni F (2009) A phylogenetic estimation of trophic transition networks for ascomycetous fungi: are lichens cradles of symbiotrophic fungal diversification? Syst Biol 58:283-297

Arnold ML, Bulger MR, Burke JM, Hempel AL, Williams JH (1999) Natural hybridization: how low can you go and still be important? Ecology 80:371-381

Arup U, Sandler-Berlin E (2011) A taxonomic study of Melanelixia fuliginosa in Europe. Lichenologist 43:89-97

Arup U, Søchting U, Frödén P (2013) A new taxonomy of the family Teloschistaceae. Nord J Bot 31:16-83

Articus K, Mattsson JE, Tibell L, Grube M, Wedin M (2002) Ribosomal DNA and $\beta$-tubulin data do not support the separation of the lichens Usnea florida and U. subfloridana as distinct species. Mycol Res 106:412-418

Arvidsson L (1982) A monograph of the lichen genus Coccocarpia. Opera Bot 67:1-96

Aschenbrenner IA, Cernava T, Berg G, Grube M (2016) Understanding microbial multi-species symbioses. Front Microbiol 7:180

Asplund J, Wardle DA (2012) Contrasting changes in palatability following senescence of the lichenized fungi Lobaria pulmonaria and $L$. scrobiculata. Fungal Ecol 5:710-713 
Assis LC (2009) Coherence, correspondence, and the renaissance of morphology in phylogenetic systematics. Cladistics 25:528-544

Barcenas-Peña A, Leavitt SD, Huang JP, Grewe F, Lumbsch HT (2018) Phylogenetic study and taxonomic revision of the Xanthoparmelia mexicana group, including the description of a new species (Parmeliaceae, Ascomycota). MycoKeys 40:13-28

Barraclough TG, Humphreys AM (2015) The evolutionary reality of species and higher taxa in plants: a survey of post-modern opinion and evidence. New Phytol 207:291-296

Belinchón R, Ellis CJ, Yahr R (2018) Climate-woodland effects on population genetics for two congeneric lichens with contrasting reproductive strategies. FEMS Microbiol Ecol 94:fiy 159

Bendiksby M, Timdal E (2013) Molecular phylogenetics and taxonomy of Hypocenomyce sensu lato (Ascomycota: Lecanoromycetes): extreme polyphyly and morphological/ecological convergence. Taxon 62:940-956

Berdugo M, Mendoza-Aguilar DO, Rey A, Ochoa V, Gozalo B, García-Huss L, Maestre FT (2021) Litter decomposition rates of biocrust-forming lichens are similar to those of vascular plants and are affected by warming. Ecosystems. https://doi.org/10. 1007/s10021-020-00599-0

Berger SA, Stamatakis A, Lücking R (2011) Morphology-based phylogenetic binning of the lichen genera Allographa and Graphis via molecular site weight calibration. Taxon 60:1450-1457

Berkeley MJ (1857) Introduction to cryptogamic botany. Bailliere, London

Bernstein JM, Murphy JC, Voris HK, Brown RM, Ruane S (2021) Phylogenetics of mud snakes (Squamata: Serpentes: Homalopsidae): a paradox of both undescribed diversity and taxonomic inflation. Mol Phyl Evol 160:107109

Biazrov LG (1994) Decomposition of epiphytic lichen litter and the involvement of invertebrates in forests near Moscow. Cryptogamic Bot 4:130-134

Bistis GN (1981) Chemotropic interactions between trichogynes and conidia of opposite mating-type in Neurospora crassa. Mycologia 73:959-975

Blanco O, Crespo A, Elix JA, Hawksworth DL, Lumbsch HT (2004) A molecular phylogeny and a new classification of parmelioid lichens containing Xanthoparmelia type lichenan (Ascomycota: Lecanorales). Taxon 53:959-975

Boistel A (1903) Nouvelle Flore des Lichens, 2e partie (Partie Scientifique). Dupont, Paris

Boluda CG, Rico VJ, Divakar PK, Nadyeina O, Myllys L, McMullin RT, Zamora JC, Scheidegger C, Hawksworth DL (2019) Evaluating methodologies for species delimitation: the mismatch between phenotypes and genotypes in lichenized fungi (Bryoria sect. Implexae, Parmeliaceae). Persoonia 42:75-100

Bradshaw M, Grewe F, Thomas A, Harrison CH, Lindgren H, Muggia L, St. Clair LL, Lumbsch HT, Leavitt SD (2020) Characterizing the ribosomal tandem repeat and its utility as a DNA barcode in lichen-forming fungi. BMC Evol Biol 20:1-11

Briquet J (1912) International Rules of Botanical Nomenclature: Adopted by the International Botanical Congress of Vienna 1905 and Brussels 1910. Fischer, Jena

Brodo IM (1986) Interpreting chemical variation in lichens for systematic purposes. Bryologist 89:132-138

Brodo IM, Sharnoff SD, Sharnoff S (2001) Lichens of North America. Yale University Press, New Haven

Brune A, Dietrich C (2015) The gut microbiota of termites: digesting the diversity in the light of ecology and evolution. Annu Rev Microbiol 69:145-166

Buschbom J, Mueller GM (2006) Testing "species pair" hypotheses: evolutionary processes in the lichen-forming species complex Porpidia flavocoerulescens and Porpidia melinodes. Mol Biol Evol 23:574-586
Butcher BA, Smith MA, Sharkey MJ, Quicke DL (2012) A turbo-taxonomic study of Thai Aleiodes (Aleiodes) and Aleiodes (Arcaleiodes) (Hymenoptera: Braconidae: Rogadinae) based largely on COI barcoded specimens, with rapid descriptions of 179 new species. Zootaxa 3457:1-232

Caldiz MS, Brunet J, Nihlgård B (2007) Lichen litter decomposition in Nothofagus forest of northern Patagonia: biomass and chemical changes over time. Bryologist 110:266-273

Camargo A, Sites J Jr (2013) Species delimitation: a decade after the renaissance. In: Pavlinov IY (ed) The species problem—ongoing issues. IntechOpen, Rijeka, pp 225-247

Campbell J, Fredeen AL, Prescott CE (2010) Decomposition and nutrient release from four epiphytic lichen litters in sub-boreal spruce forests. Can J for Res 40:1473-1484

Cardinale M, Steinová J, Rabensteiner J, Berg G, Grube M (2012) Age, sun and substrate: triggers of bacterial communities in lichens. Environm Microbiol Rep 4:23-28

Carlsen T, Bendiksby M, Hofton TH, Reiso S, Bakkestuen V, Haugan R, Kauserud H, Timdal E (2012) Species delimitation, bioclimatic range, and conservation status of the threatened lichen Fuscopannaria confusa. Lichenologist 44:565-575

Černajová I, Škaloud P (2019) The first survey of cystobasidiomycete yeasts in the lichen genus Cladonia; with the description of Lichenozyma pisutiana gen. nov., sp. nov. Fungal Biol 123:625-637

Chagnon PL, U'Ren JM, Miądlikowska J, Lutzoni F, Arnold AE (2015) Interaction type influences ecological network structure more than local abiotic conditions: evidence from endophytic and endolichenic fungi at a continental scale. Oecologia 180:181-191

Chen KH, Miądlikowska J, Molnár K, Arnold AE, U'ren JM, Gaya E, Gueidan C, Lutzoni F (2015) Phylogenetic analyses of eurotiomycetous endophytes reveal their close affinities to Chaetothyriales, Eurotiales, and a new order: Phaeomoniellales. Mol Phyl Evol 85:117-130

Chiasson WB, Sabo NJ, Vis ML (2005) Affinities of freshwater putative chantransia stages (Rhodophyta) from molecular and morphological data. Phycologia 44:163-168

Ciferri R, Tomaselli R (1953a) Saggio di una sistematica microlichenologica. Atti Ist Bot Lab Crittog Univ Pavia Ser 5(10):25-84

Ciferri R, Tomaselli R (1953b) The taxonomy and nomenclature of the fungal symbionts of lichens. Proposal no. 46 submitted to the Paris Congress. Taxon 2:194-196

Ciferri R, Tomaselli R (1954a) Specierum fungorum qui in lichenibus insunt descriptiones. Atti Ist Bot Lab Crittog Univ Pavia Ser 5(10):253-295

Ciferri R, Tomaselli R (1954b) Reply to Santesson's criticism on taxonomy of fungal symbionts of lichens. Taxon 3:230-231

Ciferri R, Tomaselli R (1955) The symbiotic fungi of lichens and their nomenclature. Taxon 4:190-192

Ciferri R, Tomaselli R (1957) Prospetto di una sistematica microlichenologica. Atti Ist Bot Lab Crittog Univ Pavia Ser $5(14): 247-262$

Clarke JL (2016) Neanderthals: species or subspecies? Compass 2:24-31

Clements FE (1897) The polyphyletic disposition of lichens. Am Nat $31: 277-284$

Clements FE (1909) The genera of fungi. Wilson, Minneapolis

Clements FE, Shear CL (1931) The genera of fungi. Wilson, New York

Clerc P (1987) Systematics of the Usnea fragilescens aggregate and its distribution in Scandinavia. Nord J Bot 7:479-495

Coca LF, Lücking R, Moncada B (2018) Two new, sympatric and semicryptic species of Sulzbacheromyces (Lichenized Basidiomycota, Lepidostromatales) from the Chocó Biogeographic Region in Colombia. Bryologist 121:297-305 
Cohan FM, Hoffmann AA (1989) Uniform selection as a diversifying force in evolution: evidence from Drosophila. Am Nat 134:613-637

Collins RA, Cruickshank RH (2013) The seven deadly sins of DNA barcoding. Mol Ecol Res 13:969-975

Cornejo C, Scheidegger C (2015) Multi-gene phylogeny of the genus Lobaria: evidence of species-pair and allopatric cryptic speciation in East Asia. Am J Bot 102:2058-2073

Corsie EI, Harrold P, Yahr R (2019) No combination of morphological, ecological or chemical characters can reliably diagnose species in the Parmelia saxatilis aggregate in Scotland. Lichenologist 51:107-121

Crespo A, Lumbsch HT (2010) Cryptic species in lichen-forming fungi. IMA Fungus 1(2):167-170

Crespo A, Pérez-Ortega S (2009) Cryptic species and species pairs in lichens: a discussion on the relationship between molecular phylogenies and morphological characters. Anal Jard Bot Madrid 66:71-81

Crespo A, Rico VJ, Garrido E, Lumbsch HT, Divakar PK (2020) A revision of species of the Parmelia saxatilis complex in the Iberian Peninsula with the description of $P$. rojoi, a new potentially relict species. Lichenologist 52:365-376

Crisp MD, Chandler GT (1996) Paraphyletic species. Telopea 6:813-844

Crous PW, Hawksworth DL, Wingfield MJ (2015) Identifying and naming plant-pathogenic fungi: past, present, and future. Ann Rev Phytopathol 53:247-267

Cubero OF, Crespo A, Esslinger TL, Lumbsch HT (2004) Molecular phylogeny of the genus Physconia (Ascomycota, Lecanorales) inferred from a Bayesian analysis of nuclear ITS rDNA sequences. Mycol Res 108:498-505

Culberson CF, Kristinsson H (1970) A standardized method for the identification of lichen products. J Chromatogr 46:85-93

Culberson WL (1960) Parmelia pseudoborreri Asahina, lichen nouveau pour la flore d'Europe et remarques sur "especes chimiques" en lichenologie. Rev Bryol Lichenol 29:321-325

Culberson WL (1963) The lichen genus Thamnolia. Brittonia 15:140-144

Culberson WL (1969) The use of chemistry in the systematics of the lichens. Taxon 18:152-166

Culberson WL (1970) Chemosystematics and ecology of lichen-forming fungi. Ann Rev Ecol Syst 1:153-170

Culberson WL (1973) The Parmelia perforata group: niche characteristics of chemical races, speciation by parallel evolution, and a new taxonomy. Bryologist 76:20-29

Culberson WL, Culberson CF (1967) Habitat selection by chemically differentiated races of lichens. Science 158:1195-1197

Culberson WL, Culberson CF (1973) Parallel evolution in the lichenforming fungi. Science 180:196-198

Culberson WL, Culberson CF, Johnson A (1993) Speciation in lichens of the Ramalina siliquosa complex (Ascomycotina, Ramalinaceae): gene flow and reproductive isolation. Am J Bot 80:1472-1481

Davis PH, Heywood VH (1963) Principles of angiosperm taxonomy. Oliver \& Boyd, Edinburgh

Davydov EA, Oleg BB, Kashevarov GP, Grakhov VP (2019) Umbilicaria subpolyphylla Oxner: the correct name for $U$. iberica Sancho \& Krzewicka and its bipolar distribution pattern. Lichenologist 51:205-220

Dayrat B (2005) Towards integrative taxonomy. Biol J Linn Soc 85:407-417

De Bary A (1866) Morphology und Physiologie der Pilze, Flechten und Myxomyceten. [Hofmeisters Handbuch der physiologischen Botanik II]. Engelmann, Leipzig
De Queiroz K (1998) The general lineage concept of species, species criteria, and the process of speciation. In: Howard DJ, Berlocher SH (eds) Endless forms: species and speciation. Oxford University Press, Oxford, pp 57-75

De Queiroz K (2007) Species concepts and species delimitation. Syst Biol 56:879-886

De Queiroz K (2011) Branches in the lines of descent: Charles Darwin and the evolution of the species concept. Biol J Linn Soc 103:19-35

Degtjarenko P, Mark K, Moisejevs R, Himelbrant D, Stepanchikova I, Tsurykau A, Randlane T, Scheidegger C (2020) Low genetic differentiation between apotheciate Usnea florida and sorediate Usnea subfloridana (Parmeliaceae, Ascomycota) based on microsatellite data. Fungal Biol 124:892-902

Del-Prado R, Divakar PK, Crespo A (2011) Using genetic distances in addition to ITS molecular phylogeny to identify potential species in the Parmotrema reticulatum complex: a case study. Lichenologist 43:569-583

Del-Prado R, Divakar PK, Lumbsch HT, Crespo AM (2016) Hidden genetic diversity in an asexually reproducing lichen forming fungal group. PLoS ONE 11(8):e0161031

Derkarabetian S, Castillo S, Koo PK, Ovchinnikov S, Hedin, M (2019) A demonstration of unsupervised machine learning in species delimitation. Mol Phyl Evol 139:106562

Dettman JR, Jacobson DJ, Turner E, Pringle A, Taylor JW (2003) Reproductive isolation and phylogenetic divergence in Neurospora: comparing methods of species recognition in a model eukaryote. Evolution 57:2721-2741

Diederich P, Lawrey JD, Ertz D (2018) The 2018 classification and checklist of lichenicolous fungi, with 2000 non-lichenized, obligately lichenicolous taxa. Bryologist 121:340-425

Dillenius JJ (1742) ["1741"] Historia Muscorum. Sheldonian Theatre, Oxford

Disney H (2000) Hands-on taxonomy. Nature 405:619

Divakar PK, Crespo A, Nunez-Zapata J, Flakus A, Sipman HJM, Elix JA, Lumbsch HT (2013) A molecular perspective on generic concepts in the Hypotrachyna clade (Parmeliaceae, Ascomycota). Phytotaxa 132:21-38

Divakar PK, Crespo A, Wedin M, Leavitt SD, Hawksworth DL, Myllys L, Mccune B, Randlane T, Bjerke JW, Ohmura Y, Schmitt I, Boluda CG, Alors D, Roca-Valiente B, Del-Prado R, Ruibal C, Buaruang K, Núñez-Zapata J, Amo de Paz G, Rico VJ, Molina MC, Elix JA, Esslinger TL, Tronstad IKK, Lindgren H, Ertz D, Gueidan C, Saag L, Mark K, Singh G, Dal Grande F, Parnmen S, Beck A, Benatti MN, Blanchon D, Candan M, Clerc P, Goward T, Grube M, Hodkinson BP, Hur JS, Kantvilas G, Kirika PM, Lendemer J, Mattsson JE, Messuti MI, Miądlikowska J, Nelsen M, Ohlson JI, Pérez-Ortega S, Saag A, Sipman HJM, Sohrabi M, Thell A, Thor G, Truong C, Yahr R, Upreti DK, Cubas P, Lumbsch HT (2015) Evolution of complex symbiotic relationships in a morphologically derived family of lichen-forming fungi. New Phytol 208:1217-1226

Döbbeler P (1997) Biodiversity of Bryophilous Ascomycetes. Biodivers Conserv 6:721-738

Döring H, Lumbsch HT (1998) Ascoma ontogeny: is this character set of any use in the systematics of lichenized ascomycetes. Lichenologist 30:489-500

Du Rietz GE (1924) Die Soredien und Isidien der Flechten. Svensk Bot Tidskr 18:371-396

Du Rietz GE (1930) The fundamental units of biological taxonomy. Svensk Bot Tidskr 24:333-428

Duvigneaud P (1939) Les espèces chimiques en lichénologie. Ass Fr Avanc Sci 63:585-595 
Ekman S, Wedin M, Lindblom L, Jørgensen PM (2014) Extended phylogeny and a revised generic classification of the Pannariaceae (Peltigerales, Ascomycota). Lichenologist 46:627-656

Eriksson OE (1982) The families of bitunicate Ascomycetes. Opera Bot 60:1-209

Ertz D, Tehler A (2011) The phylogeny of Arthoniales (Pezizomycotina) inferred from nucLSU and RPB2 sequences. Fungal Divers 49:47-71

Esslinger TL, Leavitt SD, McCune B (2020) Two closely related but morphologically disparate new species of Physcia from western North America. Bryologist 123:204-214

Fačkovcová Z, Slovák M, Vd’ačný P, Melichárková A, ZozomováLihová J, Guttová A (2020) Spatio-temporal formation of the genetic diversity in the Mediterranean dwelling lichen during the Neogene and Quaternary epochs. Mol Phyl Evol 144:106704

Fedorenko NM, Stenroos S, Thell A, Kärnefelt I, Kondratyuk SY (2009) A phylogenetic analysis of xanthorioid lichens (Teloschistaceae, Ascomycota) based on ITS and mtSSU sequences. Biblioth Lichenol 100:49-84

Fernández-Brime S, Llimona X, Lutzoni F, Gaya E (2013) Phylogenetic study of Diploschistes (lichen-forming Ascomycota: Ostropales: Graphidaceae), based on morphological, chemical, and molecular data. Taxon 62:267-280

Fernández-Mendoza F, Fleischhacker A, Kopun T, Grube M, Muggia L (2017) ITS1 metabarcoding highlights low specificity of lichen mycobiomes at a local scale. Mol Ecol 26:4811-4830

Feuerer T, Thell A (2002) Parmelia ernstiae - a new macrolichen from Germany. Mitteil Inst Allg Bot Hamburg 30-32:49-60

Fink B (1911) The nature and classification of lichens. I. Mycologia 3:231-269

Fink B (1913) The nature and classification of lichens-II. The lichen and its algal host. Mycologia 5:97-166

Fontaine KM, Beck A, Stocker-Wörgötter E, Piercey-Normore MD (2012) Photobiont relationships and phylogenetic history of Dermatocarpon luridum var. luridum and related Dermatocarpon species. Plants 1:39-60

Franc N, Kärnefelt EI (1998) Phylogeny of Xanthoria calcicola and X. parietina, based on rDNA ITS sequences. Graphis Scr 9:49-54

Franz NM (2005) On the lack of good scientific reasons for the growing phylogeny/classification gap. Cladistics 21:495-500

Freudenstein JV, Broe MB, Folk RA, Sinn BT (2017) Biodiversity and the species concept-lineages are not enough. Syst Biol 66:644-656

Friedl T (1987) Thallus development and phycobionts of the parasitic lichen Diploschistes muscorum. Lichenologist 19:183-191

Friedl T, Büdel B (2008) Photobionts. In: Nash III TH (ed) Lichen biology, 2nd edn. Cambridge University Press, Cambridge, pp 7-26

Fries EM (1821) Systema mycologicum, vol 1. Ex Officina Berlingiana, Lund

Frisch A, Thor G, Ertz D, Grube M (2014) The Arthonialean challenge: restructuring Arthoniaceae. Taxon 63:727-744

Frisch A, Moen VS, Grube M, Bendiksby M (2020) Integrative taxonomy confirms three species of Coniocarpon (Arthoniaceae) in Norway. MycoKeys 62:27-51

Frolov I, Vondrák J, Fernández-Mendoza F, Wilk K, Khodosovtsev A, Halıc1 MG (2016) Three new, seemingly-cryptic species in the lichen genus Caloplaca (Teloschistaceae) distinguished in twophase phenotype evaluation. Ann Bot Fenn 53:243-262

Fryday AM, Schmitt I, Pérez-Ortega S (2017) The genus Endocena (Icmadophilaceae): DNA evidence suggests the same fungus forms different morphologies. Lichenologist 49:347-363

Fünfstück M (1907) A. Allgemeiner Teil. In: Engler A, Prantl K (eds) Natürliche Pflanzenfamilien. Teil 1, Abteilung $1^{*}$. Lichenes (Flechten). Engelmann, Leipzig, pp 1-49

Fujisawa T, Barraclough TG (2013) Delimiting species using singlelocus data and the Generalized Mixed Yule Coalescent approach: a revised method and evaluation on simulated data sets. Syst Biol 62:707-724

Fujita MK, Leaché AD, Burbrink FT, McGuire JA, Moritz C (2012) Coalescent-based species delimitation in an integrative taxonomy. Trends Ecol Evol 27:480-488

Funk DJ, Omland KE (2003) Species-level paraphyly and polyphyly: frequency, causes, and consequences, with insights from animal mitochondrial DNA. Ann Rev Ecol Evol Syst 34:397-423

Galloway DJ (2007) Flora of New Zealand Lichens. Revised Second Edition Including Lichen-Forming and Lichenicolous Fungi, vol 1 and 2. Manaaki Whenua Press, Lincoln

Garnett ST, Christidis L (2017) Taxonomy anarchy hampers conservation. Nat News 546:25

Gaya E, Redelings BD, Navarro-Rosinés P, Llimona X, Cáceres MES, Lutzoni F (2011) Align or not to align? Resolving species complexes within the Caloplaca saxicola group as a case study. Mycologia 103:361-378

Gaya E, Högnabba F, Holguin Á, Molnar K, Fernández-Brime S, Stenroos S, Arup U, Søchting U, van den Boom P, Lücking R, Sipman HJM, Lutzoni F (2012) Implementing a cumulative supermatrix approach for a comprehensive phylogenetic study of the Teloschistales (Pezizomycotina, Ascomycota). Mol Phyl Evol 63:374-387

Gerlach ACL, Clerc P, Da Silveira RMB (2017) Taxonomy of the corticolous, shrubby, esorediate, neotropical species of Usnea Adans. (Parmeliaceae) with an emphasis on southern Brazil. Lichenologist 49:199-238

Gerlach ACL, Toprak Z, Naciri Y, Caviró EA, de Silveira RMB, Clerc P (2019) New insights into the Usnea cornuta aggregate (Parmeliaceae, lichenized Ascomycota): molecular analysis reveals high genetic diversity correlated with chemistry. Mol Phyl Evol 131:125-137

Gerlach ACL, da Silveira RMB, Rojas C, Clerc P (2020) Naming and describing the diversity in the Usnea cornuta aggregate (lichenized Ascomycota, Parmeliaceae) focusing on Brazilian specimens. Plant Fungal Syst 65:272-302

Gimmler H (2001) Mutualistic relationships between algae and fungi (excluding lichens). In: Esser K, Lüttge U, Kadereit JW, Beyschlag W (eds) Progress in botany, vol 62. Springer, Berlin, pp 194-214

Glass NL, Kuldau GA (1992) Mating type and vegetative incompatibility in filamentous ascomycetes. Ann Rev Phytopathol 30:201-224

Goffinet B, Bayer RJ (1997) Characterization of mycobionts of photomorph pairs in the Peltigerineae (lichenized ascomycetes) based on internal transcribed spacer sequences of the nuclear ribosomal DNA. Fungal Gen Biol 21:228-237

Goulding TC, Dayrat B (2016) Integrative taxonomy: ten years of practice and looking into the future. Arch Zool Mus Lomonosov Moscow State Univ 54:116-133

Goward T (1994) Living antiquities. Nat Canada Summer 1994:14-21

Goward T (2008) Nameless little things. Evansia 25:54-56

Green TGA, Lange OL (1991) Ecophysiological adaptations of the lichen genera Pseudocyphellaria and Sticta to south temperate rainforests. Lichenologist 23:267-282

Greenfield LG (1993) Decomposition studies on New Zealand and Antarctic lichens. Lichenologist 25:73-82

Greuter W, Barrie FR, Burdet HM, Chaloner WG, Demoulin V, Hawksworth DL, Jørgensen PM, Nicholson DH, Silva PC, Trehane P, McNeill J (1994) International Code of Botanical Nomenclature (Tokyo Code), [Regnum Vegetabile Vol. 31]. Koeltz Scientific Books, Königstein

Grewe F, Lagostina E, Wu H, Printzen C, Lumbsch HT (2018) Population genomic analyses of RAD sequences resolves the 
phylogenetic relationship of the lichen-forming fungal species Usnea antarctica and Usnea aurantiacoatra. MycoKeys 43:91-113

Grimm M, Grube M, Schiefelbein U, Zühlke D, Bernhardt J, Riedel K (2021) The lichens' microbiota, still a mystery? Front Microbiol $12: 714$

Grognet P, Silar P (2015) Maintaining heterokaryosis in pseudohomothallic fungi. Comm Integr Biol 8:e994382

Grube M, Hafellner J (1990) Studien an flechtenbewohnenden Pilzen der Sammelgattung Didymella (Ascomycetes, Dothideales). Nova Hedwigia 51:283-360

Grube M, Kroken S (2000) Molecular approaches and the concept of species and species complexes in lichenized fungi. Mycol Res 104:1284-1294

Grube M, Lücking R (2002) Fine structures of foliicolous lichens and their lichenicolous fungi studied by epifluorescence. Symbiosis 32:229-246

Grube M, Wedin M (2018) Lichenized fungi and the evolution of symbiotic organization. In: Heitman J, Howlett BJ, Crous PW, Stukenbrock EH, James TY, Gow NAR (eds) The Fungal Kingdom. American Society for Microbiology, Washington, DC, pp 749-765

Grube M, Cardinale M, Berg G (2012) Bacteria and the lichen symbiosis. In: Hock B (ed) The Mycota IX. Fungal Associations, 2nd edn. Springer, Berlin, pp 363-372

Grube M, Cernava T, Soh J, Fuchs S, Aschenbrenner I, Lassek C, Wegner U, Becher D, Riedel K, Sensen CW, Berg G (2015) Exploring functional contexts of symbiotic sustain within lichen-associated bacteria by comparative omics. ISME J 9:412-424

Guerrero RF, Hahn MW (2017) Speciation as a sieve for ancestral polymorphism. Mol Ecol 26:5362-5368

Guttová A, Zozomová-Lihová J, Timdal E, Kučera J, Slovák M, Piknová K, Paoli L (2014) First insights into genetic diversity and relationships of European taxa of Solenopsora (Catillariaceae, Ascomycota) with implications for their delimitation. Bot J Linn Soc 176:203-223

Guzman G, Quilhot W, Galloway DJ (1990) Decomposition of species of Pseudocyphellaria and Sticta in a southern Chilean forest. Lichenologist 22:325-331

Hale ME (1955) Studies on the chemistry and distribution of North American lichens (1-5). Bryologist 58:242-246

Hale ME (1968) Biochemical systematics in lichens: another viewpoint. Intern Lichenol Newsl 2(1):1-3

Hamilton CW, Reichard SH (1992) Current practice in the use of subspecies, variety, and forma in the classification of wild plants. Taxon 41:485-498

Hammer S (1997) Vegetative establishment and expansion by the mycobiont of Cladina subtenuis. Lichenologist 29:369-377

Harrington TC, Rizzo DM (1999) Defining species in the fungi. In: Worrall JJ (ed) Structure and dynamics of fungal populations. Springer, Dordrecht, pp 43-71

Harris RC (1990) Some Florida Lichens. Published by the Author, Bronx, NY

Harris RC (1995) More Florida Lichens. Including the $10 \varnothing$ Tour of the Pyrenolichens. Published by the Author, Bronx, NY

Haugan R, Timdal E (2018) Lecidea toensbergii, the first described sorediate species in Lecidea sensu stricto. Graphis Scr 30:51-58

Haugan R, Timdal E (2019) The morphologically cryptic lichen species Parmelia ernstiae and P. serrana new to Norway. Graphis Scr 31:5-13

Hawksworth DL (1974) Mycologist's handbook. Commonwealth Mycological Institute, Kew.

Hawksworth DL (1976) Lichen chemotaxonomy. In: Brown DH, Hawksworth DL, Bailey RH (eds) Lichenology: s. Academic Press, London, pp 139-184
Hawksworth DL (1978) The taxonomy of lichen-forming fungi: reflections on some fundamental problems. In: Street HE (ed) Essays in plant taxonomy. Academic Press, London, pp 211-243

Hawksworth DL (1988) The variety of fungal-algal symbioses, their evolutionary significance, and the nature of lichens. Bot J Linnean Soc 96:3-20

Hawksworth DL (2000) Freshwater and marine lichen-forming fungi. Fungal Divers 5:1-7

Hawksworth DL (2003) The lichenicolous fungi of Great Britain and Ireland: an overview and annotated checklist. Lichenologist $35: 191-232$

Hawksworth DL (2005) Life-style choices in lichen-forming and lichen-dwelling fungi. Mycol Res 109:135-136

Hawksworth DL, Eriksson OE (1994) Systema Ascomycetum: the concept. In: Hawksworth DL (ed) Ascomycete systematics. Springer, Boston, MA, pp 349-360

Hawksworth DL, Grube M (2020) Lichens redefined as complex ecosystems. New Phytol 227:1281-1283

Hawksworth DL, Hill DJ (1984) The Lichen-forming fungi. Blackie, Glasgow

Hawksworth DL, Lücking R (2018) Fungal diversity revisited: 2.2 to 3.8 million species. In: Heitman J, Howlett BJ, Crous PW, Stukenbrock EH, James TY, Gow NAR (eds) The Fungal Kingdom. American Society for Microbiology, Washington, DC, pp 79-95

Hawksworth DL, Honegger R (1994) The lichen thallus: a symbiotic phenotype of nutritionally specialized fungi and its response to gall producers. In: Williams, MAJ (ed.) Plant Galls. organisms, interactions, populations [The Systematics Association Special Volume 49] Clarendon Press, Oxford, pp 77-98

Hawksworth DL, Sutton BC, Ainsworth GC (1983) Ainsworth \& Bisby's dictionary of the fungi, 7th edn. Commonwealth Mycological Institute, Kew

Hawksworth DL, Crous PW, Redhead SA, Reynolds DR, Samson RA, Seifert KA, Taylor JW, Wingfield MJ, Abaci Ö, Aime C, Asan A (2011) The Amsterdam declaration on fungal nomenclature. IMA Fungus 2(1):105-111

Hayward GC, Blanchon DJ, Lumbsch HT (2014) molecular data support Ramalina ovalis as a distinct lineage (Ramalinaceae, Ascomycota). Lichenologist 46:553-561

Heiđmarsson S, Gueidan C, Miądlikowska J, Lutzoni F (2017) Multilocus phylogeny supports the placement of Endocarpon pulvinatum within Staurothele s. str. (lichenised ascomycetes, Eurotiomycetes, Verrucariaceae). Phytotaxa 306:37-48

Heintz-Buschart A, Wilmes P (2018) Human gut microbiome: function matters. Trends Microbiol 26:563-574

Hennig W (1950) Grundzüge einer Theorie der Phylogenetischen Systematik. Zentralverlag, Berlin

Hennig W (1966) Phylogenetic systematics. University of Illinois Press, Chicago

Henssen A, Jahns HM (1973 ["1974"]) Lichenes. Thieme, Stuttgart

Hibbett DS, Donoghue MJ (1998) Integrating phylogenetic analysis and classification in fungi. Mycologia 90:347-356

Hibbett DS, Binder M, Bischoff JF, Blackwell M, Cannon PF, Eriksson OE, Huhndorf S, James T, Kirk PM, Lücking R, Lumbsch HT, Lutzoni F, Matheny PB, McLaughlin DJ, Powell MJ, Redhead S, Schoch CL, Spatafora JW, Stalpers JA, Vilgalys R, Aime MC, Aptroot A, Bauer R, Begerow D, Benny GL, Castlebury LA, Crous PW, Dai YC, Gams W, Geiser DM, Griffith GW, Gueidan C, Hawksworth DL, Hestmark G, Hosaka K, Humber RA, Hyde K, Ironside JE, Kõljalg U, Kurtzman CP, Larsson KH, Lichtwardt R, Longcore J, Miądlikowska J, Miller A, Moncalvo JM, Mozley-Standridge S, Oberwinkler F, Parmasto E, Reeb V, Rogers JD, Roux C, Ryvarden L, Sampaio JP, Schüssler A, Sugiyama J, Thorn RG, Tibell L, Untereiner WA, Walker C, Wang Z, Weir A, Weiss M, White MM, Winka 
K, Yao YJ, Zhang N (2007) A higher-level phylogenetic classification of the Fungi. Mycol Res 111:509-547

Hodkinson BP, Lendemer JC (2011) Molecular analyses reveal semi-cryptic species in Xanthoparmelia tasmanica. Biblioth Lichenol 106:108-119

Honegger R (1984) Scanning electron microscopy of the contact site of conidia and trichogynes in Cladonia furcata. Lichenologist 16:11-19

Honegger R (1991) Functional aspects of the lichen symbiosis. Ann Rev Plant Phys Plant Mol Biol 42:553-578

Honegger R (1993) Developmental biology of lichens [Tansley Review No. 60]. New Phytol 125:659-677

Honegger R (1998) The lichen symbiosis-what is so spectacular about it? Lichenologist 30:193-212

Honegger R (2001) The symbiotic phenotype of lichen-forming ascomycetes. In: Hock B (ed) The Mycota IX. Fungal associations. Springer, Berlin, pp 165-188

Honegger R (2012) The symbiotic phenotype of lichen-forming ascomycetes and their endo- and epibionts. In: Hock B (ed) The Mycota IX. Fungal associations, 2nd edn. Springer, Berlin, pp 287-339

Honegger R, Zippler U, Gansner H, Scherrer S (2004) Mating systems in the genus Xanthoria (lichen-forming ascomycetes). Mycol Res 108:480-488

Hubka V, Kolarik M (2012) $\beta$-tubulin paralogue tubC is frequently misidentified as the benA gene in Aspergillus section Nigri taxonomy: primer specificity testing and taxonomic consequences. Persoonia 29:1-10

Hugenholtz P, Huber T (2003) Chimeric 16S rDNA sequences of diverse origin are accumulating in the public databases. Int $\mathbf{J}$ Syst Evol Microbiol 53:289-293

Humphreys AM, Barraclough TG (2014) The evolutionary reality of higher taxa in mammals. Proc Royal Soc B 281:2013-2750

Huneck S, Yoshimura I (1996) Identification of lichen substances. Springer, Berlin

Huovinen K (1985) Variation of lichen acids in Cladina stellaris and Cladina rangiferina in Finland and north Norway. Acta Pharm Fenn 94:113-123

Hyvärinen M, Härdling R, Tuomi J (2002) Cyanobacterial lichen symbiosis: the fungal partner as an optimal harvester. Oikos 98:498-504

Jahns HM, Sensen M, Ott S (1995) Significance of developmental structures in lichens, especially in the genus Cladonia. Ann Bot Fenn 32:35-48

James PW, Henssen A (1976) The morphological and taxonomic significance of cephalodia. In: Brown DH, Hawksworth DL, Bailey RH (eds) Lichenology: progress and problems. Academic Press, London, pp 27-77

James TY, Stajich JE, Hittinger CT, Rokas A (2020) Toward a fully resolved fungal tree of life. Ann Rev Microbiol 74:291-313

Joly S, McLenachan PA, Lockhart PJ (2009) A statistical approach for distinguishing hybridization and incomplete lineage sorting. Am Nat 174:E54-E70

Jørgensen PM (2000) Survey of the lichen family Pannariaceae on the American continent, north of Mexico. Bryologist 103:670-704

Jørgensen PM (2017) The development of lichenology in the history of botany. Bryologist 120:37-44

Jørgensen PM (2019) The troublesome genus Thamnolia (lichenized Ascomycota). Lichenologist 51:221-226

Jørgensen PM, Tønsberg T (2007) Lobariaceae. Nordic Lichen Flora. Cyanolichens, vol 3. Nordic Lichen Society, Uddevalla, pp 77-96

Johnson NF, Triplehorn CA (2005) Borror and DeLong's introduction to the study of insects, 7 th edn. Cengage Learning, Boston

Joppa LN, Roberts DL, Pimm SL (2011) How many species of flowering plants are there? Proc Royal Soc B 278:554-559
Kalisz S, Vogler DW (2003) Benefits of autonomous selfing under unpredictable pollinator environments. Ecol 84:2928-2942

Kasalicky T, Döring H, Rambold G, Wedin M (2000) A comparison of ITS and LSU nrDNA phylogenies of Fulgensia (Teloschistaceae, Lecanorales), a genus of lichenised ascomycetes. Can J Bot 78:1580-1589

Keeling PJ, Inagaki Y (2004) A class of eukaryotic GTPase with a punctate distribution suggesting multiple functional replacements of translation elongation factor 1 alpha. Proc Natl Acad Sci USA 101:15380-15385

Keller C, Scheidegger C (2016) Multiple mating events and spermatiamediated gene flow in the lichen-forming fungus Lobaria pulmonaria. Herzogia 29:435-450

Kendrick WB, Proctor JR (1964) Computer taxonomy in the fungi imperfecti. Can J Bot 42:65-88

Keuler R, Garretson A, Saunders T, Erickson RJ, Andre NS, Grewe F, Smith H, Lumbsch HT, Huang JP, Clair LLS, Leavitt SD (2020) Genome-scale data reveal the role of hybridization in lichenforming fungi. Sci Rep 10:1-14

Kirk PM, Cannon PF, Minter DW, Stalpers JA (eds) (2008) Dictionary of the fungi, 10th edn. CABI, Netherlands

Kistenich S, Bendiksby M, Ekman S, Cáceres MES, Timdal E (2019) Towards an integrative taxonomy of Phyllopsora (Ramalinaceae). Lichenologist 51:323-392

Knowles LL, Carstens BC (2007) Delimiting species without monophyletic gene trees. Syst Biol 56:887-895

Körber GW (1839) De Gonidiis Lichenum. Nietackianis, Berlin

Körber GW (1853) Ueber die Sporen der Flechten. Jahresber Schles Ges Vaterl Cultur 31:168-172

Kohlmeyer J, Kohlmeyer E (1972) Is Ascophyllum nodosum lichenized? Bot Marina 15:109-112

Kondratyuk S, Kärnefelt I, Elix JA, Thell A (2008) A new circumscription of the genus Xanthodactylon (Teloschistaceae, lichenized Ascomycetes). Sauteria 15:265-282

Kraichak E, Lücking R, Aptroot A, Beck A, Dornes P, John V, Lendemer JC, Nelsen MP, Neuwirth G, Nutakki A, Parnmen S, Sohrabi M, Tønsberg T, Lumbsch HT (2015) Hidden diversity in the morphologically variable script lichen (Graphis scripta) complex (Ascomycota, Ostropales, Graphidaceae). Org Divers Evol 15:447-458

Kraichak E, Huang JP, Nelsen MP, Leavitt SD, Lumbsch HT (2018) A revised classification of orders and families in the two major subclasses of Lecanoromycetes (Ascomycota) based on a temporal approach. Bot J Linn Soc 188:233-249

Krespach MK, García-Altares M, Flak M, Schoeler H, Scherlach K, Netzker T, Schmalzl A, Mattern DJ, Schroeckh V, Komor A, Mittag M, Hertweck C, Brakhage AA (2020) Lichen-like association of Chlamydomonas reinhardtii and Aspergillus nidulans protects algal cells from bacteria. ISME J 14:2794-2805

Krishnamurthy KV, Upreti DK (2001) Reproductive biology of lichens. In: Johri BM, Srivastava PS (eds) Reproductive biology of plants. Springer \& Narosa Publishing House, New Dehli, pp 127-147

Krog H (1969) Kjemiens rolle i lavsystematikken. The role of chemistry in lichen systematics. Blyttia 27:65-79

Kroken S, Taylor JW (2001) A gene genealogical approach to recognize phylogenetic species boundaries in the lichenized fungus Letharia. Mycologia 93:38-53

Kondratyuk SY, Lőkös L, Farkas E, Jang SH, Liu D, Halda J, Persson PE, Hansson M, Kärnefelt I, Thell A, Hur JS (2019) Three new genera of the Ramalinaceae (lichen-forming Ascomycota) and the phenomenon of presence of 'extraneous mycobiont DNA in lichen associations. Acta Bot Hung 61:275-323

Lagostina E, Dal Grande F, Andreev M, Printzen C (2018) The use of microsatellite markers for species delimitation in Antarctic Usnea subgenus Neuropogon. Mycologia 110:1047-1057 
LaGreca S, Lumbsch HT, Kukwa M, Wei X, Han JE, Moon KH, Kashiwadani H, Aptroot A, Leavitt SD (2020) A molecular phylogenetic evaluation of the Ramalina siliquosa complex, with notes on species circumscription and relationships within Ramalina. Lichenologist 52:197-211

Lakatos M, Rascher U, Büdel B (2006) Functional characteristics of corticolous lichens in the understory of a tropical lowland rain forest. New Phytol 172:679-695

Lamarck JBPAM, Poiret JLM (1813) Encyclopédie Méthodique. Botanique. Supplément, Tome III. Agasse, Paris

Lamb IM (1951) Biochemistry in the taxonomy of lichens. Nature 168:38

Lanjouw J, Baehni C, Merrill ED, Rickett HW, Robyns W, Sprague TA, Stafleu FA (1952) International Code of Botanical Nomenclature Adopted by the Seventh International Botanical Congress, Stockholm, July 1950 [Regnum Vegetabile 3]. Koeltz Scientific Books, Oberreifenberg

Larcher W, Vareschi V (1988) Variation in morphology and functional traits of Dictyonema glabratum from contrasting habitats in the Venezuelan Andes. Lichenologist 20:269-277

Laurin M (2010) The subjective nature of Linnaean categories and its impact in evolutionary biology and biodiversity studies. Contrib Zool 79:131-146

Lawrey JD (1984) Biology of lichenized fungi. Praeger, New York

Lawrey JD (1995) The chemical ecology of lichen mycoparasites. Can J Bot 73(Suppl 1):603-608

Lawrey JD, Diederich P (2003) Lichenicolous fungi: interactions, evolution, and biodiversity. Bryologist 106:81-120

Lazo WR (1966) An experimental association between Chlorella xanthella and Streptomyces. Am J Bot 53:105-107

Leavitt SD, Johnson LA, Goward T, St. Clair LL (2011a) Species delimitation in taxonomically difficult lichen-forming fungi: an example from morphologically and chemically diverse Xanthoparmelia (Parmeliaceae) in North America. Mol Phyl Evol 60:317-332

Leavitt SD, Johnson L, St. Clair LL, (2011b) Species delimitation and evolution in morphologically and chemically diverse communities of the lichen-forming genus Xanthoparmelia (Parmeliaceae, Ascomycota) in western North America. Am J Bot 98:175-188

Leavitt SD, Moreau CS, Lumbsch HT (2015) The dynamic discipline of species delimitation: progress toward effectively recognizing species boundaries in natural populations. In: Upreti DK, Divakar PK, Shukla V, Bajpai R (eds) Recent advances in lichenology. Modern methods and approaches in lichen systematics and culture techniques, vol 2. Springer, New Delhi, pp 11-44

Leavitt SD, Divakar PK, Crespo A, Lumbsch HT (2016a) A matter of time-understanding the limits of the power of molecular data for delimiting species boundaries. Herzogia 29:479-492

Leavitt SD, Esslinger TL, Divakar PK, Crespo A, Lumbsch HT (2016b) Hidden diversity before our eyes: delimiting and describing cryptic lichen-forming fungal species in camouflage lichens (Parmeliaceae, Ascomycota). Fungal Biol 120:1374-1391

Leavitt SD, Kirika PM, De Paz GA, Huang JP, Hur JS, Grewe F, Divakar PK, Lumbsch HT (2018) Assessing phylogeny and historical biogeography of the largest genus of lichen-forming fungi, Xanthoparmelia (Parmeliaceae, Ascomycota). Lichenologist 50:299-312

Lendemer JC (2011) A taxonomic revision of the North American species of Lepraria sl that produce divaricatic acid, with notes on the type species of the genus $L$. incana. Mycologia 103:1216-1229

Lendemer JC (2021) Proposed best practices for taxonomic innovations in lichen and allied Fungi: a framework derived from analysis of more than 1,000 new taxa and new combinations. Bryologist 124:90-99

Lendemer JC, O'Brien HE (2011) How do you reconcile molecular and non-molecular datasets? A case study where new molecular data prompts a revision of Peltigera hydrothyria s.1. in North America and the recognition of two species. Opusc Philolich 9:99-110

Lendemer JC, Allen JL, Noell N (2015) The Parmotrema acid test: a look at species delineation in the $P$. perforatum group 40 y later. Mycologia 107:1120-1129

Lendemer JC, Keepers KG, Tripp EA, Pogoda CS, McCain CM, Kane NC (2019) A taxonomically broad metagenomic survey of 339 species spanning 57 families suggests cystobasidiomycete yeasts are not ubiquitous across all lichens. Am J Bot 106:1090-1095

Letrouit-Galinou MA (1968) The apothecia of the discolichens. Bryologist 71:297-327

Letrouit-Galinou MA, Parguey-Leduc A, Janex-Favre MC (1994) Ascoma structure and ontogenesis in ascomycete systematics. In: Hawksworth DL (ed) Ascomycete systematics. Problems and perspectives in the nineties [NATO Advanced Science Institutes Series]. Plenum Press, New York, pp 23-36

Li Y, Steenwyk JL, Chang Y, Wang Y, James TY, Stajich JE, Spatafora JW, Groenewald M, Dunn CW, Hittinger CT, Shen XX, Rokas A (2021) A genome-scale phylogeny of the kingdom Fungi. Curr Biol 31:1653-1665

Lin X, Heitman J (2007) Mechanisms of homothallism in fungi and transitions between heterothallism and homothallism. In: Heitman J, Kronstad JW, Taylor JW, Casselton LA (eds) Sex in fungi: molecular determination and evolutionary implications. ASM Press, Washington, pp 35-57

Lindau G (1895) Die Beziehungen der Flechten zu den Pilzen. Hedwigia 34:195-204

Linder CR, Rieseberg LH (2004) Reconstructing patterns of reticulate evolution in plants. Am J Bot 91:1700-1708

Linnaeus C (1753) Species Plantarum. Tomus I. Salvius, Holm

Liu D, Hur JS (2019) Revision of the lichen genus Phaeophyscia and allied atranorin absent taxa (Physciaceae) in South Korea. Microorganisms 7:242

Liu D, Goffinet B, Ertz D, de Kesel A, Wang X, Hur JS, Shi H, Zhang Y, Yang M, Wang L (2017 ["2018"]) Circumscription and phylogeny of the Lepidostromatales (lichenized Basidiomycota) following discovery of new species from China and Africa. Mycologia 109:730-748

Liu F, Wang M, Damm U, Crous PW, Cai L (2016) Species boundaries in plant pathogenic fungi: a Colletotrichum case study. BMC Evol Biol 16:1-14

Llewellyn T (2019) Revisiting generic concepts in the Teloschistaceae (lichen-forming Ascomycota) using molecular phylogenetics, algorithmic taxa delimitation and molecular networks. MSc Thesis, Royal Botanic Gardens Kew, UK

Loeffler J, Hebart H, Bialek R, Hagmeyer L, Schmidt D, Serey FP, Hartmann M, Eucker J, Einsele H (1999) Contaminations occurring in fungal PCR assays. J Clin Microbiol 37:1200-1202

Lohtander K, Myllys L, Sundin R, Källersjö M, Tehler A (1998) The species pair concept in the lichen Dendrographa leucophaea (Arthoniales): analyses based on ITS sequences. Bryologist 101:404-411

Lohtander K, Källersjö M, Moberg R, Tehler A (2000) The family Physciaceae in Fennoscandia: phylogeny inferred from ITS sequences. Mycologia 92:728-735

Lohtander K, Ahti T, Stenroos S, Urbanavichus G (2008) Is Anaptychia monophyletic? A phylogenetic study based on nuclear and mitochondrial genes. Ann Bot Fenn 45:55-60

Lohtander K, Myllys L, Källersjö M, Moberg R, Stenroos S, Tehler A (2009) New entities in Physcia aipolia - P. caesia group (Physciaceae, Ascomycetes): an analysis based on mtSSU, ITS, group I intron and betatubulin sequences. Ann Bot Fenn 46:43-53

Lotsy JP (1916) Evolution by means of hybridization. Martinus Nijhoff, The Hague

Lotsy JP (1925) Species or linneon. Genetica 7:487-506 
Ludwig LR (2011) Marginal soralia and conidiomata in Icmadophila splachnirima (Icmadophilaceae) from southern New Zealand. Austral Lichenol 68:4-11

Ludwig LR (2015) The reproductive ecology of Icmadophila splachnirima, including aspects of the reproduction in additional members of Icmadophilaceae. Doctoral Dissertation, University of Otago

Ludwig LR, Summerfield TC, Lord JM, Singh G (2017) Characterization of the mating-type locus (MAT) reveals a heterothallic mating system in Knightiella splachnirima. Lichenologist 49:373-385

Lücking R (1991) Neue Arten foliikoler Flechten aus Costa Rica, Zentralamerika. Nova Hedwigia 52:267-304

Lücking R (2008) Foliicolous lichenized fungi. Fl Neotrop Monogr 103:1-867

Lücking R (2009) The taxonomy of the genus Graphis sensu Staiger (Ascomycota: Ostropales: Graphidaceae). Lichenologist 41:319-362

Lücking R (2012) Predicting species richness in tropical lichenized fungi with 'modular' combinations of character states. Biodivers Cons 21:2341-2360

Lücking R (2014) A key to species of the Ocellularia papillata, perforata and terebrata morphodemes (Ascomycota: Graphidaceae). Glalia 6(3): 1-35

Lücking R (2019) Stop the abuse of time! A critical review of temporal banding for rank-based classifications in Fungi (including lichens) and other organisms. Crit Rev Plant Sci 38:199-253

Lücking R (2020) Three challenges to contemporaneous taxonomy from a licheno-mycological perspective. Megataxa 1:78-103

Lücking R (2021) Peter D. Crittenden: meta-analysis of an exceptional two-decade tenure as senior editor of The Lichenologist, the flagship journal of lichenology. Lichenologist 53:3-19

Lücking R, Hawksworth DL (2007) Names for lichen-forming fungi introduced by Ciferri and Tomaselli are illegitimate and not available for use, except for three cases. Taxon 56:1274-1284

Lücking R, Kalb K (2018) Formal instatement of Allographa (Graphidaceae): how to deal with a hyperdiverse genus complex with cryptic differentiation and paucity of molecular data. Herzogia $31: 525-561$

Lücking R, Lücking A (1995) Foliicolous lichens and bryophytes from Cocos Island, Costa Rica. A taxonomical and ecogeographical study. I. Lichens [Foliikole Flechten und Bryophyten der Kokosinsel, Costa Rica. Eine taxonomisch-ökogeografische Studie. I. Flechten]. Herzogia 11:143-174

Lücking R, Lumbsch HT (2014) Lichens: fungal farmers. Fungi Mag 7(2-3):7-12

Lücking R, Moncada B (2017) Dismantling Marchandiomphalina into Agonimia (Verrucariaceae) and Lawreymyces gen. nov. (Corticiaceae): setting a precedent to the formal recognition of thousands of voucherless fungi based on type sequences. Fungal Divers 84:119-138

Lücking R, Nelsen MP (2018) On Ediacarans, protolichens, and lichen-derived Penicillium: a critical reassessment of the evolution of lichenization in fungi. In: Krings M, Harper CJ, Cuneo NR, Rothwell GW (eds) Transformative paleobotany. Academic Press, San Diego, pp 551-590

Lücking R, Sérusiaux E, Maia LC, Pereira EC (1998) A revision of the names of foliicolous lichenized fungi published by Batista and co-workers between 1960 and 1975. Lichenologist 30:121-191

Lücking R, Sérusiaux E, Santesson R (2002) Ceratopycnidium citricola is Byssoloma lueckingii. Lichenologist 34:270-272

Lücking R, Stuart BL, Lumbsch HT (2004) Phylogenetic relationships of Gomphillaceae and Asterothyriaceae: evidence from a combined Bayesian analysis of nuclear and mitochondrial sequences. Mycologia 96:283-294
Lücking R, Sérusiaux E, Vezda A (2005) Phylogeny and systematics of the lichen family Gomphillaceae (Ostropales) inferred from cladistic analysis of phenotype data. Lichenologist 37:123-170

Lücking R, del Prado R, Lumbsch HT, Will-Wolf S, Aptroot A, Sipman HJM, Umaña L, Chaves JL (2008) Phylogenetic patterns of morphological and chemical characters and reproductive mode in the Heterodermia obscurata group in Costa Rica (Ascomycota, Physciaceae). Syst Biodivers 6:31-41

Lücking R, Archer AW, Aptroot A (2009a) A world-wide key to the genus Graphis (Ostropales: Graphidaceae). Lichenologist 41:363-452

Lücking R, Lawrey JD, Sikaroodi M, Gillevet PM, Chaves JL, Sipman HJM, Bungartz F (2009b) Do lichens "evolve" photobionts like farmers "evolve" crops? Evidence from a previously unrecognized lineage of filamentous cyanobacteria. Am J Bot 96:1409-1418

Lücking R, Rivas Plata E, Chaves JL, Umaña L, Sipman HJM (2009c) How many tropical lichens are there... really? Biblioth Lichenol 100:399-418

Lücking R, Dal-Forno M, Lawrey JD, Bungartz F, Rojas MEH, Marcelli MP, Moncada B, Morales EA, Nelsen MP, Salcedo L, Spielmann AA (2013) Ten new species of lichenized Basidiomycota in the genera Dictyonema and Cora (Agaricales: Hygrophoraceae), with a key to all accepted genera and species in the Dictyonema clade. Phytotaxa 139:1-38

Lücking R, Dal Forno M, Sikaroodi M, Gillevet PM, Bungartz F, Moncada B, Yánez-Ayabaca A, Chaves JL, Coca LF, Lawrey JD (2014) A single macrolichen constitutes hundreds of unrecognized species. Proc Natl Acad Sci USA 111:11091-11096

Lücking R, Mangold A, Rivas Plata E, Parnmen S, Kraichak E, Lumbsch HT (2015) Morphology-based phylogenetic binning to assess a taxonomic challenge: a case study in Graphidaceae (Ascomycota) requires a new generic name for the widespread Leptotrema wightii. Bot J Linn Soc 179:436-443

Lücking R, Nelsen MP, Aptroot A, Barillas de Klee R, Bawingan PA, Benatti MN, Binh NQ, Bungartz F, Cáceres MES, Canêz LS, Chaves JL, Ertz D, Esquivel RE, Ferraro LI, Grijalva A, Gueidan C, Hernández-M JE, Knight A, Lumbsch HT, Marcelli MP, Mercado-Díaz JA, Moncada B, Morales EA, Naksuwankul K, Orozco T, Parnmen S, Rivas Plata E, Salazar-Allen N, Spielmann AA, Ventura N (2016) A phylogenetic framework for reassessing generic concepts and species delimitation in the lichenized family Trypetheliaceae (Ascomycota: Dothideomycetes). Lichenologist 48:739-762

Lücking R, Hodkinson BP, Leavitt SD (2017a) ["2016"]. The 2016 classification of lichenized fungi in the Ascomycota and Basidiomycota-approaching one thousand genera. Bryologist 119:361-416

Lücking R, Dal Forno M, Moncada B, Coca LF, Vargas-Mendoza 1Y, Aptroot A, Arias LJ, Besal B, Bungartz F, Cabrera-Amaya DM, Cáceres MES, Chaves JL, Eliasaro S, Gutiérrez MC, Hernández-M, JE, Herrera-Campos MA, Holgado-Rojas ME, Jonitz H, Kukwa M, Lucheta F, Madriñán S, Marcelli MP, Martins SMA, Mercado-Díaz JA, Molina JA, Morales EA, Nelson PR, Nugra F, Ortega F, Paredes T, Patiño AL, Peláez-Pulido RN, Pérez-Pérez RE, Perlmutter GB, Rivas-Plata ME, Robayo J, Rodríguez C, Simijaca DF, Soto-Medina E, Spielmann AA, Suárez-Corredor A, Torres JM, Vargas CA, Yánez-Ayabaca A, Weerakoon G, WilkK, Celis-Pacheco M, Diazgranados M, Brokamp G, Borsch T, Gillevet PM, Sikaroodi M, Lawrey JD (2017b) Turbo-taxonomy to assemble a megadiverse lichen genus: seventy new species of Cora (Basidiomycota: Agaricales: Hygrophoraceae) honouring David Leslie Hawksworth's seventieth birthday Fungal Divers 84:139-207

Lücking R, Moncada B, McCune B, Farkas EE, Goffinet B, Parker D, Chaves JL, Lőkös L, Nelson PR, Spribille T, Stenroos S, 
Wheeler T, Yánez-Ayabaca A, Dillman K, Gockman OT, Goward T, Hollinger J, Tripp EA, Villella J, Álvaro-Alba WR, Arango CJ, Cáceres MES, Coca LF, Printzen C, Rodríguez C, Scharnagl K, Rozzi R, Soto-Medina E, Yakovchenko LS (2017c) Pseudocyphellaria crocata (Ascomycota: Lobariaceae) in the Americas reveals to be ten species, and none of them is Pseudocyphellaria crocata. Bryologist 120:441-500

Lücking R, Aime MC, Robberts B, Miller AN, Ariyawansa HA, Aoki T, Cardinali G, Crous PW, Druzhinina IS, Geiser DM, Hawksworth DL, Hyde KD, Irinyi L, Jeewon R, Johnston PR, Kirk PM, Malosso E, May TW, Meyer W, Öpik M, Robert V, Stadler M, Thines M, Vu D, Yurkov AM, Zhang N, Schoch CL (2020a) Unambiguous identification of fungi: where do we stand and how accurate and precise is fungal barcoding? IMA Fungus 11:14

Lücking R, Nadel MRA, Araujo E, Gerlach ACL (2020b) Two decades of DNA barcoding in the genus Usnea (Parmeliaceae): how useful and reliable is the ITS? Plant Fungal Syst 65:303-357

Lücking R, Kaminsky L, Perlmutter GB, Lawrey JD, Dal Forno M (2020c) Cora timucua (Hygrophoraceae), a new and potentially extinct, previously misidentified basidiolichen of Florida inland scrub documented from historical collections. Bryologist 123:657-673

Lücking R, Aime MC, Robbertse B, Miller AN, Aoki T, Ariyawansa HA, Cardinali G, Crous PW, Druzhinina IS, Geiser DM, Hawksworth DL, Hyde KD, Irinyi L, Jeewon R, Johnston PR, Kirk PM, Malosso E, May TW, Meyer W, Nilsson HR, Öpik M, Robert V, Stadler M, Thines M, Vu D, Yurkov AM, Zhang N, Schoch CL (2021a) Current status of fungal identifications and the naming of "dark taxa". Nature Microbiol (in press)

Lücking R, Moncada B, Widhelm TJ, Lumbsch HT, Blanchon DJ, de Lange PJ (2021b) The Sticta filix - Sticta lacera conundrum (lichenized Ascomycota: Peltigeraceae subfamily Lobarioideae): unresolved lineage sorting or developmental switch? Bot J Linnean Soc (in press)

Lumbsch HT (1998) The use of metabolic data in lichenology at the species and subspecific levels. Lichenologist 30:357-367

Lumbsch HT, Huhndorf SM (2010) Myconet Volume 14. Part One. Outline of Ascomycota - 2009. Part Two. Notes on Ascomycete Systematics. Nos. 4751-5113. Fieldiana 1:1-64

Lumbsch HT, Leavitt SD (2011) Goodbye morphology? A paradigm shift in the delimitation of species in lichenized fungi. Fungal Divers 50:59-72

Lumbsch HT, Tehler A (1998) A cladistic analysis of the genus Diploschistes (Ascomycotina, Thelotremataceae). Bryologist 101:398-403

Lutsak T, Fernández-Mendoza F, Kirika P, Wondafrash M, Printzen C (2020) Coalescence-based species delimitation using genomewide data reveals hidden diversity in a cosmopolitan group of lichens. Org Divers Evol 20:189-218

Lutzoni F, Pagel M, Reeb V (2001) Major fungal lineages are derived from lichen symbiotic ancestors. Nature 411:937-940

Maddison WP, Knowles LL (2006) Inferring phylogeny despite incomplete lineage sorting. Syst Biol 55:21-30

Magain N, Sérusiaux E (2014) Do photobiont switch and cephalodia emancipation act as evolutionary drivers in the lichen symbiosis? A case study in the Pannariaceae (Peltigerales). PLoS ONE 9(2): 889876

Magain N, Sérusiaux E (2015) Dismantling the treasured flagship lichen Sticta fuliginosa (Peltigerales) into four species in Western Europe. Mycol Progr 14:1-33

Magain N, Goffinet B, Sérusiaux E (2012) Further photomorphs in the lichen family Lobariaceae from Reunion (Mascarene archipelago) with notes on the phylogeny of Dendriscocaulon cyanomorphs. Bryologist 115:243-254
Magain N, Sérusiaux E, Zhurbenko MP, Lutzoni F, Miądlikowska J (2016) Disentangling the Peltigera polydactylon species complex by recognizing two new taxa, $P$. polydactylon subsp. udeghe and $P$. seneca. Herzogia 29:514-528

Magain N, Miądlikowska J, Mueller O, Gajdeczka M, Troung C, Salamov AA, Dubchak I, Grigoriev IV, Goffinet B, Sérusiaux E, Lutzoni F (2017) Conserved genomic collinearity as a source of broadly applicable fast evolving markers to resolve species complexes: a case study using the lichen-forming genus Peltigera section Polydactylon. Mol Phyl Evol 110:10-29

Mallet J (2007) Subspecies, semispecies, superspecies. Encyclop Biodivers 5:523-526

Marchetti MP, Moyle PB (2010) Species. The basic unit of conservation. In: Marchetti MP, Moyle PB (eds) Protecting life on earth: an introduction to the science of conservation. University of California Press, Berkeley, Los Angeles, London, pp 37-48

Marhold K (2011) Multivariate morphometrics and its application to monography at specific and infraspecific levels. In: Stuessy TF, Lack HW (eds) Monographic plant systematics: fundamental assessment of plant biodiversity. Gantner, Ruggell, pp 75-101

Mark K, Saag L, Leavitt SD, Will-Wolf S, Nelsen MP, Tõrra T, Saag A, Randlane T, Lumbsch HT (2016) Evaluation of traditionally circumscribed species in the lichen-forming genus Usnea, section Usnea (Parmeliaceae, Ascomycota) using a six-locus dataset. Org Divers Evol 16:497-524

Mark K, Laanisto L, Bueno CG, Niinemets Ü, Keller C, Scheidegger C (2020) Contrasting co-occurrence patterns of photobiont and cystobasidiomycete yeast associated with common epiphytic lichen species. New Phytol 227:1362-1375

Marthinsen G, Rui S, Timdal E (2019) OLICH: A reference library of DNA barcodes for Nordic lichens. Biodivers Data J 7:e36252

Martín MP, LaGreca S, Lumbsch HT (2003) Molecular phylogeny of Diploschistes inferred from ITS sequence data. Lichenologist 35:27-32

Matallana G, Godinho MAS, Guilherme FAG, Belisario M, Coser TS, Wendt T (2010) Breeding systems of Bromeliaceae species: evolution of selfing in the context of sympatric occurrence. Plant Syst Evol 289:57-65

Mattsson JE, Lumbsch HT (1989) The use of the species pair concept in lichen taxonomy. Taxon 38:238-241

May TW, Redhead SA, Bensch K, Hawksworth DL, Lendemer JC, Lombard L (2018) Turland NJ (2019) Chapter F of the International Code of Nomenclature for algae, fungi, and plants as approved by the 11th International Mycological Congress, San Juan, Puerto Rico. IMA Fungus 10(1):1-14

Mayden RL (1997) A hierarchy of species concepts: the denoument in the saga of the species problem. In: Claridge MF, Dawah HA, Wilson MR (eds) Species: the units of diversity. Chapman and Hall, London, pp 381-423

Mayr E (1944) Systematics and the origin of species from the viewpoint of a zoologist. Columbia University Press, New York

Mayr E (1968) The role of systematics in biology. Science 159:595-599

McCabe T (2021) Descent and logic in biosystematics. Perseverant Publishing

McCune B, Altermann S (2009) Letharia gracilis (Parmeliaceae), a new species from California and Oregon. Bryologist 112:375-378

McCune B, Daly WJ (1994) Consumption and decomposition of lichen litter in a temperate coniferous rainforest. Lichenologist 26:67-71

McDade LA (1995) Species concepts and problems in practice: insight from botanical monographs. Syst Bot 20:606-622

McGuigan K, Chenoweth SF, Blows MW (2005) Phenotypic divergence along lines of genetic variance. Am Nat 165:32-43

Melton AE, Chen S, Zhao Y, Fu C, Xiang QY, Cheng S, Wong GKS, Soltis PS, Soltis DE, Gitzendanner MA (2020) Genetic insights 
into the evolution of genera with the eastern Asia-eastern North America floristic disjunction: a transcriptomics analysis. Am J Bot 107:1736-1748

Mercader RJ, Aardema ML, Scriber JM (2009) Hybridization leads to host-use divergence in a polyphagous butterfly sibling species pair. Oecologia 158:651-662

Mercado-Díaz JA, Lücking R, Moncada B, Widhelm TJ, Lumbsch HT (2020) Elucidating species richness in lichen fungi: the genus Sticta (Ascomycota: Peltigeraceae) in Puerto Rico. Taxon 69:851-891

Messuti MI, Archer AW (2009) ¿Cuántos taxones pueden incluirse teóricamente en el género Pertusaria? How many taxa can theoretically be included in Pertusaria? Glalia 2(3):1-8

Messuti MI, Passo A, Scervino JM, Vidal-Russell R (2016) The species pair Pseudocyphellaria pilosella-piloselloides (lichenized Ascomycota: Lobariaceae) is a single species. Lichenologist 48:141-146

Miądlikowska J, Kauff F, Hofstetter V, Fraker E, Grube M, Hafellner J, Reeb V, Hodkinson BP, Kukwa M, Lücking R, Hestmark G, Otalora MG, Rauhut A, Büdel B, Scheidegger C, Timdal E, Stenroos S, Brodo I, Perlmutter GB, Ertz D, Diederich P, Lendemer JC, Tripp E, Yahr R, May P, Gueidan C, Arnold AE, Robertson C, Lutzoni F (2006) New insights into classification and evolution of the Lecanoromycetes (Pezizomycotina, Ascomycota) from phylogenetic analyses of three ribosomal RNA- and two proteincoding genes. Mycologia 98:1088-1103

Miądlikowska J, Schoch CL, Kageyama SA, Molnar K, Lutzoni F, McCune B (2011) Hypogymnia phylogeny, including Cavernularia, reveals biogeographic structure. Bryologist 114:392-400

Miądlikowska J, Kauff F, Högnabba F, Oliver JC, Molnár K, Fraker E, Gaya E, Hafellner J, Hofstetter V, Gueidan C, Kukwa M, Lücking R, Björk C, Sipman HJM, Burgaz AR, Thell A, Passo A, Myllys L, Goward T, Fernández-Brime S, Hestmark G, Lendemer J, Lumbsch HT, Schmull M, Schoch C, Sérusiaux E, Maddison DR, Arnold AE, Lutzoni F, Stenroos S (2014a) A multigene phylogenetic synthesis for the class Lecanoromycetes (Ascomycota): 1307 fungi representing 1139 infrageneric taxa, 312 genera and 66 families. Mol Phyl Evol 79:132-168

Miądlikowska J, Richardson D, Magain N, Ball B, Anderson F, Cameron R, Lendemer JC, Truong C, Lutzoni F (2014b) Phylogenetic placement, species delimitation, and cyanobiont identity of endangered aquatic Peltigera species (lichen-forming Ascomycota, Lecanoromycetes). Am J Bot 101:1141-1156

Michelius PA (1729) Nova Plantarum Genera juxta Tournefortii Methodum Disposita. Papirini, Florentiae

Miller KB, Alarie Y, Wolfe GW, Whiting MF (2005) Association of insect life stages using DNA sequences: the larvae of Philodytes umbrinus (Motschulsky) (Coleoptera: Dytiscidae). Syst Entomol 30:499-509

Minks A (1874) Thamnolia vermicularis. Eine Monographie. Flora 57(337-347):353-362

Mirarab S, Reaz R, Bayzid MS, Zimmermann T, Swenson MS, Warnow T (2014) ASTRAL: genome-scale coalescent-based species tree estimation. Bioinformatics 30:i541-i548

Miralles A, Vences M (2013) New metrics for comparison of taxonomies reveal striking discrepancies among species delimitation methods in Madascincus lizards. PLoS ONE 8(7):e68242

Moeller DA (2006) Geographic structure of pollinator communities, reproductive assurance, and the evolution of self-pollination. Ecol 87:1510-1522

Molina MC, Crespo A, Blanco O, Hladun N, Hawksworth DL (2002) Molecular phylogeny and status of Diploicia and Diplotomma, with observations on Diploicia subcanescens and Diplotomma rivas-martinezii. Lichenologist 34:509-519

Molina MC, Crespo A, Blanco O, Lumbsch HT, Hawksworth DL (2004) Phylogenetic relationships and species concepts in
Parmelia s. str. (Parmeliaceae) inferred fromnuclear ITS rDNA and $\beta$-tubulin sequences. Lichenologist 36:37-54

Molina MC, Del-Prado R, Divakar PK, Sánchez-Mata D, Crespo A (2011) Another example of cryptic diversity in lichen-forming fungi: the new species Parmelia mayi (Ascomycota: Parmeliaceae). Org Divers Evol 11:331-342

Molina MC, Divakar PK, Zhang N, González N, Struwe L (2013) Non-developing ascospores in apothecia of asexually reproducing lichen-forming fungi. Int Microbiol 16:145-155

Moncada B (2012) El Género Sticta (Schreb.) Ach. en Colombia: Taxonomía, Ecogeografía e Importancia. PhD Dissertation, Universidad Nacional de Colombia, Bogotá DC

Moncada B, Coca LF, Lücking R (2013a) Neotropical members of Sticta (lichenized Ascomycota: Lobariaceae) forming photosymbiodemes, with the description of seven new species. Bryologist 116:169-200

Moncada B, Lücking R, Betancourt-Macuase L (2013b) Phylogeny of the Lobariaceae (lichenized Ascomycota: Peltigerales), with a reappraisal of the genus Lobariella. Lichenologist 45:203-263

Moncada B, Lücking R, Suárez A (2014) Molecular phylogeny of the genus Sticta (lichenized Ascomycota: Lobariaceae) in Colombia. Fungal Divers 64:205-231

Moncada B, Suárez A, Lücking R (2015) Nine new species of the genus Sticta (Ascomycota liquenizados: Lobariaceae) of the fuliginosa sensu lato morphodeme from Colombia. Rev Acad Col Cienc Exact Fís Nat 39:50-66

Moncada B, Pérez-Pérez RE, Lücking R (2019) The lichenized genus Cora (Basidiomycota: Hygrophoraceae) in Mexico: high species richness, multiple colonization events, and high endemism. Plant Fungal Syst 64:393-411

Moncada B, Sipman HJM, Lücking R (2020a) Testing DNA barcoding in Usnea (Parmeliaceae) in Colombia using the internal transcribed spacer (ITS). Plant Fungal Syst 65:358-385

Moncada B, Lücking R, Lumbsch HT (2020b) Rewriting the evolutionary history of the lichen genus Sticta (Ascomycota: Peltigeraceae subfam. Lobarioideae) in the Hawaiian islands. Plant Fungal Syst 65:95-119

Moncada B, Mercado-Díaz JA, Smith CW, Bungartz F, Sérusiaux E, Lumbsch HT, Lücking R (2021a) Two new common, previously unrecognized species in the Sticta weigelii morphodeme (Ascomycota: Peltigeraceae). Willdenowia 51:35-45

Moncada B, Mercado-Díaz JA, Magain N, Hodkinson BP, Smith CW, Bungartz F, Pérez-Pérez RE, Gumboski E, Sérusiaux E, Lumbsch HT, Lücking R (2021b) Phylogenetic diversity of two geographically overlapping lichens: isolation by distance, environment, or fragmentation? J Biogeogr 48:676-689

Mooers AØ (2007) The diversity of biodiversity. Nature 445:717-718

Moritz C (1994) Defining "Evolutionarily Significant Units" for conservation. Trends Ecol Evol 9:373-375

Motyka J (1960) Zmiennosc Thamnolia vermicularis (Sw.) Schaer. De variabilitate Thamnoliae vermicularis (Sw.) Schaer. Fragm Flor Geobot 6:627-635

Muggia L, Baloch E, Stabentheiner E, Grube M, Wedin M (2011) Photobiont association and genetic diversity of the optionally lichenized fungus Schizoxylon albescens. FEMS Microbiol Ecol $75: 255-272$

Muggia L, Ametrano CG, Sterflinger K, Tesei D (2020) An overview of genomics, phylogenomics and proteomics approaches in Ascomycota. Life 10(12):356

Muñoz-Benavent M, Pérez-Cobas AE, García-Ferris C, Moya A, Latorre A (2020) Insects' potential: understanding the functional role of their gut microbiome. J Pharm Biomed Anal 94:113787

Murtagh GJ, Dyer PS, Crittenden PD (2000) Sex and the single lichen. Nature 404:564-564 
Myllys L, Lohtander K, Källersjö M, Tehler A (1999) Sequence insertions and ITS data provide congruent information on Roccella canariensis and $R$. tuberculata (Arthoniales, Euascomycetes) phylogeny. Mol Phyl Evol 12:295-309

Myllys L, Lohtander K, Tehler A (2001) $\beta$-tubulin, ITS and group I intron sequences challenge the species pair concept in Physcia aipolia and $P$. caesia. Mycologia 93:335-343

Myllys L, Stenroos S, Thell A, Ahti T (2003) Phylogeny of bipolar Cladonia arbuscula and Cladonia mitis (Lecanorales, Euascomycetes). Mol Phyl Evol 27:58-69

Naciri Y, Linder HP (2015) Species delimitation and relationships: the dance of the seven veils. Taxon 64:3-16

Necchi O Jr, Zucchi MR (1997) Audouinella macrospora (Acrochaetiaceae, Rhodophyta) is the chantransia stage of Batrachospermum (Batrachospermaceae). Phycologia 36:220-224

Necchi O Jr, Garcia Fo AS, Paiano MO, Vis ML (2019) Revision of Batrachospermum section Macrospora (Batrachospermales, Rhodophyta) with the establishment of the new genus Montagnia. Phycologia 58:582-591

Nelsen MP, Gargas A (2009) Assessing clonality and chemotype monophyly in Thamnolia (Icmadophilaceae). Bryologist 112:42-53

Nelsen MP, Lücking R, Grube M, Mbatchou JS, Muggia L, Rivas Plata E, Lumbsch HT (2009) Unravelling the phylogenetic relationships of lichenised fungi in Dothideomyceta. Stud Mycol 64:135-144

Nelsen MP, Lücking R, Mbatchou JS, Andrew CJ, Spielmann AA, Lumbsch HT (2011) New insights into relationships of lichenforming Dothideomycetes. Fungal Divers 51:155-162

Nelsen MP, Lücking R, Boyce CK, Lumbsch HT, Ree RH (2020) The macroevolutionary dynamics of symbiotic and phenotypic diversification in lichens. Proc Natl Acad Sci USA 117:21495-21503

Neuwirth G, Aptroot A (2011) Recognition of four morphologically distinct species in the Graphis scripta complex in Europe. Herzogia 24:207-230

Ni M, Feretzaki M, Sun S, Wang X, Heitman J (2011) Sex in fungi. Ann Rev Gen 45:405-430

Nilsson RH, Kristiansson E, Ryberg M, Hallenberg N, Larsson KH (2008) Intraspecific ITS variability in the kingdom Fungi as expressed in the international sequence databases and its implications for molecular species identification. Evol Bioinform 4:EBO-S653

Nilsson RH, Tedersoo L, Ryberg M, Kristiansson E, Hartmann M, Unterseher M, Porter TM, Bengtsson-Palme J, Walker DM, de Sousa F, Gamper HA, Larsson E, Larsson KH, Kõljalg U, Edgar RC, Abarenkov K (2015) A comprehensive, automatically updated fungal ITS sequence dataset for reference-based chimera control in environmental sequencing efforts. Microb Environm 30:145-150

Nuñez-Zapata J, Divakar PK, Ruth DP, Cubas P, Hawksworth DL, Crespo A (2011) Conundrums in species concepts: the discovery of a new cryptic species segregated from Parmelina tiliacea (Ascomycota: Parmeliaceae). Lichenologist 43:603-616

Nyati S, Beck A, Honegger R (2007) Fine structure and phylogeny of green algal photobionts in the microfilamentous genus Psoroglaena (Verrucariaceae, lichen-forming ascomycetes). Plant Biol 9:390-399

Nylander W (1858) Synopsis Methodica Lichenum Omnium Hucusque Cognitorum Praemissa Introductione Lingua Gallica Tractata. Martinet, Paris

Nylander W (1863) Lichenographiae Novo-Granatensis Prodromus. Acta Soc Sci Fenn 7:415-504

O'Brien SJ, Mayr E (1991) Bureaucratic mischief: recognizing endangered species and subspecies. Science 251:1187-1188

Ohkuma M (2008) Symbioses of flagellates and prokaryotes in the gut of lower termites. Trends Microbiol 16:345-352
Ohmura Y (2020) Usnea nipparensis and U. sinensis form a "species pair" presuming morphological, chemical and molecular phylogenetic data. Plant Fungal Syst 65:265-271

Onuţ-Brännström I, Tibell L, Johannesson H (2017) A worldwide phylogeography of the whiteworm lichens Thamnolia reveals three lineages with distinct habitats and evolutionary histories. Ecol Evol 7:3602-3615

Onuţ-Brännström I, Johannesson H, Tibell L (2018) Thamnolia tundrae sp. nov., a cryptic species and putative glacial relict. Lichenologist 50:59-75

Orange A (2012) Semi-cryptic marine species of Hydropunctaria (Verrucariaceae, lichenized Ascomycota) from north-west Europe. Lichenologist 44:299-320

Orange A (2018) A new species-level taxonomy for Trapelia (Trapeliaceae, Ostropomycetidae) with special reference to Great Britain and the Falkland Islands. Lichenologist 50:3-42

Otálora MA, Aragón G, Molina MC, Martinez I, Lutzoni F (2010a) Disentangling the Collema-Leptogium complex through a molecular phylogenetic study of the Collemataceae (Peltigerales, lichen-forming Ascomycota). Mycologia 102:279-290

Otálora MA, Martínez I, Aragón G, Molina MC (2010b) Phylogeography and divergence date estimates of a lichen species complex with a disjunct distribution pattern. Am J Bot 97:216-223

Otálora MA, Salvador C, Martínez I, Aragón G (2013) Does the reproductive strategy affect the transmission and genetic diversity of bionts in cyanolichens? A case study using two closely related species. Microb Ecol 65:517-530

Ott S, Brinkmann M, Wirtz N, Lumbsch HT (2004) Mitochondrial and nuclear ribosomal DNA data do not support the separation of the Antarctic lichens Umbilicaria kappenii and Umbilicaria antarctica as distinct species. Lichenologist 36:227-234

Padial JM, Miralles A, De la Riva I, Vences M (2010) The integrative future of taxonomy. Front Zool 7:1-14

Park ST, Hong SC (1985) Comparison of prinicipal component analysis and correspondence analysis on numerical taxonomic study of Cladonia. Basic Sci 8:27-36

Parker CT, Tindall BJ, Garrity GM (eds) (2019) International Code of Nomenclature of Prokaryotes: Prokaryotic Code (2008 revision). Int J Syst Evol Microbiol 69:S1-S111

Parnmen S, Rangsiruji A, Mongkolsuk P, Boonpragob K, Elix JA, Lumbsch HT (2010) Morphological disparity in Cladoniaceae: The foliose genus Heterodea evolved from fruticose Cladia species (Lecanorales, lichenized Ascomycota). Taxon 59:841-849

Parnmen S, Lücking R, Lumbsch HT (2012) Phylogenetic classification at generic level in the absence of distinct phylogenetic patterns of phenotypical variation: a case study in Graphidaceae (Ascomycota). PLoS ONE 7(12):51392

Patten MA (2015) Subspecies and the philosophy of science. Auk 132:481-485

Paz GA, Cubas P, Crespo A, Elix JA, Lumbsch HT (2012) Transoceanic dispersal and subsequent diversification on separate continents shaped diversity of the Xanthoparmelia pulla group (Ascomycota). PLoS ONE 7(6): 39683

Pérez-Ortega S, de los Ríos A, Crespo A, Sancho LG (2010) Symbiotic lifestyle and phylogenetic relationships of the bionts of Mastodia tessellata (Ascomycota, incertae sedis). Am J Bot 97:738-752

Pérez-Ortega S, Fernández-Mendoza F, Raggio R, Vivas M, Ascaso C, Sancho LG, Printzen C, De Los RA (2012) Extreme phenotypic variation in Cetraria aculeata (lichenized Ascomycota): Adaptation or incidental modification? Ann Bot 109:1133-1148

Perez-Ortega S, Miller KA, De Los RA (2018) Challenging the lichen concept: Turgidosculum ulvae (Verrucariaceae) represents an independent photobiont shift to a multicellular blade-like alga. Lichenologist 50:341-356

Perlmutter GB, Rivas Plata E, LaGreca S, Aptroot A, Lücking R, Tehler A, Ertz D (2020) Biatora akompsa is revealed as a disjunct North 
American species of Pentagenella (Opegraphaceae) through molecular phylogenetic analysis and phenotype-based binning. Bryologist 123:502-516

Pfennig DW, Rice AM, Martin RA (2007) Field and experimental evidence for competition's role in phenotypic divergence. Evolution 61:257-271

Piercey-Normore MD, Ahti T, Goward T (2010) Phylogenetic and haplotype analyses of four segregates within Cladonia arbuscula sl. Botany 88:397-408

Pino-Bodas R, Martin MP, Burgaz AR (2010a) Insight into the Cladonia convoluta-C. foliacea (Cladoniaceae, Ascomycota) complex and related species, revealed through morphological, biochemical and phylogenetic analyses. Syst Biodivers 8:575-586

Pino-Bodas R, Burgaz AR, Martín MP (2010b) Elucidating the taxonomic rank of Cladonia subulata versus C. rei (Cladoniaceae). Mycotaxon 113:311-326

Pizarro D, Divakar PK, Grewe F, Leavitt SD, Huang JP, Dal Grande F, Schmitt I, Wedin M, Crespo A, Lumbsch HT (2018) Phylogenomic analysis of 2556 single-copy protein-coding genes resolves most evolutionary relationships for the major clades in the most diverse group of lichen-forming fungi. Fungal Divers 92:31-41

Pizarro D, Dal Grande F, Leavitt SD, Dyer PS, Schmitt I, Crespo A, Lumbsch HT, Divakar PK (2019) Whole-genome sequence data uncover widespread heterothallism in the largest group of lichenforming fungi. Genome Biol Evol 11:721-730

Poelt J (1970) Das Konzept der Artenpaare bei den Flechten. Deutsche Bot Gesellsch Neue Folge 4:187-198

Poelt J (1972a) Die taxonomische Behandlung von Artenpaaren bei den Flechten. Bot Not 125:77-81

Poelt J (1972b) Systematik Der Flechten. Forschr Bot 34:361-380

Prashanth SR, Bharath P, Valarmathi R, Balaji P, Parida A, Hariharan GN (2008) Species status and relationship between Roccella montagnei and Roccella belangeriana using DNA sequence data of nuclear ribosomal internal transcribed spacer region. J Plant Biochem Biotechnol 17:91-94

Pressel S, Bidartondo MI, Ligrone R, Duckett JG (2014) Fungal symbioses in bryophytes: new insights in the twenty first century. Phytotaxa 9:238-253

Prieto M, Wedin M (2017) Phylogeny, taxonomy and diversification events in the Caliciaceae. Fungal Divers 82:221-238

Printzen C (2010) Lichen systematics: the role of morphological and molecular data to reconstruct phylogenetic relationships. Prog Botany 71:233-275

Printzen C (2014) A molecular phylogeny of the lichen genus Biatora including some morphologically similar species. Lichenologist 46:441-453

Puillandre N, Lambert A, Brouillet S, Achaz G (2012) ABGD, Automatic Barcode Gap Discovery for primary species delimitation. Mol Ecol 21:1864-1877

Purvis OW (2000) Lichens. Natural History Museum, London \& Smithsonian Institution, London, Washington DC

Ranft H, Moncada B, De Lange PJ, Lumbsch HT, Lücking R (2018) The Sticta filix morphodeme (Ascomycota: Lobariaceae) in New Zealand, with the newly recognized species $S$. dendroides and $S$. menziesii: indicators of forest health in a threatened island biota? Lichenologist 50:185-210

Raposo MA, Kirwan GM, Lourenço ACC, Sobral G, Bockmann FA, Stopiglia R (2020) On the notions of taxonomic "impediment", gap", inflation' and "anarchy", and their effects on the field of conservation. Syst Biodivers. https://doi.org/10.1080/14772000. 2020.1829157

Redhead SA (1984) Arrhenia and Rimbachia, expanded generic concepts, and a reevaluation of Leptoglossum with emphasis on muscicolous North American taxa. Can J Bot 62:865-892
Redhead SA, Kuyper TW (1987) Lichenized agarics: taxonomic and nomenclatural riddles. In: Laursen GA, Ammirati JF, Redhead SA (eds) Arctic and alpine mycology, vol II. Springer, Boston, pp 319-348

Reinke J (1896) Abhandlungen über Flechten V. Das Natürliche Flechtensystem Jahrb Wissensch Bot 29:171-236

Resl P, Schneider K, Westberg M, Printzen C, Palice Z, Thor G, Fryday A, Mayrhofer H, Spribille T (2015) Diagnostics for a troubled backbone: testing topological hypotheses of trapelioid lichenized fungi in a large-scale phylogeny of Ostropomycetidae (Lecanoromycetes). Fungal Divers 73:239-258

Ride WDL, Cogger HG, Dupuis C, Kraus O, Minelli A, Thompson FC, Tubbs PK (1999) International code of zoological nomenclature. Fourth Edition: Adopted by the International Union of Biological Sciences. The Natural History Museum, London, La Garangola, Padova

Riedel A, Sagata K, Suhardjono YR, Tänzler R, Balke M (2013) Integrative taxonomy on the fast track-towards more sustainability in biodiversity research. Front Zool 10:1-9

Rivas Plata E, Lumbsch HT (2011) Parallel evolution and phenotypic disparity in lichenized fungi: a case study in the lichen-forming fungal family Graphidaceae (Ascomycota: Lecanoromycetes: Ostropales). Mol Phyl Evol 61:45-63

Rivas Plata E, Hernández-M JE, Lücking R, Staiger B, Kalb K, Cáceres MES (2011) Graphis is two genera-a remarkable case of parallel evolution in lichenized Ascomycota. Taxon 60:99-107

Rivas Plata E, Lücking R, Lumbsch HT (2012) Molecular phylogeny and systematics of the Ocellularia clade (Ascomycota: Ostropales: Graphidaceae). Taxon 61:1161-1179

Rivas Plata E, Parnmen S, Staiger B, Mangold A, Frisch A, Weerakoon G, Hernández-M JE, Cáceres MES, Kalb K, Sipman HJM, Common RS, Nelsen MP, Lücking R, Lumbsch HT (2013) A molecular phylogeny of Graphidaceae (Ascomycota: Lecanoromycetes: Ostropales) including 428 species. MycoKeys 6:55-94

Rizzi G, Giordani P (2013) The ecology of the lichen genus Xanthoparmelia in Italy: an investigation throughout spatial scales. Plant Biosyst 147:33-39

Robinson HE (1975) Considerations on the evolution of lichens. Phytologia 32:407-413

Rogers RW (1989) Chemical variation and the species concept in lichenized ascomycetes. Bot J Linn Soc 101:229-239

Roux C, Bellemere A, Boissiere JC, Esnault J, Janex-Favre MC, Letrouit-Galinou MA, Wagner J (1986) Les bases de la systematique moderne des lichens. Bull Soc Bot Fr 133(2):7-40

Rundel PW, Bowler PA (1976) Ramalina leptocarpha and R. subleptocarpha: a fertile-sorediate species pair. Bryologist 79:364-369

Saini KC, Nayaka S, Bast F (2019) Diversity of lichen photobionts: their coevolution and bioprospecting potential. In: Satyanarayana T, Das SK, Johri BN (eds) Microbial diversity in ecosystem sustainability and biotechnological applications. Soil \& agroecosystems, vol 2. Springer Nature, Singapore, pp 307-323

Sanders WB (2001a) Preliminary light microscope observations of fungal and algal colonization and lichen thallus initiation on glass slides placed near foliicolous lichen communities within a lowland tropical forest. Symbiosis 31:85-94

Sanders WB (2001b) Lichens: the interface between mycology and plant morphology. Bioscience 51:1025-1035

Sanders WB (2001c) Composite lichen thalli of Sticta sp. from Brazil, with morphologically similar lobes containing either a chlorobiont or a cyanobiont layer. Symbiosis 31:47-55

Sanders WB (2005) Observing microscopic phases of lichen life cycles on transparent substrata placed in situ. Lichenologist 37:373-382

Sanders WB (2014) Complete life cycle of the lichen fungus Calopadia puiggarii (Pilocarpaceae, Ascomycetes) documented in situ: Propagule dispersal, establishment of symbiosis, thallus 
development, and formation of sexual and asexual reproductive structures. Am J Bot 101:1836-1848

Sanders WB, Lücking R (2002) Reproductive strategies, relichenization and thallus development observed in situ in leaf-dwelling lichen communities. New Phytol 155:425-435

Santesson R (1953) The new systematics of lichenized fungi. In: Osvald H, Ảberg E (eds) Proceedings of the seventh international botanical congress, Stockholm 1950. Almqvist and Wiksell, Stockholm, pp 809-810

Santesson R (1954) Fungal symbionts of lichens. Taxon 3:147-148

Santesson R (2004) Two new species of Thamnolia. Symb Bot Upsal 34(1):393-397

Santos LA, Aptroot A, Lücking R, Cáceres MES (2019) High diversification in the Neoprotoparmelia multifera complex (Ascomycota, Parmeliaceae) in northeast Brazil revealed by DNA barcoding and phenotypical characters. Bryologist 122:539-552

Schardl CL, Craven KD (2003) Interspecific hybridization in plant-associated fungi and oomycetes: a review. Mol Ecol 12:2861-2873

Scheelings TF, Moore RJ, Van TTH, Klaassen M, Reina RD (2020) Microbial symbiosis and coevolution of an entire clade of ancient vertebrates: the gut microbiota of sea turtles and its relationship to their phylogenetic history. Anim Microbiome 2:1-12

Schillaci MA, Froehlich JW (2001) Nonhuman primate hybridization and the taxonomic status of Neanderthals. Am J Phys Anthropol 115:157-166

Schlueter PM, Ruas PM, Kohl G, Ruas CF, Stuessy TF, Paulus HF (2009) Genetic patterns and pollination in Ophrys iricolor and O. mesaritica (Orchidaceae): sympatric evolution by pollinator shift. Bot J Linn Soc 159:583-598

Schmitt I, Mueller G, Lumbsch HT (2005a) Ascoma morphology is homoplaseous and phylogenetically misleading in some pyrenocarpous lichens. Mycologia 97:362-374

Schmitt I, Martín MP, Kautz S, Lumbsch HT (2005b) Diversity of non-reducing polyketide synthase genes in the Pertusariales (lichenized Ascomycota): a phylogenetic perspective. Phytochemistry 66:1241-1253

Schmitt I, Yamamoto Y, Lumbsch HT (2006) Phylogeny of Pertusariales (Ascomycotina): resurrection of Ochrolechiaceae and new circumscription of Megasporaceae. J Hattori Bot Lab 100:753-764

Schneider K, Resl P, Spribille T (2016) Escape from the cryptic species trap: lichen evolution on both sides of a cyanobacterial acquisition event. Mol Ecol 25:3453-3468

Schoch CL, Seifert KA, Huhndorf S, Robert V, Spouge JL, Levesque CA, Chen W, Fungal Barcoding Consortium (2012) Nuclear ribosomal internal transcribed spacer (ITS) region as a universal DNA barcode marker for Fungi. Proc Natl Acad Sci USA 109:6241-6246

Schoustra SE, Punzalan D, Dali R, Rundle HD, Kassen R (2012) Multivariate phenotypic divergence due to the fixation of beneficial mutations in experimentally evolved lineages of a filamentous fungus. PLoS ONE 7(11):e50305

Schwendener S (1868) Ueber die Beziehungen zwischen Algen und Flechtengonidien. Bot Zeitung 1868:289-292

Selosse MA, Le Tacon F (1998) The land flora: a phototroph-fungus partnership? Trends Ecol Evol 13:15-20

Seymour FA, Crittenden PD, Dyer PS (2005) Sex in the extremes: lichen-forming fungi. Mycologist 19:51-58

Seymour FA, Crittenden PD, Wirtz N, Ovstedal DO, Dyer PS, Lumbsch HT (2007) Phylogenetic and morphological analysis of Antarctic lichen-forming Usnea species in the group Neuropogon. Antarctic Sci 19:71-82

Sheard JW (1978) The taxonomy of the Ramalina siliquosa species aggregate (lichenized Ascomycetes). Can J Bot 56:916-938
Sheik CS, Reese BK, Twing KI, Sylvan JB, Grim SL, Schrenk MO, Sogin ML, Colwell FS (2018) Identification and removal of contaminant sequences from ribosomal gene databases: lessons from the census of deep life. Front Microbiol 9:840

Sidney E (1846) Blights of the wheat, and their remedies. Religious Tract Society, London

Simon A, Goffinet B, Magain N, Sérusiaux E (2018) High diversity, high insular endemism and recent origin in the lichen genus Sticta (lichenized Ascomycota, Peltigerales) in Madagascar and the Mascarenes. Mol Phyl Evol 122:15-28

Simons P (2013) Vague kinds and biological nominalism. Metaphysica $14: 275-282$

Sipman HJM, Lücking R, Aptroot A, Chaves JL, Kalb K, Umaña-Tenorio L (2012) A first assessment of the Ticolichen biodiversity inventory in Costa Rica and adjacent areas: the thelotremoid Graphidaceae (Ascomycota: Ostropales). Phytotaxa 55:1-214

Smith BE, Johnston MK, Lücking R (2016) From GenBank to GBIF: phylogeny-based predictive niche modeling tests accuracy of taxonomic identifications in large occurrence data repositories. PLoS ONE 11(3):e0151232

Smith CW, Aptroot A, Coppins BJ, Fletcher A, Gilbert OL, James PW, Wolseley PA (eds) (2009) The Lichens of Great Britain and Ireland. British Lichen Society, London

Smith ML, Carstens BC (2020) Process-based species delimitation leads to identification of more biologically relevant species. Evolution 74:216-229

Sneath PH (2005) Numerical taxonomy. In: Brenner DJ, Krieg NR, Staley JT, Garrity GM (eds) Bergey’s Manual ${ }^{\circledR}$ of systematic bacteriology, vol Two. The proteobacteria, part a: introductory essays. Springer, Boston, pp 39-42

Sneath PH, Sokal RR (1962) Numerical taxonomy. Nature 193:855-860

Sneath PH, Sokal RR (1973) Numerical taxonomy. The principles and practice of numerical classification. Freeman \& Co, San Francisco

Spribille T, Tuovinen V, Resl P, Vanderpool D, Wolinski H, Aime MC, Schneider K, Stabentheiner E, Toome-Heller M, Thor G, Mayrhofer H (2016) Basidiomycete yeasts in the cortex of ascomycete macrolichens. Science 353:488-492

Spribille T, Fryday AM, Pérez-Ortega S, Svensson M, Tønsberg T, Ekman S, Holien H, Resl P, Schneider K, Stabentheiner E, Thüs H (2020) Lichens and associated fungi from Glacier Bay National Park, Alaska. Lichenologist 52:61-181

Stafleu FA, Demoulin V, Greuter W, Hiepko P, Linczevski IA, McVaugh R, Meikle RD, Rollins RC, Ross R, Schopf JM, Voss EG (1978) International Code of Botanical Nomenclature: Adopted by the Twelfth International Botanical Congress, Leningrad, July 1975 [Regnum Vegetabile Vol. 97]. Bohn, Scheltema \&Holkema, Utrecht

Stamatakis A (2014) RAxML version 8: a tool for phylogenetic analysis and post-analysis of large phylogenies. Bioinformatics 30:1312-1313

Steenkamp ET, Wingfield MJ, McTaggart AR, Wingfield BD (2018) Fungal species and their boundaries matter-definitions, mechanisms and practical implications. Fungal Biol Rev 32:104-116

Stegenga J, Menon T (2017) Robustness and independent evidence. Philos Sci 84:414-435

Steinova J, Stenroos S, Grube M, Skaloud P (2013) Genetic diversity and species delimitation of the zeorin-containing red-fruited $\mathrm{Cla}$ donia species (lichenized Ascomycota) assessed with ITS rDNA and $\beta$-tubulin data. Lichenologist 45:665-684

Stenroos S, Laukka T, Huhtinen S, Döbbeler P, Myllys L, Syrjänen K, Hyvönen J (2010) Multiple origins of symbioses between ascomycetes and bryophytes suggested by a five-gene phylogeny. Cladistics 26:281-300 
Stenroos S, Pino-Bodas R, Hyvönen J, Lumbsch HT, Ahti T (2019) Phylogeny of the family Cladoniaceae (Lecanoromycetes, Ascomycota) based on sequences of multiple loci. Cladistics 35:351-384

Stojanovic N, Chang JL, Lehoczky J, Zody MC, Dewar K (2002) Identification of mixups among DNA sequencing plates. Bioinformatics 18:1418-1426

Sukumaran J, Knowles LL (2017) Multispecies coalescent delimits structure, not species. Proc Natl Acad Sci USA 114:1607-1612

Sundin R, Tehler A (1996) The genus Dendrographa (Roccellaceae). Bryologist 99:19-31

Shushan S, Anderson RA (1969) Catalog of the lichens of Colorado. Bryologist 72:451-483

Swinscow TDV, Krog H (1988) Macrolichens of East Africa. British Museum of Natural History, London

Tahseen Q (2014) Taxonomy-the crucial yet misunderstood and disregarded tool for studying biodiversity. J Biodivers Endang Species 2:128

Taylor PJ (2009) Evolution and the species concept. In: Minelli A, Contrafatto G (eds) Biological science fundamentals and systematics, vol 1. Encyclopedia of Life Support Systems (EOLSS), Oxford, pp 289-310

Taylor JW (2011) One Fungus = One Name: DNA and fungal nomenclature twenty years after PCR. IMA Fungus 2:113-120

Tedersoo L, Sánchez-Ramírez S, Koljalg U, Bahram M, Döring M, Schigel D, May T, Ryberg M, Abarenkov K (2018) High-level classification of the Fungi and a tool for evolutionary ecological analyses. Fungal Divers 90:135-159

Tehler A (1982) The species pair concept in lichenology. Taxon 31:708-714

Tehler A (1983) The genera Dirina and Roccellina. Opera Bot 70:1-86

Tehler A (1990) A new approach to the phylogeny of Euascomycetes with a cladistic outline of Arthoniales focussing on Roccellaceae. Can J Bot 68:2458-2492

Tehler A (1993) The genus Schismatomma (Arthoniales, Euascomycetidae). Opera Bot 118:1-38

Tehler A, Källersjö M (2001) Parmeliopsis ambigua and P. hyperopta (Parmeliaceae): species or chemotypes? Lichenologist 33:403-408

Tehler A, Irestedt M, Bungartz F, Wedin M (2009) Evolution and reproduction modes in the Roccella galapagoensis aggregate (Roccellaceae, Arthoniales). Taxon 58:438-456

Tehler A, Irestedt M, Wedin M, Ertz D (2010) The Old World Roccella species outside Europe and Macaronesia: taxonomy, evolution and phylogeny. Syst Biodivers 8:223-246

Tehler A, Ertz D, Irestedt M (2013) The genus Dirina (Roccellaceae, Arthoniales) revisited. Lichenologist 45:427-476

Thell A, Stenroos S, Myllys L (2000) A DNA study of the Cetraria aculeata and C. islandica groups [Cetraria aculeata ja C. islandica rühmade DNA-st]. Folia Cryptogam Estonica 36:95-106

Thines M, Aoki T, Crous PW, Hyde KD, Lücking R, Malosso E, May TW, Miller AN, Redhead SA, Yurkov AM, Hawksworth DL (2020) Setting scientific names at all taxonomic ranks in italics facilitates their quick recognition in scientific papers. IMA Fungus 11:1-5

Thiyagaraja V, Lücking R, Ertz D, Wanasinghe DN, Karunarathna SC, Camporesi E, Hyde KD (2020) Evolution of non-lichenized, saprotrophic species of Arthonia (Ascomycota, Arthoniales) and resurrection of Naevia, with notes on Mycoporum. Fungal Divers 102:205-224

Thomas EA (1939) Über die Biologie von Flechtenbildnern. Beitr Kryptogamenfl Schweiz 9:1-208

Thomas MA, Nash TH III, Gries C (1997) Ecophysiological comparison of two tropical/subtropical lichen species: Dictyonema glabratum from an alpine habitat and Coenogonium interplexum from a lowland forest. Biblioth Lichenol 67:183-195
Thwaites GHK (1849) XXV—on the gonidia of lichens. Ann Mag Nat Hist 3:219-222

Tobias JA, Seddon N, Spottiswoode CN, Pilgrim JD, Fishpool LD, Collar NJ (2010) Quantitative criteria for species delimitation. Ibis 152:724-746

Torsell G (1843) Enumeratio Lichenum et Byssacearum Scandinaviae Hucusque Cognitorum. Uppsala

Torzilli AP, Balakrishna S, O'Donnell K, Lawrey JD (2002) The degradative activity of a lichenicolous Fusarium sp. compared to related entomogenous species. Mycol Res 106:1204-1210

Tripathi M, Joshi Y (2019) Endolichenic fungi: present and future trends. Springer Nature, Singapore

Tripp EA (2016) Is asexual reproduction an evolutionary dead end in lichens? Lichenologist 48:559-580

Tripp EA, Lendemer JC (2018) Twenty-seven modes of reproduction in the obligate lichen symbiosis. Brittonia 70:1-14

Truong C, Divakar PK, Yahr R, Crespo A, Clerc P (2013) Testing the use of ITS rDNA and protein-coding genes in the generic and species delimitation of the lichen genus Usnea (Parmeliaceae, Ascomycota). Mol Phyl Evol 68:357-372

Tuovinen V, Ekman S, Thor G, Vanderpool D, Spribille T, Johannesson $\mathrm{H}$ (2019) Two basidiomycete fungi in the cortex of wolf lichens. Curr Biol 29:476-483

Tuovinen V, Millanes AM, Freire-Rallo S, Rosling A, Wedin M (2021) Abundant and widespread yeast stages in Lecanora lichens. Environm Microbiol. https://doi.org/10.1111/1462-2920.15455

Turland NJ, Wiersema JH, Barrie FR, Greuter W, Hawksworth DL, Herendeen PS, Knapp S, Kusber WH, Li DZ, Marhold K, May TW, McNeill J, Monro AM, Prado J, Price MJ, Smith G F (eds) (2018) International Code of Nomenclature for algae, fungi, and plants (Shenzhen Code) adopted by the Nineteenth International Botanical Congress Shenzhen, China, July 2017 [Regnum Vegetabile 159] Koeltz Botanical Books, Glashütten

Uyenco FR (1965) Studies on some lichenized Trentepohlia associated in lichen thalli with Coenogonium. Trans Am Microscop Soc 84:1-14

van den Boom PP, Sipman HJM (2016) Foliicolous lichens from Suriname and Guyana: new records and three new species. Folia Cryptogam Estonica 53:101-110

Vězda A (1994) Neue foliicole Flechten II. Nova Hedwigia 58:123-143 Vigoder FM, Souza NA, Brazil RP, Bruno RV, Costa PL, Ritchie MG, Klaczko LB, Peixoto AA (2015) Phenotypic differentiation in love song traits among sibling species of the Lutzomyia longipalpis complex in Brazil. Paras Vect 8:1-14

Vinarski MV (2020) The roots of the taxonomic impediment: is the 'integrativeness'a remedy? Integr Zool 15:2-15

Vis ML, Entwisle TJ, West JA, Ott FD (2006) Ptilothamnion richardsii (Rhodophyta) is a chantransia stage of Batrachospermum. Eur J Phycol 41:125-130

Vitikainen O (1976) Erik Acharius. In: Acharius, E., Lichenographia Universalis. Reprinted by Richmond Publishing, Richmond, England

Vondrak J, Ríha P, Arup U, Søchting U (2009) The taxonomy of the Caloplaca citrina group (Teloschistaceae) in the Black Sea region; with contributions to the cryptic species concept in lichenology. Lichenologist 41:571-604

Vondrák J, Ismailov A, Urbanavichus G (2017) Lichens of the family Teloschistaceae in Dagestan, an eastern part of the Caucasian biodiversity hot-spot. Nova Hedwigia 104:483-498

Vondrák J, Shahidin H, Moniri MH, Halıcı G, Košnar J (2018) Taxonomic and functional diversity in Calogaya (lichenised Ascomycota) in dry continental Asia. Mycol Progr 17:897-916

Vondrák J, Frolov I, Košnar J, Arup U, Veselská T, Halıcı G, Malíček J, Søchting U (2020) Substrate switches, phenotypic innovations and allopatric speciation formed taxonomic diversity within the lichen genus Blastenia. J Syst Evol 58:295-330 
Voss EG, Burdet HM, Chaloner WG, Demoulin V, Hiepko P, Mcneill J, Meikle RD, Nicolson DH, Rollins RC, Silva PC, Greuter W (1983) International Code of Botanical Nomenclature adopted by the Thirteenth International Botanical Congress, Sydney, August 1981 [Regnum Vegetabile Vol. 111]. Bohn, Scheltema \& Holkema, Utrecht, Junk, Boston

Walser JC, Gugerli F, Holderegger R, Kuonen D, Scheidegger C (2004) Recombination and clonal propagation in different populations of the lichen Lobaria pulmonaria. Heredity 93:322-329

Watson HC (1843) Remarks on the distinction of species in nature, and in books. Lond J Bot 2:613-622

Weber WA (2003) The middle Asian element in the southern Rocky Mountain flora of the western United States: a critical biogeographical review. J Biogeogr 30:649-685

Wedin M, Döring H, Gilenstam G (2004) Saprotrophy and lichenization as options for the same fungal species on different substrata: environmental plasticity and fungal lifestyles in the Stictis-Conotrema complex. New Phytol 164:459-465

Wedin M, Wiklund E, Jørgensen PM, Ekman S (2009) Slippery when wet: phylogeny and character evolution in the gelatinous cyanobacterial lichens (Peltigerales, Ascomycetes). Mol Phyl Evol 53:862-871

Wendt T, Canela MBF, Klein DE, Rios RI (2002) Selfing facilitates reproductive isolation among three sympatric species of Pitcairnia (Bromeliaceae). Plant Syst Evol 232:201-212

Werth S, Meidl P, Scheidegger C (2021) Deep divergence between island populations in lichenized fungi. Sci Rep 11:7428

Westberg M, Arup U (2011) Candelaria pacifica sp. nova (Ascomycota, Candelariales) and the identity of Candelaria vulgaris. Biblioth Lichenol 106:353-364

Wheeler QD, Nixon KC (1990) Another way of looking at the species problem: a reply to De Queiroz and Donoghue. Cladistics 6:77-81

Wheeler QD, Platnik NI (2000) The phylogenetic species concept (sensu Wheeler and Platnick). In: Wheeler QD, Meier R (eds) Species concepts and phylogenetic theory: a debate. Columbia University Press, New York, pp 55-69

Widhelm TJ, Egan RS, Bertoletti FR, Asztalos MJ, Kraichak E, Leavitt SD, Lumbsch HT (2016) Picking holes in traditional species delimitations: an integrative taxonomic reassessment of the Parmotrema perforatum group (Parmeliaceae, Ascomycota). Bot $\mathrm{J}$ Linn Soc 182:868-884

Widhelm TJ, Grewe F, Huang JP, Mercado-Díaz JA, Goffinet B, Lücking R, Moncada B, Mason-Gamer R, Lumbsch HT (2019) Multiple historical processes obscure phylogenetic relationships in a taxonomically difficult group (Lobariaceae, Ascomycota). Sci Rep 9:8968

Widhelm TJ, Grewe F, Huang JP, Ramanauskas K, Mason-Gamer R, Lumbsch HT (2021) Using RADseq to understand the circumAntarctic distribution of a lichenized fungus, Pseudocyphellaria glabra. J Biogeogr 48:78-90 (first published online 6 October 2020)

Wilk K, Pabijan M, Saługa M, Gaya E, Lücking R (2021) Phylogenetic revision of South American Teloschistaceae (lichenized Ascomycota, Teloschistales) reveals three new genera and species. Mycologia 113:278-299

Wilkins JS (2009) Species. A history of the idea. University of California Press, Berkeley

Wilkins JS (2018) Species: the evolution of the idea. CRC Press, Bota Raton

Will KW, Mishler BD, Wheeler QD (2005) The perils of DNA barcoding and the need for integrative taxonomy. Syst Biol 54:844-851

Wilson EO (1988) The current state of biological diversity. In: Wilson EO (ed) Biodiversity. National Academic Press, Washington, DC, pp 3-20
Wilson EO, Brown WL Jr (1953) The subspecies concept and its taxonomic application. Syst Zool 2:97-111

Winston JE (1999) Describing species: practical taxonomic procedure for biologists. Columbia University Press, New York

Wirth M, Hale ME Jr (1978) Morden-Smithsonian expedition to Dominica: the lichens (Graphidaceae). Smiths Contr Bot 40:1-64

Wirtz N, Printzen C, Lumbsch HT (2008) The delimitation of Antarctic and bipolar species of neuropogonoid Usnea (Ascomycota, Lecanorales): a cohesion approach of species recognition for the Usnea perpusilla complex. Mycol Res 112:472-484

Wirtz N, Printzen C, Lumbsch HT (2012) Using haplotype networks, estimation of gene flow and phenotypic characters to understand species delimitation in fungi of a predominantly Antarctic Usnea group (Ascomycota, Parmeliaceae). Org Divers Evol 12:17-37

Yakovchenko LS, Vondrák J, Ohmura Y, Korchikov ES, Vondrakova OS, Davydov EA (2017) Candelariella blastidiata sp. nov. (Ascomycota, Candelariaceae) from Eurasia and North America, and a key for grey thalli Candelariella. Lichenologist 49:117-126

Yang MZ, Wang LS, Wang XY (2015) Taxonomic and geographic study on the lichen genus Thamnolia from China. Plant Sci J 33:133-140

Yang Z (2015) The BPP program for species tree estimation and species delimitation. Curr Zool 61:854-865

Yang Z, Rannala B (2010) Bayesian species delimitation using multilocus sequence data. Proc Natl Acad Sci USA 107:9264-9269

Yeates DK, Seago A, Nelson L, Cameron SL, Leo J, Trueman JW (2011) Integrative taxonomy, or iterative taxonomy? Syst Entomol 36:209-217

Xavier-Leite AB, Cáceres MES, Aptroot A, Moncada B, Lücking R, Tomio Goto B (2021) Phylogenetic revision of the lichenized family Gomphillaceae (Ascomycota: Graphidales) suggests post$\mathrm{K}-\mathrm{Pg}$ boundary diversification and phylogenetic signal in asexual reproductive structures. Mol Phyl Evol (in press)

Xu M, Heidmarsson S, Thorsteinsdottir M, Eiriksson FF, Omarsdottir S, Olafsdottir ES (2017) DNA barcoding and LC-MS metabolite profiling of the lichen-forming genus Melanelia: specimen identification and discrimination focusing on Icelandic taxa. PLoS ONE 12(5):e0178012

Zachos FE (2016) Species concepts in biology historical development. Theoretical foundations and practical relevance. Springer, Cham

Zachos FE, Apollonio M, Bärmann EV, Festa-Bianchet M, Göhlich U, Habel JC, Haringa E, Kruckenhauser L, Lovari S, McDevitt $\mathrm{AD}$, Pertoldi C, Rössner GE, Sánchez-Villagra MR, Scandura M, Suchentrunk F (2013) Species inflation and taxonomic artefacts-a critical comment on recent trends in mammalian classification. Mamm Biol 78:1-6

Zahlbruckner A (1907) B. Specieller Teil. In: Engler A, Prantl K (eds) Natürliche Pflanzenfamilien. Teil 1, Abteilung 1*. Lichenes (Flechten). Engelmann, Leipzig, pp 49-249

Zahlbruckner A (1926) Lichenes (Flechten). In: Engler A, Prantl K (eds) Die Natürlichen Pflanzenfamilien nebst ihren Gattungen und wichtigeren Arten, insbesondere den Nutzpflanzen, Zweite Ausgabe, 8B. Engelmann, Leipzig, pp 61-270

Zahradníková M (2017) Taxonomy and Phylogeny of the Family Fuscideaceae (Umbilicariales, Ascomycota) with Special Emphasis on Fuscidea. PhD Thesis, AIT Bjerch AS, University of Bergen

Zahradníková M, Andersen HL, Tønsberg T (2018) Fuscidea lightfootii and F. pusilla (Fuscideaceae, Umbilicariomycetidae, Ascomycota), two similar but genetically distinct species. Lichenologist 50:425-438

Zakeri Z, Otte V, Sipman HJM, Malíček J, Cubas P, Rico VJ, Lenzová V, Svoboda D, Divakar PK (2019) Discovering cryptic species in the Aspiciliella intermutans complex (Megasporaceae, Ascomycota) - first results using gene concatenation and coalescentbased species tree approaches. PLoS ONE 14(5):0216675 
Zhang J, Kapli P, Pavlidis P, Stamatakis A (2013) A general species delimitation method with applications to phylogenetic placements. Bioinformatics 29:2869-2876

Zhao X, Fernández-Brime S, Wedin M, Locke M, Leavitt SD, Lumbsch HT (2017) Using multi-locus sequence data for addressing species boundaries in commonly accepted lichen-forming fungal species. Org Divers Evol 17:351-363

Zhao Z, Liu H, Luo Y, Zhou S, An L, Wang C, Jin Q, Zhou M, Xu JR (2014) Molecular evolution and functional divergence of tubulin superfamily in the fungal tree of life. Sci Rep 4:6746
Zopf W (1903) Zur Kenntnis der Flechtenstoffe. Liebigs Ann Chem 327:317-354

Zvyagintsev DG, Zenova GM, Lobakova ES, Nikolaev GM, Omarova EO, Ivanova EA, Savelyev IB (2010) Morphological and physiological modifications of cyanobacteria in experimental cyanobacterium-actinomycete associations. Microbiology 79:314-320

\section{Authors and Affiliations}

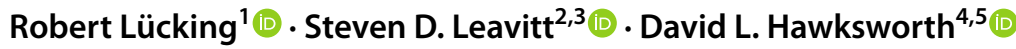

\section{Robert Lücking}

r.luecking@bgbm.org

Steven D. Leavitt

steve_leavitt@byu.edu

David L. Hawksworth

d.hawksworth@nhm.ac.uk

1 Botanischer Garten Und Botanisches Museum, Freie Universität Berlin, Königin-Luise-Str. 6-8, 14195 Berlin, Germany
2 Department of Biology, Brigham Young University, 4102 Life Science Building, Provo, UT 84602, USA

3 M. L. Bean Life Science Museum, Brigham Young University, 1115 MLBM, Provo, UT 84602, USA

4 Department of Life Sciences, The Natural History Museum, London SW7 5BD, UK

5 Comparative Plant and Fungal Biology, Royal Botanic Gardens, Kew, Richmond TW9 2AB, Surrey, UK 